\title{
Soil water balance models for determining crop water and irrigation requirements and irrigation scheduling focusing on the FAO56 method and the dual $\mathrm{K}_{\mathrm{c}}$ approach
}

\author{
L.S. Pereira ${ }^{\mathrm{a}}$, P. Paredes ${ }^{\mathrm{a}, *}$, N. Jovanovic ${ }^{\mathrm{b}}$ \\ ${ }^{a}$ LEAF- Linking Landscape, Environment, Agriculture and Food, Instituto Superior de Agronomia, Universidade de Lisboa, Tapada da Ajuda, 1349-017 Lisbon, Portugal \\ ${ }^{\mathrm{b}}$ CSIR, Water Centre, Stellenbosch, South Africa
}

\section{A R T I C L E I N F O}

\section{Keywords:}

Crop coefficients

Crop evapotranspiration

Dual $\mathrm{K}_{\mathrm{c}}$ approach

Real time irrigation management

Water use assessment

SIMDualKc model

\begin{abstract}
A B S T R A C T
This study reviews soil water balance (SWB) model approaches to determine crop irrigation requirements and scheduling irrigation adopting the FAO56 method. The $\mathrm{K}_{\mathrm{c}}-\mathrm{ET}_{\mathrm{o}}$ approach is discussed with consideration of baseline concepts namely standard vs. actual $\mathrm{K}_{\mathrm{c}}$ concepts, as well as single and dual $\mathrm{K}_{\mathrm{c}}$ approaches. Requirements for accurate SWB and appropriate parameterization and calibration are introduced. The one-step vs. the two-step computational approaches is discussed before the review of the FAO56 method to compute and partition crop evapotranspiration and related soil water balance. A brief review on transient state models is also included. Baseline information is concluded with a discussion on yields prediction and performance indicators related to water productivity. The study is continued with an overview on models development and use after publication of FAO24, essentially single $\mathrm{K}_{\mathrm{c}}$ models, followed by a review on models following FAO56, particularly adopting the dual $K_{c}$ approach. Features of dual $K_{c}$ modeling approaches are analyzed through a few applications of the SWB model SIMDualKc, mainly for derivation of basal and single $K_{c}$, extending the basal $K_{c}$ approach to relay intercrop cultivation, assessing alternative planting dates, determining beneficial and nonbeneficial uses of water by an irrigated crop, and assessing the groundwater contribution to crop ET in the presence of a shallow water table. The review finally discusses the challenges placed to SWB modeling for real time irrigation scheduling, particularly the new modeling approaches for large scale multi-users application, use of cloud computing and adopting the internet of things (IoT), as well as an improved wireless association of modeling with soil and plant sensors. Further challenges refer to the use of remote sensing energy balance and vegetation indices to map $\mathrm{K}_{\mathrm{c}}$, ET and crop water and irrigation requirements. Trends are expected to change research issues relative to SWB modeling, with traditional models mainly used for research while new, fastresponding and multi-users models based on cloud and IoT technologies will develop into applications to the farm practice. Likely, the $\mathrm{K}_{\mathrm{c}}-\mathrm{ET}_{\mathrm{o}}$ will continue to be used, with $\mathrm{ET}_{\mathrm{o}}$ from gridded networks, re-analysis and other sources, and $\mathrm{K}_{\mathrm{c}}$ data available in real time from large databases and remote sensing.
\end{abstract}

\section{Introduction}

The current imbalance between water demand and supply in agriculture has driven the search for new equilibria through adopting modern technologies and management tools to optimize irrigation water use (Pereira et al., 2009; Pereira, 2017; Jovanovic et al., 2020). The successful use of these tools depends, however, upon their adaptation to prevailing social, economic, institutional, climatic, soil and other environmental conditions.

Reducing the vulnerability of agriculture to climate change, and ultimately decreasing the risks associated to food security, requires integrated and sustainable water management, including the adaptation of cropping systems and management practices adopting an efficient use of both rainfall and irrigation water. The need for such sustainable water management practices is particularly critical considering the steady increase of global population and the limitations on availability of natural resources, particularly in vulnerable agricultural areas where water scarcity is of great importance (Smith, 2000; Pereira, 2017).

Sustainable water management at farm level assumes an enormous relevance, namely in terms of adopting adequate irrigation schedules, that should lead to optimal yields and agricultural and irrigation

\footnotetext{
* Corresponding author.

E-mail address: pparedes@isa.ulisboa.pt (P. Paredes).
} 
practices that allow reducing but optimizing water use, particularly non-beneficial ones (Pereira et al., 2009, 2012; Jovanovic et al., 2020).

Numerous irrigation scheduling simulation models have been produced and made available to support irrigation decision-making since the 80's as reported in various international conferences (ASAE, 1981, 1985, 1990; Feyen, 1987; Pereira et al., 1992, 1995; Ragab et al., 1996; Smith et al., 1996). The reported irrigation scheduling models were often based upon crop evapotranspiration and yield-water relations proposed in FAO manuals 24 and 33 (Doorenbos and Pruitt, 1977; Doorenbos and Kassam, 1979). Reported soil water balance (SWB) models include steady state and transient state models. Steady state models solve the law of conservation of mass within a selected time step, generally a day, while transient state models contain the time variable explicitly and computations refer to the fluxes of water within and through the boundaries of the control volume of soil. The latter, highly exigent in terms of data and using mechanistic approaches to simulate soil water processes, often include mechanistic sub-models to simulate plant growth, predict crop yields as influenced by various environmental factors, and to assess the transport of salt, chemicals and pollutants that impact farm water use and sustainability. Steady state SWB models are less exigent in terms of parameterization and, when properly calibrated, are very accurate and easier to use for irrigation scheduling, as well as to assess the impact of changing environmental conditions on crops evapotranspiration and yield, which may be predicted when the model is associated to, or incorporates yield-water functions.

A variety of tools, namely using hyperspectral reflectance data (Melton et al., 2012; Campos et al., 2017; Pôças et al., 2017; Saadi et al., 2018), can be used to support improved irrigation scheduling. More commonly, remote sensing vegetation indices may be used in combination with ground data after integration in current SWB model approaches (Olioso et al., 2005; Er-Raki et al., 2007; Santos et al., 2008; Vazifedoust et al., 2009; Pôças et al., 2015; Thorp et al., 2015; Corbari et al., 2019), although adopting a variety of data and integrative solutions. The current paper is focusing on steady state SWB simulation models having a known software and, mainly, when adopting the FAO56 method to determine $\mathrm{ET}_{\mathrm{c}}$ from the reference $\mathrm{ET}_{\mathrm{o}}$ and a crop coefficient. Particular attention is given to models that adopt the dual $\mathrm{K}_{\mathrm{c}}$ approach due to the relevance of determining transpiration and soil evaporation, the former consisting of the beneficial consumptive use of water.

Considering the vast panoply of innovation tools that support sustainable water use on farms, the overarching aim of this paper is to provide a review of the advances gained in modelling with the FAO56 method in the past two decades. The specific objectives of this paper are: (a) to discuss simple approaches to steady state water balance modelling in contrast with transient state, mechanistic soil water, crop growth and yield models; (b) to provide for an overview on models/ software used to improve irrigation scheduling and management, with focus on dual $\mathrm{K}_{\mathrm{c}}$ modelling with consideration of water scarcity and saving; c) to show examples of model applications and water use assessment based on the SIMDualKc model; and d) to analyze current trends and opportunities, focusing particularly on real time irrigation scheduling using modern information technologies.

This article consists of various Sections. After the current Introduction, Section 2 refers to main concepts and calculation approaches of the FAO56 method and includes discussions on the one-step approach, transient state modeling, crop growth and yield prediction, and water use indicators. Section 3 presents an overview of SWB models aimed at improving irrigation scheduling and management, and Section 4 focuses on the dual $\mathrm{K}_{\mathrm{c}}$ approaches taking the SIMDualKc model as an example for adopting and extending the use of the FAO56 dual $\mathrm{K}_{\mathrm{c}}$ approach. Section 5 discusses real time irrigation scheduling and latest developments, namely related to the applications of remote sensing and internet platforms aimed at multi-users, while Section 6 presents the main conclusions and future trends.

\section{Reference concepts}

\subsection{Crop evapotranspiration, crop water requirements and irrigation requirements}

The FAO56 method (Allen et al., 1998) uses the simple $\mathrm{K}_{\mathrm{c}}-\mathrm{ET}_{\mathrm{o}}$ approach to determine crop evapotranspiration as the product of a crop coefficient $\left(\mathrm{K}_{\mathrm{c}}\right)$ and the grass reference evapotranspiration $\left(\mathrm{ET}_{\mathrm{o}}\right)$ computed with the FAO Penman-Monteith equation (PM-ET ${ }_{\mathrm{o}}$ ). The PM-ET equation is derived from the Penman-Monteith (PM) combination equation (Monteith, 1965) when it was parameterized for the standard grass reference crop (Allen et al., 1994a,b, 1998). As analyzed in the next Section, the PM equation is often used for direct calculation of crop ET.

The FAO56 method adopted the concept of standard, optimal crop conditions as the basis for tabularizing the $\mathrm{K}_{\mathrm{c}}$ values, which consisted of a main difference to the previous FAO24 method (Pereira et al., 2015a). Thus, $\mathrm{K}_{\mathrm{c}}$ and $\mathrm{ET}_{\mathrm{c}}$ in FAO56 refer to potential crop ET rates under optimal, well-watered crop production conditions, which often differ from the field and common practice where crop conditions are often not optimal due to insufficient or non-uniform irrigation, low crop density, less adequate soil and agronomic management and/or salinity. The tabulated $\mathrm{K}_{\mathrm{c}}$ values in FAO56 or in the review papers (Jensen and Allen, 2016; Pereira et al., 2020a,b,d) refer to the standard climate and need to be adjusted to the local climate (eqs. 62 and 65 of FAO56). The potential $\mathrm{ET}_{\mathrm{c}}$ as computed from standard $\mathrm{K}_{\mathrm{c}}$ values is then replaced by the actual crop ET, $\mathrm{ET}_{\mathrm{c}}$ act, and the standard $\mathrm{K}_{\mathrm{c}}$ are replaced by the actual $\mathrm{K}_{\mathrm{c} \text { act }}$ values, with $\mathrm{K}_{\mathrm{c} \text { act }}=\mathrm{K}_{\mathrm{s}} \mathrm{K}_{\mathrm{c}}$ where $\mathrm{K}_{\mathrm{s}}$ is a stress coefficient due to water deficiency or salinity effects, and that can be extended to other cultivation stresses.

The concept of dual $\mathrm{K}_{\mathrm{c}}$ was also adopted in addition to the traditional single one. The single $\mathrm{K}_{\mathrm{c}}$ represents averaged soil evaporation $\left(\mathrm{E}_{\mathrm{s}}\right)$ and crop transpiration $\left(\mathrm{T}_{\mathrm{c}}\right)$ from a cropped surface for typical frequencies of wetting. However, as noted by in the review by Pereira et al. (2015a), the single $\mathrm{K}_{\mathrm{c}}$ only represents typical conditions that can vary with the wetting frequency by precipitation and irrigation, with the type of irrigation practiced and with crop management, namely the inter-row management in row crops. Adopting the concept of dual crop coefficient, $\mathrm{K}_{\mathrm{c}}=\mathrm{K}_{\mathrm{cb}}+\mathrm{K}_{\mathrm{e}}$, where $\mathrm{K}_{\mathrm{cb}}$ is the basal crop coefficient representing primarily plant transpiration and $\mathrm{K}_{\mathrm{e}}$ is the evaporation coefficient that represents the contribution of evaporation from soil to total ET, the variation of both $\mathrm{E}_{\mathrm{s}}$ and $\mathrm{T}_{\mathrm{c}}$ are considered independently. In view of this, the partition of $\mathrm{ET}_{\mathrm{c}}$ or $\mathrm{ET}_{\mathrm{c}}$ act into both these components as proposed by FAO56 (Allen et al., 1998, 2005a) allows to better represent field and management issues when acting differently on $E_{s}$ and $\mathrm{T}_{\mathrm{c}}$. The two stage evaporation model of Ritchie (1972) is adopted for the calculation of $\mathrm{K}_{\mathrm{e}}$, which implies performing an independent water balance of the evaporation top layer of the soil.

The FAO56 method is dealt in detail with the very recent reviews and updates of the single and basal crop coefficients (Pereira et al., 2020a through d). These reviews also focused on the accuracy of diverse ET measurement methods, namely the measurement of changes of soil water, eddy covariance, Bowen ratio energy balance, sap-flow, and remote sensing vegetation indices (Allen et al., 2011b; Pereira et al., 2020a,b).

Crop water requirements (CWR, $\mathrm{mm}$ ) consist of the seasonal amount of water required by a crop to achieve its potential production under a given environment. CWR correspond to the seasonal potential crop ET $\left(\mathrm{ET}_{\mathrm{c}}, \mathrm{mm}\right)$ and added the seasonal leaching requirement (LR, $\left.\mathrm{mm}\right)$ required to control effects of soil and water salinity in case of cropping in saline soils or when using salty water (including treated wastewater). LR is herein considered as part of the CWR given the importance for the crop yield and the soil environment to adopt appropriate salinity control. Salinity effects and related water management control measures were recently reviewed and discussed by Minhas et al. (2020).

The net irrigation requirements (NIR, $\mathrm{mm}$ ) consist of the amount of 
water that needs to be applied to the crop to fully satisfy its CWR when the water available through precipitation $(\mathrm{P}, \mathrm{mm})$, capillary rise (CR, $\mathrm{mm})$ and soil water storage variation $\left(\mathrm{SW}_{\mathrm{var}}, \mathrm{mm}\right)$ are insufficient. NIR relative to the crop season, or to any selected time period, is given by the soil water balance as:

$\mathrm{NIR}=\mathrm{CWR}-\left(\mathrm{P}+\mathrm{SW}_{\mathrm{var}}+\mathrm{CR}\right)+\mathrm{DP}+\mathrm{RO}$

where, in addition to variables previously defined, DP is deep percolation from the soil root zone $(\mathrm{mm})$ and RO is runoff $(\mathrm{mm})$, with all variables referring to the time period considered for the computation. The gross irrigation requirements (GIR, $\mathrm{mm}$ ) for any time step is given as:

$$
\mathrm{GIR}=\frac{\mathrm{NIR}+\mathrm{LR}}{\mathrm{BWUF}}
$$

where BWUF is the beneficial water use fraction of the applied irrigation water (Pereira et al., 2012). BWUF is commonly referred as application efficiency when referring to the field, or combined conveyance, distribution and application efficiency when considering the operational losses in the conveyance and distribution canal and/or conduits systems in addition to application on the farm (Burt et al., 1997; Bos et al., 2005; Heermann and Solomon, 2007).

\subsection{Computing the crop evapotranspiration: the one-step vs. the two-step approaches}

The Penman-Monteith combination equation (Monteith, 1965) may be used for computing crop ET as a one-step approach contrarily to the FAO56 method that adopts the two-step $\mathrm{K}_{\mathrm{c}}-\mathrm{ET}_{\mathrm{o}}$ product referred above. With the Penman-Monteith combination equation (PM-eq), crop ET is computed using the aerodynamic and bulk surface resistances of the crop; differently, with the FAO method crop ET is given as the product of the grass reference ET $\left(\mathrm{ET}_{\mathrm{o}}\right)$ by the crop coefficient $\left(\mathrm{K}_{\mathrm{c}}\right) . \mathrm{K}_{\mathrm{c}}$ represents the integrated differences between the considered crop and the reference crop in terms of aerodynamic and bulk surface resistances. $\mathrm{ET}_{\mathrm{o}}$ is derived from the PM combination equation parameterized for the grass reference crop.

The Penman-Monteith combination equation (Monteith, 1965) is generally written as

$E T=\frac{1}{\lambda} \frac{\Delta\left(R_{n}-G\right)+\rho c_{p}\left(e_{s}-e_{a}\right) / r_{a}}{\Delta+\gamma\left(1+r_{s} / r_{a}\right)}$

where $\lambda$ is the latent heat of vaporization $\left[M J \mathrm{~kg}^{-1}\right], \mathrm{R}_{\mathrm{n}}-\mathrm{G}$ is the net balance of energy available at the surface $\left[M J \mathrm{~m}^{-2} \mathrm{~d}^{-1}\right],\left(\mathrm{e}_{\mathrm{s}}-\mathrm{e}_{\mathrm{a}}\right)$ represents the vapor pressure deficit (VPD) of air at the reference (weather measurement) height $[\mathrm{kPa}], \rho$ is mean air density $\left[\mathrm{kg} \mathrm{m}^{-3}\right], \mathrm{cp}$ is specific heat of air at constant pressure $\left[\mathrm{MJ} \mathrm{kg}^{-1}{ }^{\circ} \mathrm{C}^{-1}\right], \Delta$ represents the slope of the saturation vapor pressure-temperature relationship at mean air temperature $\left[\mathrm{kPa}{ }^{\circ} \mathrm{C}^{-1}\right], \gamma$ is the psychometric constant $\left[\mathrm{kPa}{ }^{\circ} \mathrm{C}^{-1}\right], \mathrm{r}_{\mathrm{s}}$ is the bulk surface resistance $\left[\mathrm{s} \mathrm{m}^{-1}\right]$, and $\mathrm{r}_{\mathrm{a}}$ is the aerodynamic resistance $\left[\mathrm{s} \mathrm{m}^{-1}\right]$. The transfer of heat and vapor from the evaporative surface into the air in the turbulent layer above a canopy is determined by the aerodynamic resistance $r_{a}$ between the surface and the reference level above the canopy. That transfer is determined by the wind speed, the height of wind speed, air temperature and air humidity measurements, as well as crop height and canopy architecture (Perrier, 1982). The surface resistance $r_{s}$ for full-cover canopies is often expressed as a function of the stomatal resistance of a well-illuminated leaf $\left(r_{1}\right)$ and of the effective leaf area index $\left(\mathrm{LAI}_{\text {eff }}\right)$.

The use of the PM-eq for prediction of crop water requirements is difficult because crop height and canopy architecture change throughout the crop cycle, thus changing the framework for computing $r_{a}$ and $r_{s}$, which also changes with $r_{l}$, thus with leaf age and water availability conditions, as well as with $\mathrm{LAI}_{\text {eff. }}$ In addition, for the same crop, $r_{a}$ and $r_{s}$ are influenced by differences among varieties, and crop management and irrigation practices. Moreover, resistances $r_{l}$ and $r_{s}$ are influenced by the climate and water availability, with $r_{s}$ increasing when soil water availability limits ET, the VPD increases and $r_{a}$ is higher; $r_{s}$ decreases when the energy available at the surface increases. According to Alves et al. (1998) and Alves and Pereira (2000), $r_{s}$ may be expressed as dependent of $r_{a}$ and of the weather variables as

$r_{s}=r_{a}\left(\frac{\Delta}{\gamma} \beta-1\right)+(1+\beta) \frac{\rho c_{p} V P D}{\gamma\left(R_{n}-G\right)}$

where $\beta$ is the Bowen ratio (the ratio between the sensible and latent heat fluxes). In this equation $\beta$ plays the role of a water-stress indicator. This equation illustrates that the weather variables interact and their influences are inter-dependent, which adds to the difficulties in appropriately selecting $r_{s}$, thus creating challenges in applying the PM-eq or "multi-layer" resistance equations such as the two-source Shuttleworth and Wallace (SW) equation (Shuttleworth and Wallace, 1985).

Various applications of the PM-eq (Eq. 3) are reported in the literature and they show that the SWB is not required to consider water stress impacts since the parameterization of Eq. 3 takes into account the water stress, e.g. through the consideration of stomatal conductance or predawn leaf water potential (Rana et al., 1997, 2001; Zhang et al., 2011). However, Ortega-Farias et al. (2004, 2006) performed the adjustment to water stress using a normalized soil water factor, similar to the stress coefficient $\mathrm{K}_{\mathrm{s}}$ described in the next Section, which computation requires a simple SWB. A few studies compared the PM-eq with the $\mathrm{K}_{\mathrm{c}}-\mathrm{ET}_{\mathrm{o}}$ approach (Lovelli et al., 2008; Irmak and Mutiibwa, 2009). The accuracy of ET estimates depends upon the parameterization of the PMeq. The one-step PM and SW equations are excellent for ET simulation but they are basically used in research, while the two-step $\mathrm{K}_{\mathrm{c}}-\mathrm{ET}_{\mathrm{o}}$ is used both in research and to support field practice as per the recent reviews by Pereira et al. (2020a,b) and Rallo et al. (2020).

The PM-eq (Eq. 3) is the base for the PM-ET 1994a,b, 1998), which for daily time steps computation takes the form

$E T_{o}=\frac{0.408 \Delta\left(R_{n}-G\right)+\gamma \frac{900}{T+273} u_{2}\left(e_{s}-e_{a}\right)}{\Delta+\gamma\left(1+0.34 u_{2}\right)}$

where, in addition to variables defined for Eq. (3), T is mean daily air temperature $\left[{ }^{\circ} \mathrm{C}\right]$ and $\mathrm{u}_{2}$ is wind speed $\left[\mathrm{m} \mathrm{s}^{-1}\right]$, with measurements at $2 \mathrm{~m}$ height. This represents a hypothetical crop with an assumed height of $0.12 \mathrm{~m}$ having a surface resistance of $70 \mathrm{~s} \mathrm{~m}^{-1}$ and an albedo of 0.23 , closely resembling an extensive surface of green grass of uniform height, actively growing and adequately watered. This equation is also parameterized for hourly time steps (Allen et al., 2006).

$\mathrm{K}_{\mathrm{c}}$ represents an integration of the effects of three primary characteristics that distinguish the crop from the reference: crop height (affecting roughness and aerodynamic resistance); crop-soil surface resistance (related to leaf area, fraction of ground covered by vegetation, leaf age and condition, degree of stomatal control, and soil surface wetness); and albedo of the crop-soil surface (influenced by the fraction of ground covered by vegetation and soil surface wetness). It is defined through the ratio between potential crop evapotranspiration $\left(\mathrm{ET}_{\mathrm{c}}\right)$ and the reference $\mathrm{ET}_{\mathrm{o}}$, thus

$\mathrm{K}_{\mathrm{c}}=\mathrm{ET}_{\mathrm{c}} / \mathrm{ET}_{\mathrm{o}}$

The challenge, therefore, has been to summarize all referred differences relative to the PM-eq (Eq. 3) between the considered crop and the reference crop to just one parameter, $\mathrm{K}_{\mathrm{c}}$. Although, it was demonstrated (Pereira et al., 1999) that $\mathrm{K}_{\mathrm{c}}$ values relate intimately with the ratios between $r_{a}$ and $r_{s}$ of the considered crop and the reference crop, which makes $\mathrm{K}_{\mathrm{c}}$ a non-purely empirical parameter but a deterministic one. Though when using the two-step approach to compute crop ET, it is possible to achieve highly accurate estimation of crop ET, close to the accuracy obtained with the one-step PM-eq, despite the high requirements of the latter in terms of parameterization (Ortega-Farias et al., 2006; Lovelli et al., 2008; Irmak and Mutiibwa, 2009). 


\subsection{Soil water balance: the FAO56 method}

With the objective of managing irrigation in the day to day practice, instead of Eq. 1, the daily soil water balance applied to the entire root zone (Allen et al., 1998, 2007) may be expressed through computing the soil water depletion at the end of every day $\left(D_{r, i}, m m\right)$, which is given as:

$D_{r, i}=D_{r, i-1}-\left(P_{i}-R O_{i}\right)-I_{i}-C R_{i}+E T_{\text {c act }, i}+D P_{i}$

where $D_{r, i-1}$ is the root zone depletion at the end of previous day $\mathrm{i}-1$ $(\mathrm{mm}), \mathrm{P}_{\mathrm{i}}$ is precipitation $(\mathrm{mm}), \mathrm{RO}_{\mathrm{i}}$ is runoff $(\mathrm{mm}), \mathrm{I}_{\mathrm{i}}$ is the net irrigation depth that infiltrates the soil $(\mathrm{mm}), \mathrm{CR}_{\mathrm{i}}$ is capillary rise from the shallow groundwater table $(\mathrm{mm}), \mathrm{ET}_{\mathrm{c}}$ act,i is the actual crop evapotranspiration $(\mathrm{mm})$, and $\mathrm{DP}_{\mathrm{i}}$ is deep percolation through the bottom of the root zone $(\mathrm{mm})$, with all terms referring to day i. $\mathrm{ET}_{\mathrm{c} \text { act }}$ refers to both optimal and suboptimal crop and irrigation conditions, i.e., under full or deficit irrigation and/or diverse cropping practices.

Solving the water balance equation (Eq. 7) requires soil water content observations (or their estimation from observed soil matric potential), which allow to estimate the root zone depletion $\mathrm{D}_{\mathrm{r}}$. A computational algorithm is required to perform a daily SWB, which is based upon the knowledge of soil hydraulic properties, the field capacity and wilting point $\left(\theta_{\mathrm{FC}}\right.$ and $\left.\theta_{\mathrm{WP}}, \mathrm{m}^{3} \mathrm{~m}^{-3}\right)$ of various soil layers down to the bottom of the root zone. To estimate runoff, deep percolation and capillary rise, appropriate algorithms are required as discussed by Liu et al. (2006) and Allen et al. (2007). RO, DP and CR cannot be just estimated when an accurate SWB is to be performed, thus appropriate computational approaches are required, including simple spreadsheet applications to just support irrigation scheduling.

$\mathrm{ET}_{\mathrm{c} \text { act }}$ is computed as:

$\mathrm{ET}_{\mathrm{c} \text { act }}=\mathrm{K}_{\mathrm{s}} \mathrm{K}_{\mathrm{c}} \mathrm{ET}_{\mathrm{o}}=\left(\mathrm{K}_{\mathrm{s}} \mathrm{K}_{\mathrm{cb}}+\mathrm{K}_{\mathrm{e}}\right) \mathrm{ET}_{\mathrm{o}}$

which requires knowing the standard values of $\mathrm{K}_{\mathrm{c}}$ and/or $\mathrm{K}_{\mathrm{cb}}$ and the daily estimation of the stress coefficient $\mathrm{K}_{\mathrm{s}}$, as well as the adjustment to climate of standard $\mathrm{K}_{\mathrm{c} \text { mid }}, \mathrm{K}_{\mathrm{c} \text { end }}, \mathrm{K}_{\mathrm{cb} \text { mid }}$ and $\mathrm{K}_{\mathrm{cb} \text { end }}$ values (eqs. 62 and 65 of FAO56). $K_{c}$ ini and $K_{c b}$ ini values have to be determined as recommended by Allen et al. (1998, 2005a,2005b). Indicative $\mathrm{K}_{\mathrm{c}}$ and $\mathrm{K}_{\mathrm{cb}}$ values are tabulated by Allen et al. (1998), Allen and Pereira (2009), Jensen and Allen (2016) and updated by Pereira et al. (2020a,b) and Rallo et al. (2020).

FAO56 expressed $K_{s}$ as a linear function of root zone depletion $D_{r}$ when depletion exceeds the readily available water, RAW (mm), in the root zone, thus:

$\mathrm{K}_{\mathrm{s}}=\frac{\mathrm{TAW}-\mathrm{D}_{\mathrm{r}}}{\mathrm{TAW}-\mathrm{RAW}}=\frac{\mathrm{TAW}-\mathrm{D}_{\mathrm{r}}}{(1-\mathrm{p}) \mathrm{TAW}}$ for $\mathrm{D}_{\mathrm{r}}>\mathrm{RAW}$,

$\mathrm{K}_{\mathrm{s}}=1$ for $\mathrm{D}_{\mathrm{r}} \leq \mathrm{RAW}$

where TAW and RAW are, respectively, the total and readily available soil water ( $\mathrm{mm}$ ), and $\mathrm{p}$ is the soil water depletion fraction for no stress (Allen et al., 1998). TAW is defined as the available soil water stored in the root zone with depth $\mathrm{z}_{\mathrm{r}}(\mathrm{m})$, thus computed as $1000\left(\theta_{\mathrm{FC}}-\theta_{\mathrm{WP}}\right) \mathrm{z}_{\mathrm{r}}$, and RAW corresponds to the readily available portion of TAW, thus $\mathrm{RAW}=\mathrm{p}$ TAW. Updated values for the $\mathrm{p}$ fractions for vegetable and field crops are tabulated by Pereira et al. (2020a, b). The value for $\mathrm{K}_{\mathrm{s}}$ due to salinity stress is discussed in FAO56 (Allen et al., 1998) and in the review paper by Minhas et al. (2020).

Referring to Eq. 9, it may be deduced that when no water stress occurs $\left(K_{s}=1.0\right)$ then $\theta \geq \theta_{p}$, i.e. the soil water content is not below the threshold $\theta_{\mathrm{p}}$, which corresponds to the soil water content when the soil water depletion equals the depletion fraction $\mathrm{p}$ for no stress [0 - 1]. Therefore, $\theta_{\mathrm{p}}$ is assumed as the soil water content threshold for nostress or full irrigation:

$\theta_{\mathrm{p}}=(1-\mathrm{p})\left(\theta_{\mathrm{FC}}-\theta_{\mathrm{WP}}\right)$

A management allowed depletion (MAD) larger than $\mathrm{p}$ is selected when deficit irrigation is adopted, i.e., when the depletion fraction exceeds p. The respective soil water threshold is then $\theta_{\mathrm{MAD}}<\theta_{\mathrm{p}}$ :

$\theta_{\mathrm{MAD}}=(1-\mathrm{MAD})\left(\theta_{\mathrm{FC}}-\theta_{\mathrm{WP}}\right)$

Examples on using these thresholds are given in Section 4.4.

When adopting the dual $\mathrm{K}_{\mathrm{c}}$ approach, it is required to separately compute $\mathrm{K}_{\mathrm{cb}}$ and $\mathrm{K}_{\mathrm{e}}$ and two SWB are required, the one relative to the root zone for computing transpiration, the other relative to the top soil layer, from where evaporation occurs, to compute soil evaporation. A spreadsheet calculator was provided in Annex 8 of FAO56 (Allen et al., 1998). The computation of $K_{e}$ is based upon the assumption that evaporation from the soil is governed by the amount of water available in the upper soil layer from where water evaporates, and the amount of energy available at the soil surface. The latter depends upon the portion of wetted ground surface exposed to radiation and the portion of total energy consumed by transpiration. $\mathrm{K}_{\mathrm{e}}$ is then calculated as:(11)

$K_{e}=K_{r}\left(K_{c \max }-K_{c b}\right) \leq \mathrm{f}_{\text {ew }} \mathrm{K}_{\mathrm{c} \max }$

where $K_{r}$ is the evaporation reduction coefficient [0-1], $f_{e w}$ is the fraction of soil surface wetted and exposed to solar radiation, $\mathrm{K}_{\mathrm{cb}}$ is the basal crop coefficient representing transpiration, and $\mathrm{K}_{\mathrm{c} \max }$ is the maximum value for $K_{c}$ following rain or irrigation (Allen et al., 1998, 2005a). $K_{c} \max$ depends upon mid-season climate, through the wind speed $\mathrm{u}_{2}\left(\mathrm{~m} \mathrm{~s}^{-1}\right)$ and the minimum relative humidity $\mathrm{RH}_{\min }(\%)$, and upon crop height $\mathrm{h}(\mathrm{m})$ :

$K_{c \max }=\max \left\langle\left\{1.2+0.04\left(u_{2}-2\right)-0.004\left(R H_{\min }-45\right)\left(\frac{h}{3}\right)^{0.3}\right\}, K_{c b}+0.05\right\rangle$

where $\mathrm{u}_{2}=2 \mathrm{~m} \mathrm{~s}^{-1}$ and $\mathrm{RH}_{\min }=45 \%$ characterize the standard climate (Allen et al., 1998). The depth of water depleted from the $f_{e w}$ fraction of soil wetted and exposed $\left(D_{e}, \mathrm{~mm}\right)$, is computed from the daily water balance of the upper 0.10 to $0.15 \mathrm{~m}$ of the soil as

$D_{e i}=D_{e i-1}-\left(P_{i}-R O_{i}\right)-\frac{I_{n i}}{f_{w}}+\left(\frac{K_{e} E T_{0}}{f_{e w}}\right)_{i}+T_{s i}$

where the subscript $i$ refers to the day of estimation, $P_{i}$ is the precipitation $[\mathrm{mm}], \mathrm{RO}_{\mathrm{i}}$ is runoff $[\mathrm{mm}], \mathrm{I}_{\mathrm{i}}$ is the net irrigation depth $[\mathrm{mm}]$ that infiltrates the soil in the wetted fraction $f_{w},\left(K_{e} E T_{o} / f_{e w}\right)_{i}$ is the evaporation from the $\mathrm{f}_{\mathrm{ew}}$ fraction of the exposed soil surface $[\mathrm{mm}]$, and $T_{s i}$ is the transpiration from the $f_{w}$ fraction of the evaporating soil layer $[\mathrm{mm}]$. When $\mathrm{D}_{\mathrm{e}}$ exceeds the readily evaporable water (REW), the evaporation rate decreases in proportion to the remaining water. Therefore, $\mathrm{K}_{\mathrm{r}}$ (Eq. 11) is calculated as:

$K_{r}=1$ for $D_{e} \leq R E W$

$K_{r}=\frac{T E W-D_{e}}{T E W-R E W}$ for $D_{e}>R E W$

where REW and TEW are respectively the readily and total evaporable water in the soil evaporation layer of depth $\mathrm{z}_{\mathrm{e}}(\mathrm{m})$, which depend upon the soil textural and hydraulic characteristics of that soil layer. Further details on the water balance of the evaporation layer are discussed by Allen et al. (1998, 2005a) and Rosa et al. (2012a, b).

When the complete soil surface is fully wetted by precipitation or irrigation, the fraction $f_{e w}$ consists of the fraction of ground non-shaded by the vegetation $\left(1-f_{c}\right)$, thus $f_{\text {ew }} p=1-f_{c}$, where $f_{c}$ is the average fraction covered by vegetation $[0-1.0]$. When only a fraction of the soil surface is wetted by irrigation, $f_{e w ~} i=\min \left(1-f_{c}, f_{w}\right)$. These differences in $\mathrm{f}_{\text {ew }}$, thus in $\mathrm{f}_{\text {ew }} \mathrm{K}_{\mathrm{c} \text { max }}$ (Eq. 11), evidence that it is required to compute separately $K_{e}$ for the cases when rainfall and irrigation fully wet the ground, or when irrigation only partially wets the soil, e.g. under drip or furrow irrigation. Different $f_{\text {ew }}$ fractions then occur. A weighing coefficient for partitioning the energy available for soil evaporation depending upon $\mathrm{f}_{\mathrm{c}}$ and $\mathrm{f}_{\mathrm{w}}$ (Allen et al., 2005a, b; Rosa et al., 2012a) eases the daily $\mathrm{K}_{\mathrm{e}}$ computation. 
The fraction $f_{c}$ should be observed in the field as reviewed by Pereira et al. (2020c); otherwise, it may be estimated according to Allen et al. (1998) as:

$f_{c}=\left(\frac{K_{c b}-K_{c \min }}{K_{c \max }-K_{c \min }}\right)^{1+0.5 h}$

where $K_{c \text { min }}$ is the minimum $K_{c}$ for dry, bare soil, generally 0.15 . The exponent " $1+0.5 \mathrm{~h}$ " represents the effect of plant height on shading the soil and increasing the $\mathrm{K}_{\mathrm{cb}}$ given a specific value for $\mathrm{f}_{\mathrm{c} \cdot}\left(\mathrm{K}_{\mathrm{cb}}-\mathrm{K}_{\mathrm{c} \min }\right) \geq$ 0.01 for numerical stability.

Eq. 11 is the base for partitioning ET. On the one hand, it shows that when the crop develops, from the initial to the mid-season stage, $\mathrm{K}_{\mathrm{cb}}$ increases and the difference $\mathrm{K}_{\mathrm{c} \text { max }}-\mathrm{K}_{\mathrm{cb}}$ therefore decreases, as well as the fraction $\mathrm{f}_{\mathrm{ew}}$ since $\mathrm{f}_{\mathrm{c}}$ also increases. Therefore, $\mathrm{K}_{\mathrm{e}}$ decreases as much as $\mathrm{K}_{\mathrm{cb}}$ and $\mathrm{f}_{\mathrm{c}}$ increase. Contrarily, during the late season $\mathrm{K}_{\mathrm{e}}$ increases because $K_{c b}$ and $f_{c}$ decrease. The rates of $K_{c b}$ and $f_{c}$ variation, thus of $K_{e}$ decrease or increase, change from a crop to another and with the management practices, with $\mathrm{K}_{\mathrm{cb}}$ varying also with water and salinity stress $\left(K_{s}\right.$, Eq. 9). On the other hand, $K_{e}$ varies with the water amount available for evaporation, which depends upon $\mathrm{K}_{\mathrm{r}}$ with the irrigation method and frequency of irrigation. The advantage of the adopted approach results from combining the variation of $\mathrm{K}_{\mathrm{cb}}$ and $\mathrm{K}_{\mathrm{e}}$ and adopting $\mathrm{K}_{\mathrm{c} \max }$ as the upper limit for $\mathrm{K}_{\mathrm{cb}}+\mathrm{K}_{\mathrm{e}}$. Therefore, there is the need for performing daily the water balance of the soil evaporation layer in addition to the root zone water balance, which increases the accuracy of computations. A discussion comparing the ET partition using the FAO56 dual $\mathrm{K}_{\mathrm{c}}$ approach with that used in the popular AquaCrop model has been presented by Pereira et al. (2015b), which highlights the strengths and weaknesses of the FAO56 dual $\mathrm{K}_{\mathrm{c}}$ approach. As referred by DeJonge and Thorp (2017), reported results with maize and cotton have shown that crop coefficient simulations with the dual " $\mathrm{ET}_{\mathrm{o}}-\mathrm{K}_{\mathrm{cb}}$ method better mimicked theoretical behavior, including spikes in the soil evaporation coefficient $\left(\mathrm{K}_{\mathrm{e}}\right)$ due to irrigation and rainfall events and basal crop coefficient response as associated with simulated crop growth." Consequently, the FAO56 approach has been implemented with the DSSAT Crop System Model (DeJonge and Thorp, 2017).

\subsection{Soil water balance: transient state models}

Mechanistic approaches to the SWB commonly compute variablysaturated water flow as described by Richards' equation:

$\frac{\partial \theta}{\partial t}=\frac{\partial}{\partial z}\left[K(h) \frac{\partial h}{\partial z}-K(h)\right]-S(z, t)$

where $\theta$ is the volumetric soil water content $\left[\mathrm{L}^{3} \mathrm{~L}^{-3}\right], t$ is time $[\mathrm{T}], \mathrm{z}$ is the vertical space coordinate $[\mathrm{L}], \mathrm{h}$ is the pressure head $[\mathrm{L}], \mathrm{K}$ is the hydraulic conductivity $\left[\mathrm{L} \mathrm{T}^{-1}\right]$, and $\mathrm{S}$ is the sink term accounting for water uptake by plant roots $\left[\mathrm{L}^{3} \mathrm{~L}^{-3} \mathrm{~T}^{-1}\right]$. The unsaturated soil hydraulic properties are often described with the van Genuchten-Mualem functional relationships (van Genuchten, 1980). These relationships require appropriate calibration.

The sink term, S, may be calculated using the Feddes et al. (1978) approach where the potential transpiration rate, $\mathrm{T}_{\mathrm{p}}\left[\mathrm{L} \mathrm{T}^{-1}\right]$, is distributed over the root zone using the normalized root density distribution function, $\beta(\mathrm{z}, \mathrm{t})\left[\mathrm{L}^{-1}\right]$, and multiplied by the dimensionless stress response function, $\alpha\left(h, h_{\phi}, z, t\right)$, that accounts for water and osmotic stresses. In HYDRUS-1D (Šimünek and Hopmans, 2009; Ramos et al., 2011) we have:

$S\left(h, h_{\Phi}, z, t\right)=\alpha\left(h, h_{\Phi}, z, t\right) S_{p}(z, t)=\alpha\left(h, h_{\Phi}, z, t\right) \beta(z, t) T_{p}(t)$

where $S_{p}(z, t)$ and $S\left(h, h_{\phi}, z, t\right)$ are the potential and actual volumes of water removed from unit volume of soil per unit of time $\left[\mathrm{L}^{3} \mathrm{~L}^{-3} \mathrm{~T}^{-1}\right]$, respectively, and $\alpha\left(h, h_{\phi}, z, t\right)$ is a prescribed dimensionless function of the soil water $(h)$ and osmotic $\left(h_{\phi}\right)$ pressure heads $(0 \leq \alpha \leq 1)$. The actual transpiration rate, $T_{a}\left[\mathrm{~L} \mathrm{~T}^{-1}\right]$, is obtained by integrating Eq. (13) over the root domain $L_{R}$ :

$T_{a}=\int_{L_{R}} S\left(h, h_{\phi}, z, t\right) d z=T_{p} \int_{L_{R}} \alpha\left(h, h_{\phi}, z, t\right) \beta(z, t) d z$

It is generally assumed that the potential root water uptake is reduced when water stress occurs due to deficit irrigation and/or osmotic potential resulting from soil salinity or the use of saline irrigation waters. While the Richards' equation is commonly adopted in a variety of models, the sink term may be different from a model to another. For solving the Richards' equation, the formulation of the boundary conditions may be diverse. In SWAP (Vazifedoust et al., 2008; Xu et al., 2013), the upper boundary condition is determined by the fluxes of potential evapotranspiration computed with the PM-eq (Eq. 3). The model does not use the FAO56 method but it allows computing the actual $K_{c}$ (Xu et al., 2013). Differently, with HYDRUS, the $K_{c}-E_{o}$ approach is often used to define the potential ET flux at the upper boundary (Ramos et al., 2011); alternatively, Ramos et al. (2012) used the sum $\mathrm{K}_{\mathrm{cb}}-\mathrm{ET}_{\mathrm{o}}$ and $\mathrm{K}_{\mathrm{e}}-\mathrm{ET}_{\mathrm{o}}$ with $\mathrm{K}_{\mathrm{cb}}$ and $\mathrm{K}_{\mathrm{e}}$ obtained with a dual $\mathrm{K}_{\mathrm{c}}$ partition tool. Transient state models may be calibrated purposefully for scheduling irrigation under selected conditions, e.g. the model SWB-2D for drip irrigated hedgerow orchards (Annandale et al., 2003). Transient state models usually perform the partition of $\mathrm{ET}_{\mathrm{c} \text { act }}$ with reference to the crop leaf area index (LAI), particularly when knowing its maximum values, $\mathrm{LAI}_{\text {max }}$.

Because transient state models focus on the accurate simulation of water fluxes within and through the boundaries of the soil root zone, these models accurately compute DP and CR and, often also RO. When applied to rice, they can also simulate water depth in the paddies (Bhadra et al., 2013). These models may be used to parameterize steady state SWB models, e.g. the WAVE model was used to define the parametric DP and CR equations adopted in the model ISAREG (Liu et al., 2006) and later in SIMDualKc. Transient state models, since they are mechanistic models that accurately simulate the dynamics of transpiration, are commonly integrated with crop growth and yield models, e.g. SWACROP (Kabat et al., 1992) and SWATRER-SUCROS (Xevi and Feyen, 1992). Currently, coupling of transient state and crop growth and yield models is commonly adopted, e.g. WOFOST and HYDRUS-1D (Zhou et al., 2012) or SWAP and EPIC (Xu et al., 2013).

The advantage of transient state models is that soil water processes can be accurately described mechanistically, e.g. infiltration and water redistribution, root water uptake, deep percolation and capillary rise. However, the inputs of soil hydraulic properties, such as the soil water retention and permeability curves (respectively $\theta(\mathrm{h})$ and $\mathrm{K}(\mathrm{h})$ curves), are much more exigent than for simpler SWB models in terms of data acquisition and $\theta(\mathrm{h})$ and $\mathrm{K}(\mathrm{h})$ calibration. Often, the inverse model simulation needs to be adopted for their calibration before application. In addition, the vegetation parameters needed are much more complex than for FAO56-based SWB models. Therefore, these models are hard to parameterize and calibrate resulting more suitable for agronomic and irrigation research, and when assessing nitrates, chemicals and salinity dynamics in relation to crop growth and yield. Differently, the SWB models adopting the FAO56 methods are easier to use and appropriate to support practical irrigation scheduling and planning, as well as to assess the performance of irrigation management options. Along this line, the crop simulation models DSSAT-CSM, which basically require an accurate prediction of transpiration to predict biomass and yield accurately, recently adopted the FAO56 approaches (DeJonge and Thorp, 2017), namely the grass reference $\mathrm{ET}_{\mathrm{o}}$ and the FAO56 dual $\mathrm{K}_{\mathrm{c}}$ approach.

\subsection{Crop yields prediction and performance indicators for irrigation scheduling}

Knowledge of yield responses to water is required to construct irrigation scheduling models, namely aiming at developing appropriate 
irrigation schedules that cope with the variability of climatic conditions, water availability limitations, and the need to improve yields and economic returns. Crop growth models may then be used to predict biomass and yields in combination with predicted or assessed crop and irrigation management practices. The DSSAT-CSM models are often used for assessing yields when comparing irrigation management options (DeJonge et al., 2012; Thorp et al., 2014). By recently adopting the FAO56 $\mathrm{K}_{\mathrm{cb}}-\mathrm{ET}_{\mathrm{o}}$ approach (Thorp et al., 2017), their use for assessing irrigation management options resulted easier to interpret. The crop growth and yield SWB AquaCrop (Raes et al., 2016) is also commonly used but, contrarily to the DSSAT models, its approach to calculating ET diverges from the FAO56 method. Another approach consists of coupling a crop model with a transient state model. e.g. WOFOST and HYDRUS-1D (Zhou et al., 2012) or SWAP and EPIC (Xu et al., 2013). These models may be very demanding in terms of parameterization and input data, but they are suitable when dealing with complex hydrologic and water quality conditions.

Simple yield prediction approaches, such as the one by Jensen (1968), consist of a multiplicative parametric function that combines the effects of limited soil water on yield at various crop growth stages. Hanks (1974) developed the model PLANTGRO assuming that total dry matter production is directly proportional to the seasonal transpiration. For grain yield predictions, Hanks (1974) adapted the Jensen (1968) model and developed a multi-stage model (Hanks and Hill, 1980), while Stewart et al. (1977) assumed a linear dependence of the relative yield deficit from the relative evapotranspiration deficit, which is described as:

$1-\frac{Y_{\mathrm{a}}}{\mathrm{Y}_{\mathrm{m}}}=\mathrm{K}_{\mathrm{y}}\left(1-\frac{\mathrm{ET}_{\mathrm{cact}}}{E T_{\mathrm{c}}}\right)$

where $\mathrm{K}_{\mathrm{y}}$ is the yield response factor, $\mathrm{Y}_{\mathrm{a}}$ and $\mathrm{Y}_{\mathrm{m}}$ are, respectively, the actual and maximum (potential) yields $\left(\mathrm{kg} \mathrm{ha}^{-1}\right)$, and $\mathrm{ET}_{\mathrm{c}}$ act and $\mathrm{ET}_{\mathrm{c}}$ are, respectively, the actual and potential crop evapotranspiration $(\mathrm{mm})$ corresponding to the yields $\mathrm{Y}_{\mathrm{a}}$ and $\mathrm{Y}_{\mathrm{m}}$. $\mathrm{Y}_{\mathrm{m}}$ may be observed or estimated. $\mathrm{ET}_{\mathrm{c}}$ act and $\mathrm{ET}_{\mathrm{c}}$ may be observed or computed with a SWB model. $\mathrm{K}_{\mathrm{y}}$ values are tabulated for a wide range of crops (Doorenbos and Kassam, 1979) and they were updated recently (Minhas et al., 2020). Stewart et al. (1977) also proposed a multiple linear phasic model to account for the effects of water deficit during the vegetative, flowering and maturation stages using specific yield response factors $\left(\beta_{i}\right)$ for each stage $i$, which were tabulated by Doorenbos and Kassam (1979).

Considering that transpiration is the ET component directly responsible for yield formation, and that various models perform the partition of ET, hence estimating transpiration, a modified version of Stewart's model (Paredes et al., 2014) may be used to estimate $\mathrm{Y}_{\mathrm{a}}$ :
$\hat{Y}_{\mathrm{a}}=\mathrm{Y}_{\mathrm{m}}-\frac{\mathrm{Y}_{\mathrm{m}} \mathrm{K}_{\mathrm{y}}\left(\mathrm{T}_{\mathrm{c}}-\mathrm{T}_{\mathrm{c} \text { act }}\right)}{\mathrm{T}_{\mathrm{c}}}$

where $T_{c}$ act and $T_{c}$ are, respectively, the seasonal actual and potential crop transpiration (mm), thus replacing ET in Eq. (19). Research has shown that both Stewart's global and phasic models predict yields with appropriate accuracy for evaluating irrigation schedules, namely when using Eq. (20) with $\mathrm{T}_{\mathrm{c} \text { act }}$ data computed with the SIMDualKc model. Fig. 1a shows that maize yield predictions with Eq. (20) match well the yields observed in experiments carried out in both Portugal and Uruguay (Paredes et al., 2014; Giménez et al., 2016), and Fig. 1b shows a similar match of soybean yields relative to experiments developed in China and Uruguay (Wei et al., 2015; Giménez et al., 2017).

Water scarcity and global change lead irrigation water use to essentially aim at increased water productivity, water conservation and water saving. Water conservation refers to every policy, managerial measure, or user practice that aims at conserving or preserving the water resources and combating its degradation, namely focusing on its quality, while water saving aims at limiting or controlling the water demand and use, thus avoiding wastes and the misuse of water (Pereira et al., 2012; Pereira, 2017). A comprehensive analysis on water conservation and saving measures and practices for a variety of agricultural uses was presented by Pereira et al. $(2009,2012)$ and Jovanovic et al. (2020).

Water productivity in agriculture (WP, $\mathrm{kg} \mathrm{m}^{-3}$ ), also known as water use efficiency, may be generically defined as the ratio between the actual crop yield achieved $\left(\mathrm{Y}_{\mathrm{a}}\right)$ and the corresponding water use, which may refer to the total water use (TWU), hence including rainfall, to the irrigation water use (IWU), to the consumptive use (ET $\mathrm{C}_{\mathrm{c} \text { act }}$ ), or just to crop transpiration $\left(\mathrm{T}_{\mathrm{c} \text { act }}\right)$. Therefore, different indicators result to assess diverse irrigation scheduling scenarios:

$\mathrm{WP}_{\text {total }}=\frac{\mathrm{Y}_{\mathrm{a}}}{\mathrm{TWU}}=\frac{\mathrm{Y}_{\mathrm{a}}}{\mathrm{P}+\mathrm{CR}+\Delta \mathrm{SW}+\mathrm{I}}$

$\mathrm{WP}_{\text {Irrig }}=\frac{\mathrm{Y}_{\mathrm{a}}}{\mathrm{IWU}}$

$\mathrm{WP}_{\mathrm{ET}}=\frac{\mathrm{Y}_{\mathrm{a}}}{\mathrm{ET}_{\mathrm{c} \mathrm{act}}}$

$\mathrm{WP}_{\mathrm{Tc}}=\frac{\mathrm{Y}_{\mathrm{a}}}{\mathrm{T}_{\mathrm{c} \text { act }}}$

where $\mathrm{P}$ is rainfall, $\mathrm{CR}$ is capillary rise or groundwater contribution, $\Delta S W$ is the variation in soil water storage in the root zone from planting to harvesting, $\mathrm{I}$ is the amount of irrigation, $\mathrm{ET}_{\mathrm{c} \text { act }}$ is the actual crop evapotranspiration, and $\mathrm{T}_{\mathrm{c}}$ act is the actual crop transpiration, all expressed in $\mathrm{m}^{3}$ and referring to the crop season. $\mathrm{Y}_{\mathrm{a}}$ in Eqs. (21) through

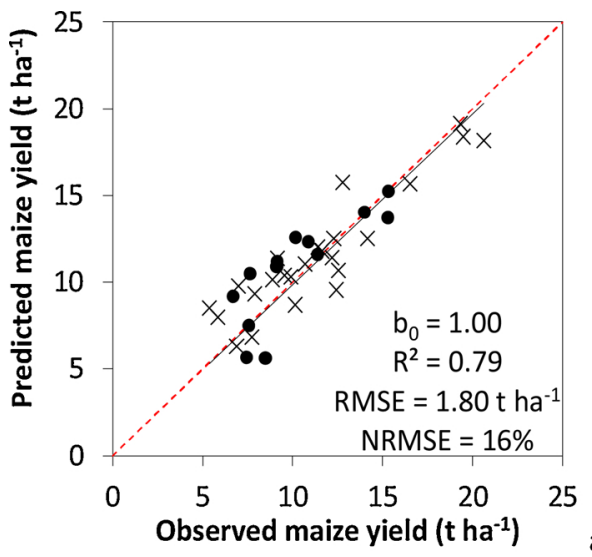

(x) Data from Paredes et al. (2014)

(•) Data from Giménez et al. (2016)

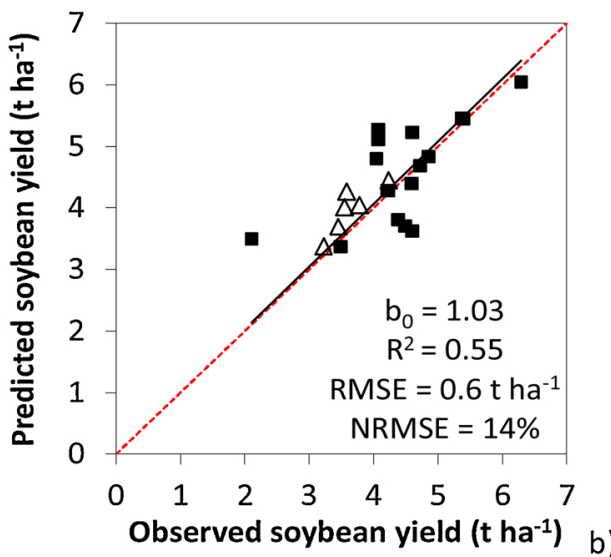

Fig. 1. Observed vs. predicted yield using the modified Stewart equation (Eq. 16) with transpiration data derived from field observations using the SIMDualKc model for (a) maize and (b) soybean $\left(b_{0}\right.$ - regression coefficient of a linear regression forced to the origin; $\mathrm{R}^{2}-$ coefficient of determination of the ordinary least squares regression, RMSE - root mean square error, NRMSE - normalized root mean square error).
(घ) Data from Wei et al. (2015)

$(\Delta)$ Data from Giménez et al. (2017) 
(24) may be observed, or may be estimated with a crop growth and yield model or with a simple water-yield parametric function as reported above. The meaning of indicators in Eqs. (21)-(24) is necessarily different and indicators should be selected considering the actual farming objectives, the respective implications in terms of resource, environment and climate change, and the data availability. An application of similar WP concepts to olive orchards, including a related economic analysis, was recently discussed by Fernández et al. (2020).

Improving WP could lead to water saving in irrigation but it requires the consideration of various factors. WP may be increased by minimizing the non-beneficial water uses such as percolation through the bottom of the root zone, runoff out of the irrigated fields, and losses by evaporation and wind drift in sprinkling. A high WP could be attained when increasing yields but, often, a higher WP is obtained when the crop is deliberately under-irrigated, thus when water stress is allowed in some less-sensitive crop stages; nevertheless, a yield reduction will then occur.

\section{Overview of models aimed at improved irrigation scheduling}

\subsection{Soil water balance simulation models from FAO24 to FAO56}

Many models have been proposed since the early 1980's following the publication of FAO24 (Doorenbos and Pruitt, 1977), which has been the landmark in the domain of crop water requirements and irrigation scheduling.

Model papers considered herein limit to those having an identified software, adequate reference to calibration and/or validation, and not referring to single uses only. In addition, since the objectives of the current review refer to FAO56 with focusing on the dual $\mathrm{K}_{\mathrm{c}}$ approach and considering that transient state models are dealt in Section 2.4, the reviewed SWB refer to models using a $\mathrm{K}_{\mathrm{c}}$ approach, mainly referring to FAO24 and to FAO56.

Numerous SWB models have been developed since the 1980's as early reviewed by Lascano (1991). Related articles were often presented in research reports or to scientific conferences (ASAE, 1981, 1990; Feyen, 1987; Pereira et al., 1992, 1995; Smith et al., 1996; Ragab et al., 1996). These articles show a great variety of approaches, using the FAO $\mathrm{K}_{\mathrm{c}}-\mathrm{ET}_{\mathrm{o}}$ and/or transient state models, which received the preference of researchers by that time (Belmans et al., 1983). Developments also included landscape and turf grass irrigation. $\mathrm{ET}_{\mathrm{o}}$ equations were diverse because FAO24 (Doorenbos and Pruitt, 1977) proposed various alternative equations. Howell et al. (1990) presented a first application of the Penman-Monteith grass reference equation proposed by Allen et al. (1989) when a commonly used $\mathrm{ET}_{\mathrm{o}}$ equation was the Penman equation. Without a common $\mathrm{ET}_{\mathrm{o}}$ definition and equation, standard $\mathrm{K}_{\mathrm{c}}$ values could not be defined despite a consolidated set of $\mathrm{K}_{\mathrm{c}}$ values was presented in FAO24 (Doorenbos and Pruitt, 1977) for numerous field, vegetable and woody crops. These authors proposed the well-known segmented FAO $\mathrm{K}_{\mathrm{c}}$ curve but various curvilinear approaches were in use (e.g., Wright, 1982; HiIl, 1991). However, the segmented $\mathrm{K}_{\mathrm{c}}$ curve was adopted by several authors (Howell et al., 1990; Combre and Kamieniarz, 1992; Teixeira and Pereira, 1992).

Single $\mathrm{K}_{\mathrm{c}}$ models of the 80's and 90's were often developed for application at farm level and evolved to support farm irrigators' communities. A first model has been developed with CIMIS, the California Irrigation Management Information System (Snyder, 1986), which keeps evolving nowadays and is based on a large grid of weather stations and a very large number of users (https://cimis.water.ca.gov/ accessed on 27 May 2020) and partners. Among the latter is the Satellite Irrigation Management Support framework (SIMS, Melton et al., 2012, 2020). The model CROPWAT (Smith, 1988, 1992) is paradigmatic since it consisted of a database built from FAO24 data (Doorenbos and Pruitt, 1977), a supplementary CLIMWAT weather database, a reference ET calculator and a water balance computational tool able to propose an irrigation scheduling calendar for the selected crop, soil and field. The model was updated after the FAO experts consultation on crop water requirements (Smith et al., 1991) and the publication of FAO 56, and has been successively upgraded. The version CROPWAT 8.0 has been recently released.

BIdriCo (Danuso et al., 1995) is updated and is operating with real time weather data to support irrigation farmers of the Friuli Venezia Giulia region, Italy. IRRICANNE is an irrigation scheduling simulation model (Combre and Kamieniarz, 1992) designed to support sugarcane producers and was used for many years in the Island of Reunion. The model RENANA (Giannerini, 1995) was applied to support farmers irrigation scheduling in the Emilia-Romagna Region and evolved to a large-scale web based DSS, IRRINET, in use by farmers of various regions of Italy (Mannini et al., 2013), as well as to support irrigation water delivery (Genovesi et al., 2019).

Three models early reported - IRSIS (de Goes Calmon et al., 1992), ISAREG (Teixeira and Pereira, 1992) and PILOTE (Mailhol et al., 1996) - were designed for both research and application in the field practice. IRSIS (Raes et al., 1988) was modified to produce BUDGET (Raes et al., 2006) that was further developed with extensions for improved water balance and yield assessment (Shrestha et al., 2010), then becoming the SWB basis of the crop model AquaCrop (Raes et al., 2016). ISAREG adopted the PM-ET o equation following the FAO Expert Consultation that decided its adoption (Smith et al., 1991). ISAREG was first modified to support real time farmers advising with the development of RELREG (Teixeira et al., 1995), later turning into a web based DSS, WEBISAREG (Branco et al., 2005), and developing GIS facilities, HYDROGEST (Mateus et al., 2007). However, since the Irrigation Associations did not develop local support to farmers, the model was used essentially for research after adoption of computational tools relative to DP, CR and salinity (Pereira et al., 2007, 2009). It is currently used in several countries, e.g. Brazil (Saraiva et al., 2017), Bulgaria (Popova et al., 2014) and China (Zheng et al., 2014). Meanwhile, ISAREG was the base of SIMDualKc (Rosa et al., 2012a), described in the next Section. PILOTE software has been continuously improved and it became a crop model with various capabilities including irrigation and crop management (Mailhol et al., 2004, 2018).

CADSM (Walker et al., 1995) was the first distributed SWB model aimed at computing the aggregated irrigation demand at the command area of a collective irrigation system using the $\mathrm{K}_{\mathrm{c}}-\mathrm{ET}_{\mathrm{o}}$ approach. It was also one of the first models using the PM-ET ${ }_{\mathrm{o}}$ equation after it was proposed to a wide audience (Allen et al., 1994a,b). Similarly, the combined use of the ISAREG model and the paddy basins simulation model IRRICEP (Paulo et al., 1995) was adopted to simulate the demand hydrographs at the sector level in a collective irrigation system using the FAO methods (Teixeira et al., 1996).

Buchleiter (1995) presented the model SCHED for scheduling irrigations with a center-pivot system. However, this type of approach is currently replaced by precision irrigation software, namely variable rate scheduling with support of wireless sensors (e.g. O'Shaughnessy et al., 2012).

Hess (1996) reported on a microcomputer irrigation-scheduling model to be available for farmers since they were progressively adopting such computing facilities; however, with changes in hardware the approach was abandoned. The SIMDSS (Malano et al., 1996) was developed for practical irrigation scheduling and improved surface irrigation practices aimed at an integrated real-time management for pastures in SE Australia. MARKVAND was a DSS system for farmers use in Denmark, which software provides information on timing and volumes of irrigation as well as on the expected economic returns (Plauborg et al., 1996). Changes in technologies led to abandon these type of models.

Models including the partitioning of ET into transpiration and soil evaporation were rare. The first was reported by Wright (1982) but his pioneer approach aimed at deriving $\mathrm{K}_{\mathrm{cb}}$ when soil water evaporation could be considered nil, i.e. the soil surface was dry but transpiration was near optimal. The approach applied well to infrequent water 
applications but not to highly frequent wettings; however, data reported by this author have been fundamental in developing the FAO56 dual $\mathrm{K}_{\mathrm{c}}$ approach (Allen et al., 1998). Tuzet et al. (1992) developed an approach where ET partition was supported by the observed LAI. Many researchers lately followed a LAI approach for partitioning ET. Further developments in using a dual $\mathrm{K}_{\mathrm{c}}$ were initiated after publication of FA056, mainly using its spreadsheet for calculation of $\mathrm{K}_{\mathrm{cb}}$ and $\mathrm{K}_{\mathrm{e}}$, which still is used at present.

A first SWB model relative to paddy rice using the $\mathrm{K}_{\mathrm{c}}-\mathrm{ET}_{\mathrm{o}}$ approach, the IRRICEP model, was reported by Paulo et al. (1995). The model required not only the calibration of $\mathrm{K}_{\mathrm{c}}$ values but the calibration of soil hydraulic properties determining the computation of percolation adopting a Darcy approach, as well as lateral seepage to downstream paddies and drainage ditches. That model was later used by Mao et al.

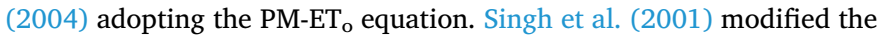
model SAWAH to adopt the $\mathrm{K}_{\mathrm{c}}-\mathrm{ET}_{\mathrm{o}}$ approach and a partition of actual crop ET based upon an empirical exponential function of LAI. Agrawal et al. (2004) developed a Visual Basic SWB model where the $\mathrm{K}_{\mathrm{c}}-\mathrm{ET}_{\mathrm{o}}$ is used, seepage is computed with the Dupuit approach and percolation is determined with a soil water simulation using partial differential equations distinguishing water ponded conditions and unsaturated conditions when intermittent irrigation is used. Transient state approaches for the ponded and the unsaturated conditions were also used by Khepar et al. (2000) when modeling intermittent paddy irrigation. A different approach is reported by Jeon et al. (2005), who developed PADDIMOD. In this model, surface drainage and percolation are estimated with parametric equations, which require parameters calibration. These referred models, despite posterior to the publication of FAO56, did not adopt the PM-ET o $_{\mathrm{o}}$ equation but FAO24 equations.

\subsection{Soil water balance simulation models after FAO56}

This review focused only on SWB simulation models using the FAO56 $\mathrm{K}_{\mathrm{c}}-\mathrm{ET}_{\mathrm{o}}$ approach and which calibration and validation procedures are recognizable. Many other publications on SWB models not using the $\mathrm{K}_{\mathrm{c}}-\mathrm{ET}_{\mathrm{o}}$ method and not adopting the $\mathrm{PM}-\mathrm{ET}_{\mathrm{o}}$ equation were not considered. The selected SWB models are presented in Table 1 for those using the single time averaged $\mathrm{K}_{\mathrm{c}}$, while Table 2 refers to the SWB models using the FAO56 dual $\mathrm{K}_{\mathrm{c}}$ approach (see Section 2.3 above) or a similar approach where LAI replaces $\mathrm{f}_{\mathrm{c}}$.

Single $\mathrm{K}_{\mathrm{c}}$ models in Table 1 are diverse in terms of the target crops; these can be single annual crops, e.g. maize, wheat, cotton or paddy rice, or various annuals and/or perennials. They have in common the use of the FAO56 PM-ET P $_{\mathrm{o}}$ equation, in some cases also considering alternative temperature based methods, and the use of the stress coefficient $\mathrm{K}_{\mathrm{s}}$ (Eq. 9), including modifications for paddies water balance. Models have a variety of base input parameters. Soil base parameters commonly include $\theta_{\mathrm{FC}}$ and $\theta_{\mathrm{WP}}$, but $\theta_{\text {sat }}$ and $\mathrm{K}_{\mathrm{sat}}$ may also be included when deep percolation and capillary rise are among the model outputs. Only one model (ISAREG) uses the input of electrical conductivity of the soil saturation extract $\left(\mathrm{EC}_{\mathrm{e}}, \mathrm{dS} \mathrm{m}^{-1}\right)$ to compute the ET reduction due to salinity $\left(\mathrm{ET}_{\text {salt }}\right)$ as described in FAO56 and by Minhas et al. (2020). All reported models were calibrated and validated, generally using SWC data, a few using $\mathrm{ET}_{\mathrm{c}}$ act or $\mathrm{T}_{\mathrm{c}}$ act (Consoli et al., 2016; Mancosu et al., 2016), and the ponded water depths in case of paddy rice (de Silva and Rushton, 2008; Inthavong et al., 2011). The model outputs are diverse but all models, in addition to ET, provide DP estimates. Several models also compute RO but CR is only provided by few models (Pereira et al., 2003; Shang and Mao, 2006; Chopart et al., 2007; Boegh et al., 2009; Consoli et al., 2016). Paddy water models outputs refer to the ponded water and to DP, seepage and drainage. References to the possible use of remote sensing data are very limited.

SWB models using the dual $\mathrm{K}_{\mathrm{c}}$ approach are referred in Table 2. As for single $\mathrm{K}_{\mathrm{c}}$ models, they are diverse in terms of the target crops but most of them can be used with both annual and perennial crops. A few refer to annuals or only to specific crops (wheat, maize, groundnuts and

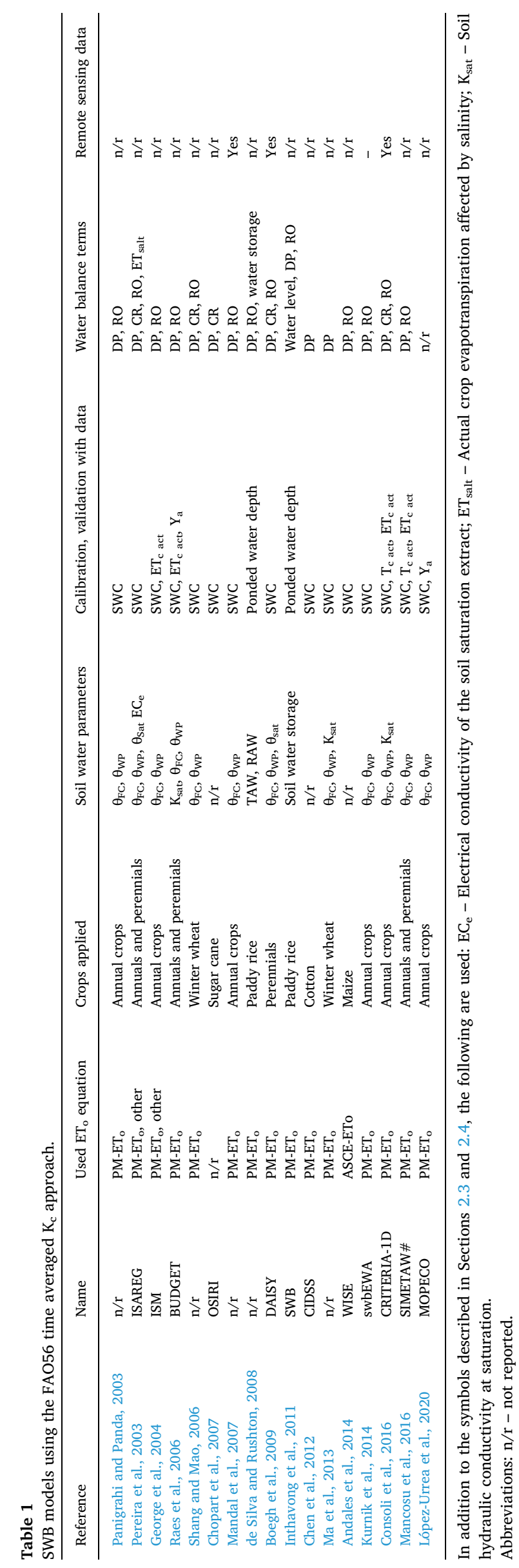




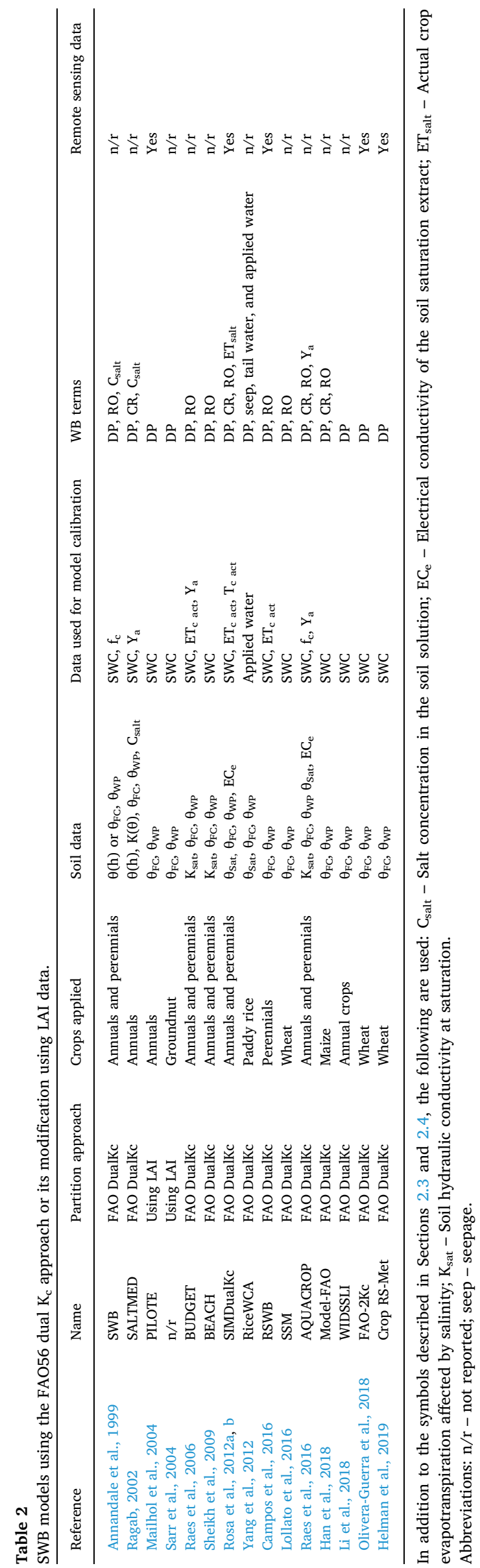

paddy rice). All use the $\mathrm{PM}-\mathrm{ET}_{\mathrm{o}}$ equation and the stress coefficient $\mathrm{K}_{\mathrm{s}}$ (Eq. 9), including those modified for paddies. Models have a variety of base soil input parameters. Soil parameters commonly include $\theta_{\mathrm{FC}}$ and $\theta_{\mathrm{WP}}$, a few $\theta_{\mathrm{sat}}$ and $\mathrm{K}_{\mathrm{sat}}$, and some models (Annandale et al., 1999; Ragab, 2002) also have a transient state approach and require $\theta(\mathrm{h})$ and $\mathrm{K}(\theta)$. Salinity base data on $\mathrm{EC}_{\mathrm{e}}$ are used in the AQUACROP and SIMDualKc models, while SALTMED and "SWB" use the salt concentration in the soil water. Models are calibrated and validated with SWC data but some models may be calibrated with $\mathrm{ET}_{\mathrm{c} \text { act }}$ or $\mathrm{T}_{\mathrm{c}}$ act data (Rosa et al., 2012a, b; Campos et al., 2016); when they also predict actual yields, $\mathrm{Y}_{\mathrm{a}}$ data may also be used for calibration (Ragab, 2002; Raes et al., 2012). Model outputs are diverse but all models, in addition to $\mathrm{ET}_{\mathrm{c} \text { act }}$ and $\mathrm{T}_{\mathrm{c}}$ act, provide for DP while a few also compute RO. The computation of $\mathrm{CR}$ is only available from the models SALTMED, AquaCrop, SIMDualKc and the model reported by Han et al. (2018). The paddy rice model RiceWCA (Yang et al., 2012) outputs are different from those referred before and include the predicted applied water, DP, seepage, and tail water runoff. A few models refer to the possibility of using remote sensing-retrieved data. This review recognized that few models are able to compute groundwater contribution from a water table as well as impacts of salinity.

DSSAT crop models using $\mathrm{K}_{\mathrm{c}}-\mathrm{ET}_{\mathrm{o}}$ with the dual $\mathrm{K}_{\mathrm{c}}$ approach (DeJonge and Thorp, 2017) could be added in Table 2 but they are very different from the listed models and rarely used for irrigation scheduling. Farmers' information models commonly using $\mathrm{K}_{\mathrm{cb}}$ values derived from remote sensing vegetation indices, such as SIMS (Melton et al., 2012, 2020; Cahn and Johnson, 2017), consist also of a peculiar group of dual $\mathrm{K}_{\mathrm{c}}$ models that require mention.

For selecting the best crop irrigation schedules, the SWB models adopt user-friendly software that helps the users to handle data and, often, to compute indicators such as those referred in Section 2.5. Performance scenarios may be the object of ranking, e.g. when DSS approaches adopt multi-criteria analysis as discussed by Darouich et al. (2014, 2017), namely when the selection of irrigation schedules is tied to the performance of the irrigation method. However, the use of multicriteria analysis is rare in irrigation scheduling and, commonly, only simple comparisons of indicators are used (Paredes et al., 2014, 2017a,b; Pereira et al., 2015b).

\section{The dual $\mathrm{K}_{\mathrm{c}}$ soil water balance approach using the model SIMDualKc}

\subsection{Brief presentation of the model}

SIMDualKc is a quite unique software model that performs a daily soil water balance at the field scale (Rosa et al., 2012a,b) adopting the dual $\mathrm{K}_{\mathrm{c}}$ approach to compute and partition crop ET into $\mathrm{T}_{\mathrm{c}}$ and $\mathrm{E}_{\mathrm{s}}$.

Data inputs and model outcomes are described in Fig. 2 where the flowchart of the model is presented. In general, compulsory data inputs are common to other SWB models that adopt the FAO56 dual $\mathrm{K}_{\mathrm{c}}$ approach, although requirements may change with the type of algorithms used in computations. Facultative data differ depending upon the specific objectives of the simulation. This is the case for data used to compute runoff, deep percolation, groundwater contribution, as well as effects of mulches and no-till planting, active ground cover, intercropping, and soil and water salinity. Naturally, model outcomes also differ depending on the modelling objectives.

Model calibration consists of adjusting the influential model parameters within their reasonable ranges so that the model results are consistent with available observed data, thus estimation errors are minimized. The process of validation permits the verification of the goodness of fitting when the model is used with the set of calibrated parameters but with different, independent data sets, without tuning such parameters. Calibration and validation of models and appropriate goodness-of-fit indicators are a must for every model as discussed by several authors (e.g., Moriasi et al., 2007; Wang et al., 2012) and by 


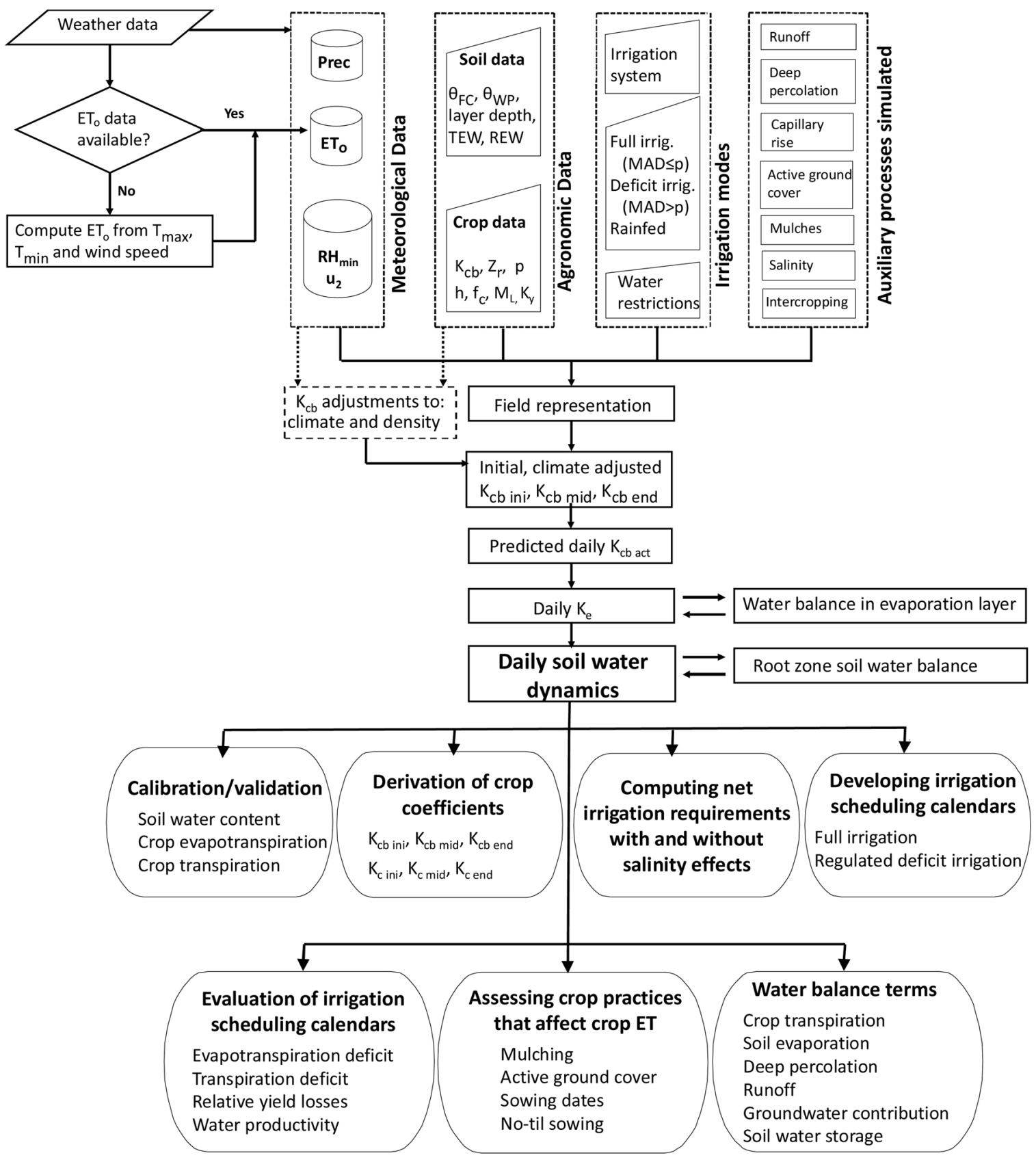

Fig. 2. Simplified flowchart of SIMDualKc model (modified from Rosa et al., 2012a).

Pereira et al. (2015b) relative to SIMDualKc.

The calibration parameters of SIMDualKc consist of: $\mathrm{K}_{\mathrm{cb}}$ and $\mathrm{p}$ relative to the various crop growth stages; $\mathrm{Z}_{\mathrm{e}}$, TEW and REW characterizing the soil evaporation layer; the parameter $\mathrm{CN}$ relative to the runoff algorithm; and the parameters relative to the DP and CR parametric functions. Initial sets of these parameters are inputs to the model, which are improved through calibration. Soil water content observations are the most commonly used for calibration, e.g. Fandiño et al. (2012, 2015) for a vineyard and for hop for industry, Zhao et al. (2013) for maize and wheat, Wu et al. (2016) for a groundwater dependent grassland, and Paredes et al. (2017a) relative to pea for industry. Calibration may also be performed by comparing observed eddy covariance ET with model computed $\mathrm{ET}_{\mathrm{c}}$ act for field crops (Zhang et al., 2013; Tian et al., 2016) and citrus orchards (Peddinti and Kambhammettu, 2019), or by comparing observed sap-flow transpiration data with simulated $\mathrm{T}_{\mathrm{c}}$ act (Paço et al., 2012, 2019; Qiu et al., 2015). Descriptions of the calibration and validation processes are provided in the cited applications.

Various methods may be used to estimate accurately actual crop ET as reviewed by Allen et al. (2011b) and Pereira et al. (2020a,b). Methods include the measurement of the soil water content for deriving ET from the SWB, the measurement of $\mathrm{ET}_{\mathrm{c}}$ act using eddy covariance (EC) or Bowen ratio energy balance (BREB) systems, as well as the measurement of $\mathrm{T}_{c}$ act with sap-flow systems. All these methods are potentially very accurate as point measurements, and the EC and BREB are used in such a way that their footprint may span a relatively large area representative of the vegetation. EC is receiving the preference of many ET users, but measurements of the soil water content (SWC) and sap-flow continue to be largely used. Fig. 3a shows the comparisons of simulated and observed seasonal SWC data of a wheat crop used to calibrate SIMDualKc, and Fig. 3b shows a similar comparison of simulated wheat $\mathrm{ET}_{\mathrm{c} \text { act }}$ with $\mathrm{EC}$ observed data, both obtained at the same location in North China plain (Zhang et al., 2013; Zhao et al., 2013). The goodness-of-fit indicators resulted similar, i.e. there was no 


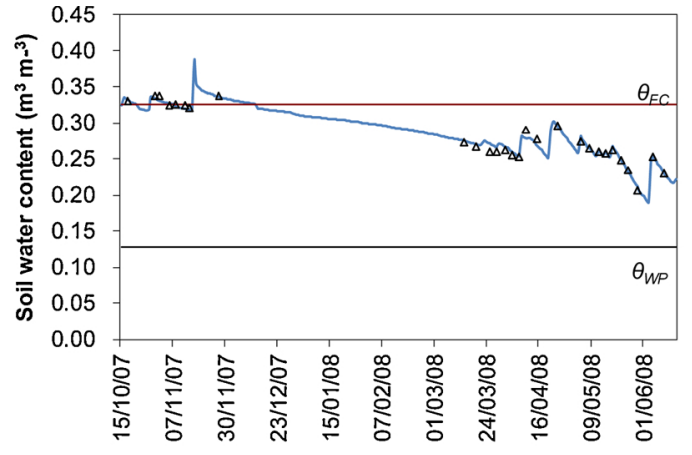

$(\Delta)$ observed and $(-)$ simulated soil water content

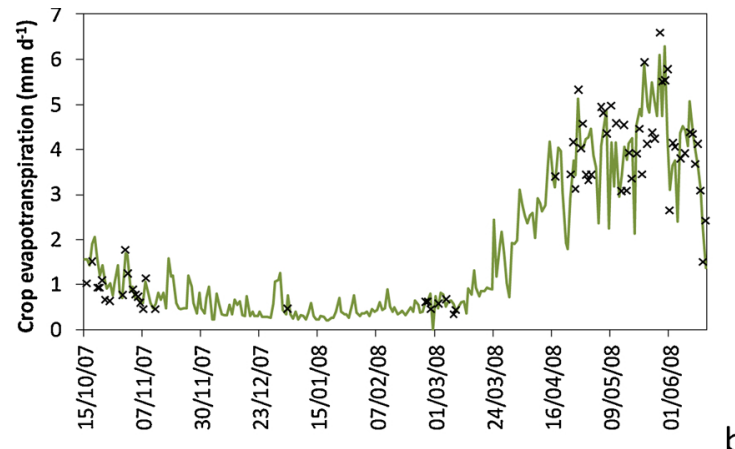

b)

(x) observed and ( - ) simulated crop evapotranspiration

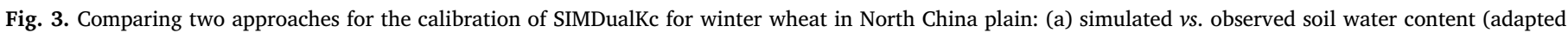
from Zhao et al., 2013) and (b) simulated $v$ s. observed $\mathrm{ET}_{\mathrm{c} \text { act }}$ (adapted from Zhang et al., 2013).

advantage of one calibration over the other, which means that a user may select the most convenient approach to calibrate a model if measurements of SWC, $\mathrm{ET}_{\mathrm{c} \text { act }}$ or $\mathrm{T}_{\mathrm{c} \text { act }}$ are accurately performed.

\subsection{Deriving crop coefficients}

Deriving $\mathrm{K}_{\mathrm{cb}}$ and $\mathrm{K}_{\mathrm{c}}$ from SWB simulations is a main capability of SWB models, e.g. SALTMED (Silva et al., 2012), which is quite common for vegetable and field crops as reported in recent reviews (Pereira et al., 2020a,b); however, it is uncommon for fruit trees and vines. In the case of evergreen trees and vines, a full crop coefficient curve requires that, in addition to the $\mathrm{K}_{\mathrm{c}}$ and $\mathrm{K}_{\mathrm{cb}}$ for the initial, mid-season and end-season, the $\mathrm{K}_{\mathrm{c}}$ and $\mathrm{K}_{\mathrm{cb}}$ values for the non-growing period are also known. Moreover, due to climate differences between the growing and non-growing seasons, the $\mathrm{K}_{\mathrm{c}}$ and $\mathrm{K}_{\mathrm{cb}}$ curves may be substantially different. Nevertheless, there are various examples of derivation of $K_{c}$ and $\mathrm{K}_{\mathrm{cb}}$ for orchards (e.g., Peddinti and Kambhammettu, 2019).

As an example for evergreen woody crops, a study performed with irrigated olives in southern Portugal (Paço et al., 2019) is analyzed. Crop transpiration was measured with the sap-flow Granier method, which data provided for calibrating SIMDualKc, thus obtaining the best $\mathrm{K}_{\mathrm{cb}}$ values for the initial, mid-season, end-season and non-growing periods. A few observations of $\mathrm{ET}_{\mathrm{c} \text { act }}$ with an EC system were also used for testing. The $\mathrm{K}_{\mathrm{cb}}$ curve (Fig. 4) resulted in a FAO segmented curve with higher $\mathrm{K}_{\mathrm{cb}}$ during the growing season, spring and summer, when irrigation was applied, and smaller $\mathrm{K}_{\mathrm{cb}}$ in the non-growing period, when transpiration is naturally low. Differently, because it depends on soil evaporation, the time averaged $\mathrm{K}_{\mathrm{c}}\left(=\mathrm{K}_{\mathrm{cb}}+\mathrm{K}_{\mathrm{e}}\right)$ resulted smaller during the active growing period, when $E_{s}$ and $K_{e}$ were low because precipitation was reduced and drip lines were located directly in line with the crop and shaded by the crop canopy, thus irrigation was applied under trees' shadow. Contrarily, $\mathrm{K}_{\mathrm{c}}$ was larger in fall and winter, when rainfall occurred (Fig. 4). A segmented $K_{c}$ curve resulted with low values by the mid-season and a $K_{c b}$ curve with a higher value during the mid-season. The $\mathrm{K}_{\mathrm{c}}$ curve changed with rainfall, with $\mathrm{K}_{\mathrm{c} \text { mid }}$ and $\mathrm{K}_{\mathrm{c}}$ in the non-growing season, which is higher when rainfall was larger (Fig. 4a) and smaller under dry conditions. Contrarily, the standard $\mathrm{K}_{\mathrm{cb}}$ values did not change. When considering the daily $\mathrm{K}_{\mathrm{cb}}$ act, changes occurred depending on the water stress of the olive crop. The daily $\mathrm{K}_{\mathrm{c}}$ act changed a lot, causing the referred changes in the $\mathrm{K}_{\mathrm{c}}$ curve.

Deriving $\mathrm{K}_{\mathrm{cb}}$ and $\mathrm{K}_{\mathrm{c}}$ from SWB simulations is also uncommon for forage crops managed with cuttings. The FAO56 approach for $\mathrm{K}_{\mathrm{cb}}$ and $\mathrm{K}_{\mathrm{c}}$ of forages managed with cuttings consists of adopting a segmented curve for each cut (Allen et al., 1998). SIMDualKc has proved appropriate to support the derivation of $\mathrm{K}_{\mathrm{cb}}$ and $\mathrm{K}_{\mathrm{c}}$ under these conditions in an application to Tifton 85 bermudagrass in Santa Maria, Brazil (Paredes et al., 2018b). The cutting treatments were spaced according to selected cumulative growth degree days (CGDD), which varied among treatments. With this approach, shorter time spans between cuttings resulted in summer and longer ones in winter. Results for $\mathrm{K}_{\mathrm{cb}}$ and $\mathrm{K}_{\mathrm{c}}$ with cuttings at CGDD of $248^{\circ} \mathrm{C}$, which refer to six forage cuttings, and $372{ }^{\circ} \mathrm{C}$, with only four cuttings, are presented in Fig. $5 \mathrm{a}$ and $5 \mathrm{~b}$ respectively. The computed time average $\mathrm{K}_{\mathrm{c}}$ before the cuttings are 0.96 for the CGDD $248^{\circ} \mathrm{C}$ and 0.97 for CGDD $372{ }^{\circ} \mathrm{C}$ while the $\mathrm{K}_{\mathrm{c}}$ after
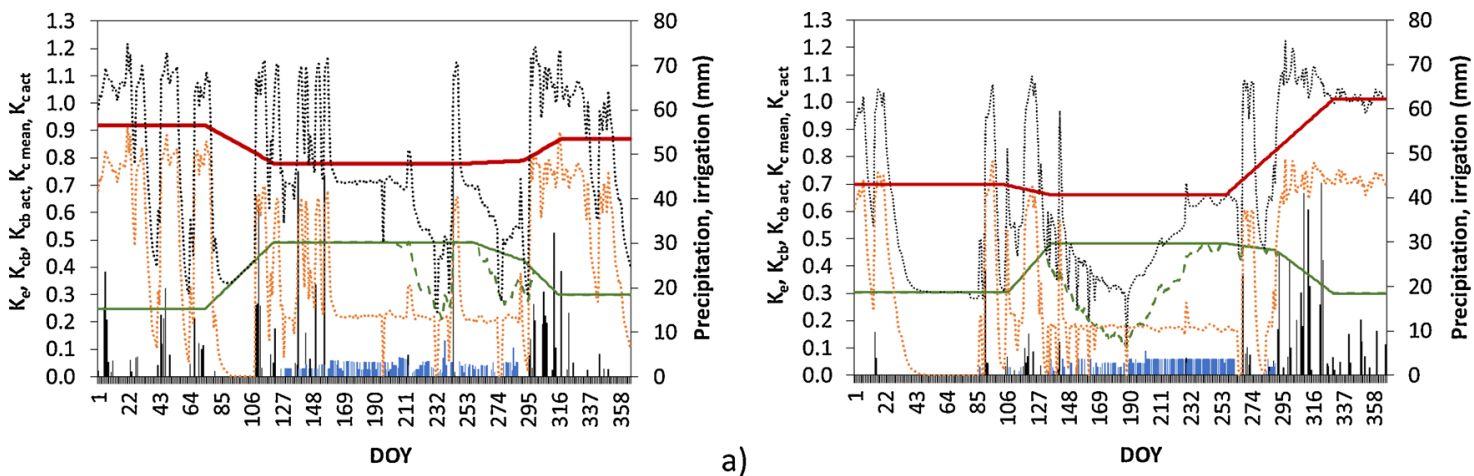

a)

DOY

b)

$(-)$ standard basal crop coefficient $\left(K_{c b}\right),(--)$ actual basal crop coefficient $\left(K_{c b}\right.$ act $),(--)$ daily soil evaporation coefficient $\left(K_{e}\right),(--)$ daily actual single crop coefficient $\left(K_{c}\right.$ act $),(-)$ time averaged single crop coefficient $\left(K_{c}\right.$ mean, -$)$, $(\mid)$ irrigation and $(\mid)$ precipitation

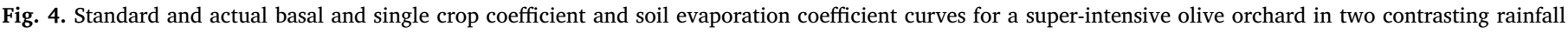
years: a) wet year and b) dry year (Paço et al., 2019). 

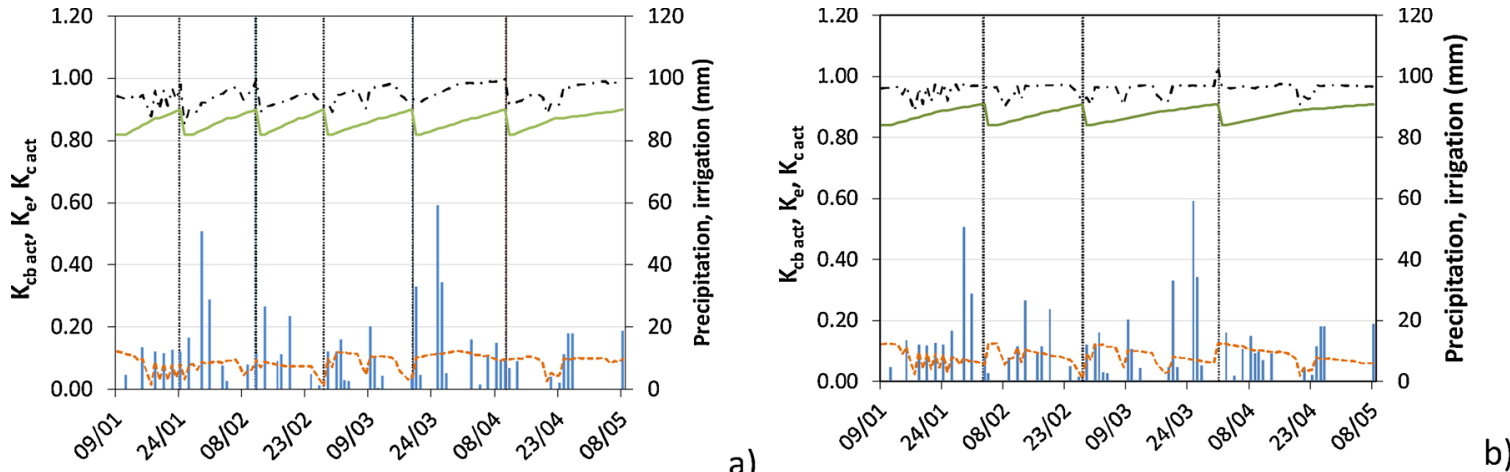

\section{$(-) \mathrm{K}_{\mathrm{cb} \text { act }},(--) \mathrm{K}_{\mathrm{e}},(-\cdot-) \mathrm{K}_{\mathrm{c} \text { act }},(\mid)$ wetting events by precipitation and irrigation}

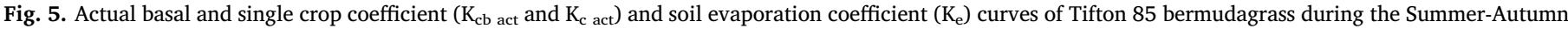

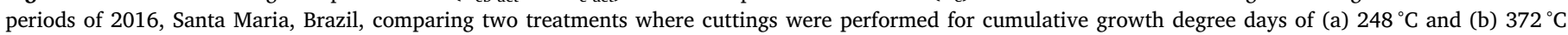
(adapted from Paredes et al., 2018b).
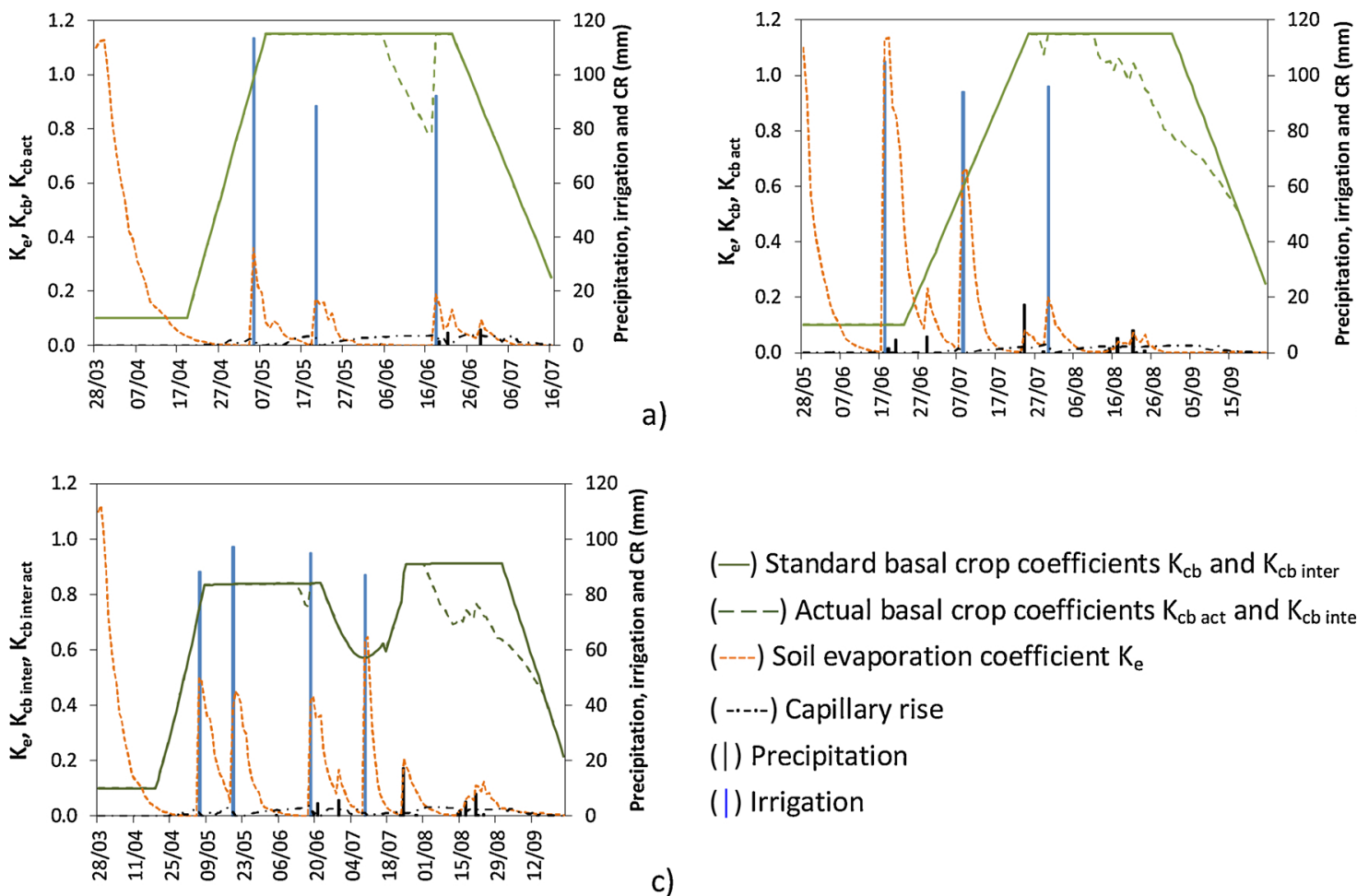

(-) Standard basal crop coefficients $K_{c b}$ and $K_{c b}$ inter

$(---)$ Actual basal crop coefficients $K_{c b}$ act and $K_{c b}$ inter act

$(---)$ Soil evaporation coefficient $K_{e}$

(-.--) Capillary rise

(|) Precipitation

( |) Irrigation

C)

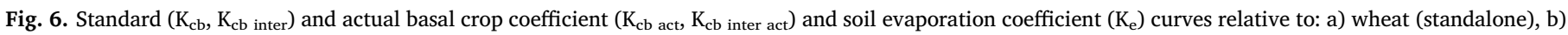
sunflower (standalone), and c) the relay intercropped wheat-sunflower in Hetao, upper Yellow River basin, China, 2011 (adapted from Miao et al., 2016).

cuttings, when the forage crop is shorter, decreased to 0.92 and 0.95 , respectively. Reported time averaged $\mathrm{K}_{\mathrm{c}}$ before and after cuttings are close due to abundant precipitation during the crop season. The standard $\mathrm{K}_{\mathrm{cb}}$ before the cuttings are 0.93 for the treatment with CGDD of $248^{\circ} \mathrm{C}$ and 0.94 for CGDD of $372^{\circ} \mathrm{C}$ while $\mathrm{K}_{\mathrm{cb}}$ values after cuttings were respectively 0.83 and 0.84 . Values for the standard $K_{c b}$ would be more distinct if the forage height would be smaller after cuttings. Results show that the approach proposed in FAO56 for $\mathrm{K}_{\mathrm{c}}$ and $\mathrm{K}_{\mathrm{cb}}$ curves for forages managed with cuttings was applicable with SIMDualKc.

\subsection{ET and crop coefficients of relay inter-cropping}

An approach based on light/shadow effects was used to estimate $\mathrm{ET}_{\mathrm{c} \text { act }}$ and its partition for crops cultivated in a relay inter-cropping system. The mutual effects of shading by the crops combined in an inter-crop system were estimated by considering the height of both crops and the fraction of ground covered by each crop throughout the crop season (Miao et al., 2016). This principle is based upon the approach of Allen and Pereira (2009) to compute $\mathrm{K}_{\mathrm{cb}}$ for a fruit crop cultivated with active ground cover.

Naming the first planted crop as dominant and the second as the subordinate crop, and considering their interaction, the $\mathrm{K}_{\mathrm{cb}}$ of the intercrop ( $\mathrm{K}_{\mathrm{cb}}$ inter $)$ may be estimated daily as (Miao et al., 2016):

$$
\begin{aligned}
& \mathrm{K}_{\mathrm{cbinter}}=\max \left[\mathrm{K}_{\mathrm{cb} \text { sub }}+\mathrm{K}_{\mathrm{ddom}}\left(\mathrm{K}_{\mathrm{cbdom}}-\mathrm{K}_{\mathrm{cb} \text { sub }}\right) ;\right. \\
& \left.\mathrm{K}_{\mathrm{cbdom}}+\mathrm{K}_{\mathrm{d} \mathrm{sub}}\left(\mathrm{K}_{\mathrm{cbsub}}-\mathrm{K}_{\mathrm{cb} \text { dom }}\right)\right]
\end{aligned}
$$

where $K_{c b}$ dom and $K_{c b}$ sub are, respectively, the $K_{c b}$ values of the dominant and subordinate crops when mono-cropped, and $\mathrm{K}_{\mathrm{d} \text { dom }}$ and $\mathrm{K}_{\mathrm{d} \text { sub }}$ are the density coefficients of the dominant and subordinate crops. $\mathrm{K}_{\mathrm{d}}$ are computed as: 

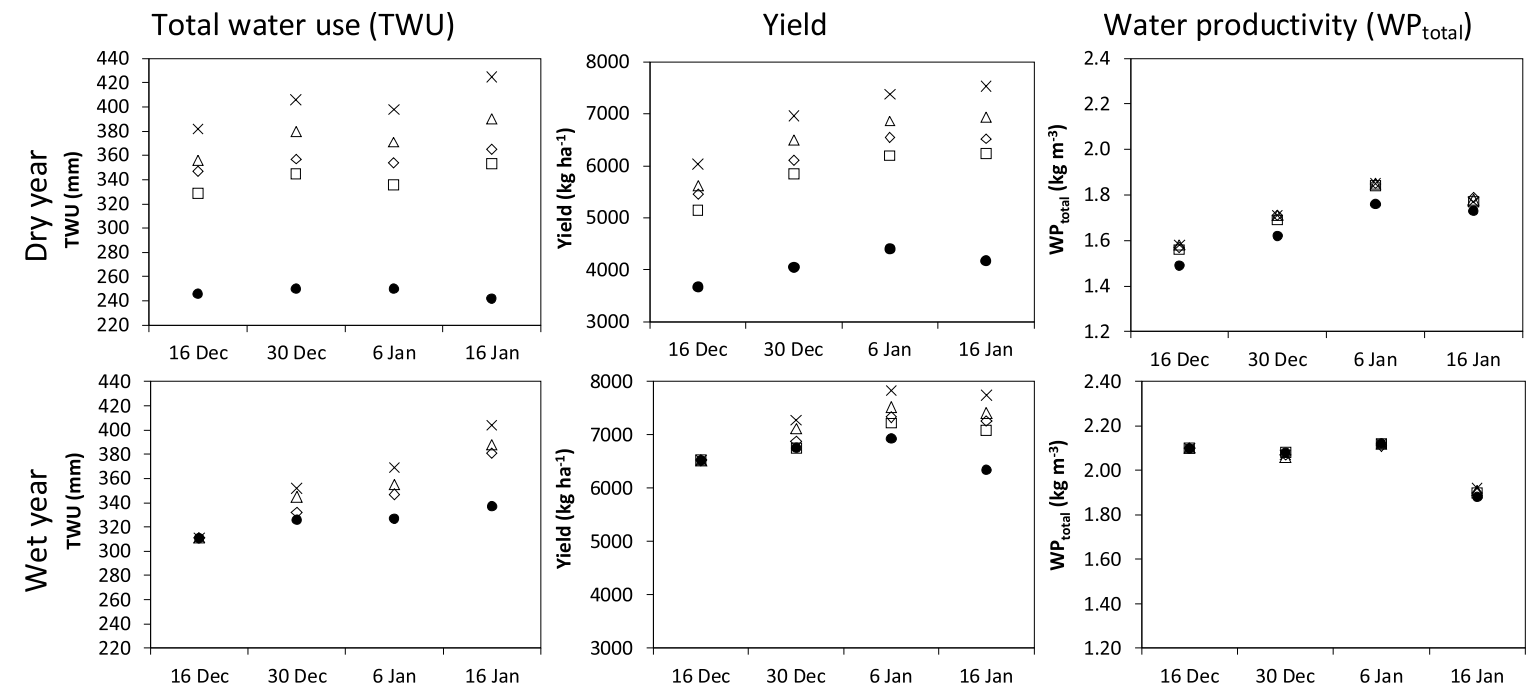

Full irrigation $(x)$, Very mild water deficit $(\Delta)$, Mild water deficit $(\diamond)$, Moderate water stress $(\square)$ and Rainfed $(\bullet)$

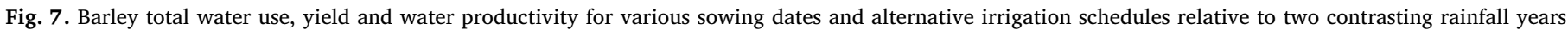
(adapted from Paredes et al., 2017b).

$\mathrm{K}_{\mathrm{d} \text { dom }}=\mathrm{f}_{\mathrm{sc} \mathrm{dom}}\left(\frac{1}{1+\max \left(\mathrm{h}_{\mathrm{dom}}-\mathrm{h}_{\mathrm{sub}} ; 0\right)}\right)$

$\mathrm{K}_{\mathrm{d} \mathrm{sub}}=\mathrm{f}_{\mathrm{sc} \mathrm{sub}}\left(\frac{1}{1+\max \left(\mathrm{h}_{\text {sub }}-\mathrm{h}_{\mathrm{dom}} ; 0\right)}\right)$

where $f_{s c}$ dom and $f_{s c}$ sub are the fractions of the soil surface cropped with the dominant and the subordinate crops, respectively, and $h_{\text {dom }}$ and $\mathrm{h}_{\text {sub }}$ are the heights of the dominant and subordinate crops, respectively. The max function in Eqs. (25) and (26) aims at considering that the conditions observed at earlier stages, $\mathrm{K}_{\mathrm{cb} \text { dom }}>\mathrm{K}_{\mathrm{cb} \text { sub }}$ and $\mathrm{h}_{\text {dom }}>\mathrm{h}_{\text {sub}}$, may change with the growth of the subordinate crop, thus making $\mathrm{K}_{\mathrm{cb} \text { sub }}>\mathrm{K}_{\mathrm{cb} \text { dom }}$ and $\mathrm{h}_{\text {sub }}>\mathrm{h}_{\text {dom. }}$. For example, this is the case of the wheat-sunflower intercrop, where sunflower develops taller than wheat when the latter matures, thus $\mathrm{K}_{\mathrm{cb} \text { sunf }}>\mathrm{K}_{\mathrm{cb}}$ wheat and $\mathrm{h}_{\text {sunf }}>\mathrm{h}_{\text {wheat }}$.

The application of this methodology to a winter wheat-sunflower relay inter-cropping in Hetao, China, is illustrated in Figs. 6a and b, which show the $K_{c b}, K_{c b}$ act and $K_{e}$ relative to wheat and sunflower mono-cropped, while Fig. $6 \mathrm{c}$ shows $\mathrm{K}_{\mathrm{cb}}, \mathrm{K}_{\mathrm{cb}}$ act and $\mathrm{K}_{\mathrm{e}}$ for the intercropping of both. Fig. 6a shows that a small stress occurred for wheat while Fig. $6 \mathrm{~b}$ evidences that sunflower was largely stressed during the mid- and late-season stages, thus indicating that a large irrigation should have been given early in the mid-season. The resulting potential $\mathrm{K}_{\mathrm{cb}}$ of the inter-cropping system (Fig. $6 \mathrm{c}$ ) was smaller than that of the crops when single-cropped, with $\mathrm{K}_{\mathrm{cb}}$ act following the trends evidenced for both crops when cropped alone. The $\mathrm{K}_{\mathrm{e}}$ values also followed the $\mathrm{K}_{\mathrm{e}}$ curves of both crops but they were different because basin irrigation was used and water was applied to the entire field, including when the second crop was not sowed yet, thus producing high evaporation in the non-cropped parts of the field. Fig. $6 \mathrm{c}$ shows that four irrigations were applied to the intercrop, however too early for sunflower that, contrarily to wheat, exhibited large water stress during mid- and late seasons. This is a consequence of avoiding irrigation by the end-season of wheat. The example shows that the use of a calibrated model helps interpreting and evaluating the irrigation schedules of intercropped crops.

\subsection{Assessing alternative planting dates}

An important issue in developing irrigation calendars is assessing the impacts of changing planting dates. Such changes may be desired when anticipating planting dates may increase the probability of rainfall early in the season, or to avoid hot waves in the late season. This search of better planting dates may be performed with irrigation scheduling models and using a statistical analysis of weather time series, namely when supplemental irrigation is practiced, such as with small grains and grain legumes in the Mediterranean area. However, few examples are available in the literature and they mostly refer to the impacts on crop yields rather than on water requirements. Abi-Saab et al. (2014) provided a good example relative to sunflower and soybean cropped in Lebanon, while Montoya and Otero (2019) reported an application to soybean in Uruguay, in both cases using the AquaCrop model. A different approach, using BUDGET, consisted of performing an analysis of risk relative to maize planting dates (Kipkorir et al., 2007).

Various supplemental irrigation schedules for malting barley for industry were assessed for two contrasting rainfall years (Pereira et al., 2015b; Paredes et al., 2017b) using a cultivar that adjusts to a wide planting period, from November to January. Center-pivot irrigation was used with depths of $8 \mathrm{~mm}$ per event and ceasing 25 days before harvest to prevent water-related diseases that could affect malt grain quality. Based upon the observed sowing dates, the following alternatives were considered: 16th and 30th of December, and 6th and 16th of January. These sowing dates were assessed in terms of impacts on the total water use (TWU), forecasted yields $\left(\mathrm{Y}_{\mathrm{a}}\right)$, and water productivity $\left(\mathrm{WP}_{\text {total }}, \mathrm{Eq}\right.$. 21) defined in Section 2.5. They were also assessed considering two contrasting rainfall years - wet (2013) and dry (2012) - and various supplemental irrigation scenarios:

Sc. 1: Full irrigation as practiced by the farmer $(\mathrm{MAD}=\mathrm{p})$;

Sc. 2 : Very mild water deficit during the entire season $(\mathrm{MAD}=1.10$ p, Eq. 10);

Sc. 3: Moderate water deficit during most of the crop season $(\mathrm{MAD}=1.20 \mathrm{p})$, but very mild (MAD $=1.10 \mathrm{p})$ during flowering/ grain filling;

Sc. 4: Moderate water stress during the entire season (MAD $=1.20$ p);

Sc. 5: Rainfed.

Fig. 7 shows the predicted TWU, yield and WP indicators for the four sowing dates and five irrigation management scenarios. The adoption of early sowing leads to a smaller TWU than late sowing, particularly in the wet year. In the dry year, differences in TWU among irrigation management scenarios are larger than those due to planting dates. Yields show to increase for the last two planting dates but, again, differences in yields are greater among irrigation scenarios. Under dry conditions, the use of supplemental irrigation to meet barley water requirements is essential since yields are much lower under rainfed 
conditions. Differences in water productivity are larger among planting dates and quite small among irrigation management scenarios. Combining information relative to these three indicators, it was identified that the best sowing dates are likely those around the first days of January. The mid-January date is discouraged because the crop cycle enters in a period of high water demand by the late season, which increases TWU and decreases WP. The consideration of economic criteria would also be beneficial. This example shows the usefulness of a SWB model in recommending best planting dates to help farmers' decisions. This can also be based on weather forecasts that provide for anticipating crop growth conditions.

\subsection{Assessing beneficial and non-beneficial water uses}

The analysis of the water use by a crop allows to perform the field water balances and assess the time dynamics of its input and output terms, thus determining which are the consumptive and non-consumptive uses of water and, likely more important, which uses and consumptions are beneficial or, contrarily, consist of water waste and losses (Pereira et al., 2012). Molden and Sakthivadivel (2011) applied similar water use concepts at the basin scale, and Lecina et al. (2010) used this type of assessment to evaluate improvements of surface and sprinkler irrigation at the project scale. An application at field scale aimed at maximizing beneficial water use and controlling the nonbeneficial one using the DSSAT-maize model is reported by Jiang et al. (2016).

An application of the SIMDualKc model to a malt barley cropped under center-pivot irrigation in Central Portugal (Pereira et al., 2015b) is used herein as example of assessing beneficial and non-beneficial water uses throughout the crop cycle. The model was calibrated using field data of the dry year 2012 and was validated with data of the wet year 2013. The various SWB terms for both years and four crop growth stages are presented in Table 3. Groundwater contribution was not included in the balance because the water table was below $10 \mathrm{~m}$ deep. Irrigation water application depths averaging $7 \mathrm{~mm}$ per event were adopted to prevent high water stress.

The non-consumptive water use terms, runoff (RO) and deep percolation (DP), were about nil in the dry year. RO was $10.5 \%$ of the seasonal precipitation $(\mathrm{P})$ in the wet year while DP, a potentially recoverable resource providing for vadose zone and aquifer recharge, represented nearly $30 \%$ of $P$. The consumptive use terms, $T_{c}$ act and $E_{s}$, respectively beneficial and non-beneficial, showed a similar partition in both years, with transpiration representing $77 \%$ of $\mathrm{ET}_{\mathrm{c}}$ act in the wet year and $79 \%$ in the dry year. $\mathrm{E}_{\mathrm{s}}$ was smaller in the dry year because there was insufficient water supply during the late season, with $\mathrm{ET}_{\mathrm{c}}$ act representing only $64 \%$ of the potential $\mathrm{ET}_{\mathrm{c}}$. This fact occurred due to irrigation cutoff 25 days before harvesting in both years, with stored soil water supplying the crop in the wet year but not in the dry year. Otherwise, differences in consumptive water use in both years are small and are due to the higher climatic demand in the dry year, when $\mathrm{ET}_{\mathrm{c}}$ was larger by $56 \mathrm{~mm}$ relative to the wet year. Performing water use assessment adopting this approach is uncommon but could be helpful when considering issues for water conservation.

\subsection{Assessing the groundwater contribution from a shallow watertable}

The assessment of groundwater contribution (GC) to crop water needs in the presence of a shallow water table is often performed with a transient state modeling approach (e.g. Ragab, 2002; Jovanovic et al., 2004; Acharya and Mylavarapu, 2015). Empirical functions are used by others, such as Yang et al. (2007), who computed GC as a function of the depth of the water table, the soil water storage and crop ET, which consists of a modification of the empirical approach proposed in FAO24 (Doorenbos and Pruitt, 1977). Differently, Liu et al. (2006) developed a parametric function for use in ISAREG and, later, with SIMDualKc, which parameters are calibrated during the process of model calibration (e.g., Cholpankulov et al., 2008). With this approach, GC is a function of the actual water table depth, the actual soil water storage in the root zone, crop evapotranspiration and potential (maximum) capillary rise, which depends upon the soil hydraulic characteristics that regulate the intensity of upward fluxes. Liu et al. (2006) proposed sets of default parameters relative to soil textural and hydraulic properties and that are improved through model calibration.

The use of SIMDualKc to assess consumptive and non-consumptive water use by a groundwater dependent Leymus chinensis grassland in eastern Inner Mongolia, China (Wu et al., 2016) is selected as an example of groundwater contribution assessment in a wet landscape. The analysis focused on the wet year of 2008 and the dry year of 2009. The daily dynamics of $\mathrm{P}, \mathrm{T}_{\mathrm{c} \text { act }}, \mathrm{E}_{\mathrm{s}}$ and GC (all in $\mathrm{mm}$ ) during the growth season is presented in Fig. 8, which clearly shows that the upward

Table 3

Water balance terms with discrimination of beneficial and non-beneficial uses (mm) relative to a supplemental irrigated barley crop in two contrasting rainfall years (adapted from Pereira et al., 2015b).

\begin{tabular}{|c|c|c|c|c|c|c|c|c|c|c|}
\hline \multirow[t]{4}{*}{ Year } & \multirow[t]{4}{*}{ Crop growth stages } & \multicolumn{3}{|c|}{ Water supply (mm) } & \multicolumn{6}{|c|}{ Water use (mm) } \\
\hline & & & & & \multicolumn{2}{|c|}{ Non-consumptive } & \multicolumn{4}{|c|}{ Consumptive } \\
\hline & & & & & N-Benef. & Benef. & & & Benef. & N-Benef. \\
\hline & & $\begin{array}{l}\mathrm{P} \\
(\mathrm{mm})\end{array}$ & $\begin{array}{l}\mathrm{I} \\
(\mathrm{mm})\end{array}$ & $\begin{array}{l}\Delta \text { ASW } \\
(\mathrm{mm})\end{array}$ & $\begin{array}{l}\mathrm{RO} \\
(\mathrm{mm})\end{array}$ & $\begin{array}{l}\mathrm{DP} \\
(\mathrm{mm})\end{array}$ & $\begin{array}{l}\mathrm{ET}_{\mathrm{c}} \\
(\mathrm{mm})\end{array}$ & $\begin{array}{l}\mathrm{ET}_{\mathrm{c} \text { act }} \\
(\mathrm{mm})\end{array}$ & $\begin{array}{l}\mathrm{T}_{\mathrm{c} \mathrm{act}} \\
(\mathrm{mm})\end{array}$ & $\begin{array}{l}\mathrm{E}_{\mathrm{s}} \\
(\mathrm{mm})\end{array}$ \\
\hline \multirow[t]{5}{*}{2012} & Initial & 2 & 0 & 16 & 0 & 0 & 18 & 18 & 3 & 15 \\
\hline & Development & 45 & 95 & -14 & 0 & 0 & 124 & 126 & 84 & 42 \\
\hline & Mid & 106 & 40 & 14 & 2 & 0 & 165 & 158 & 142 & 16 \\
\hline & Late & 2 & 10 & 52 & 0 & 0 & 100 & 64 & 60 & 4 \\
\hline & Season & 155 & 145 & 68 & 2 & 0 & 407 & 366 & 289 & 77 \\
\hline \multirow[t]{5}{*}{2013} & Initial & 62 & 0 & -43 & 2 & 0 & 17 & 17 & 2 & 15 \\
\hline & Development & 175 & 0 & -26 & 16 & 62 & 71 & 71 & 44 & 27 \\
\hline & Mid & 261 & 0 & 42 & 42 & 108 & 153 & 153 & 135 & 18 \\
\hline & Late & 70 & 0 & 40 & 0 & 0 & 110 & 110 & 89 & 21 \\
\hline & Season & 568 & 0 & 13 & 60 & 170 & 351 & 351 & 270 & 81 \\
\hline
\end{tabular}

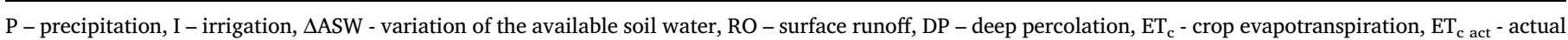
crop evapotranspiration, $\mathrm{T}_{\mathrm{c} \text { act }}$ - actual crop transpiration, $\mathrm{E}_{\mathrm{s}}$ - soil evaporation. 
Wet year

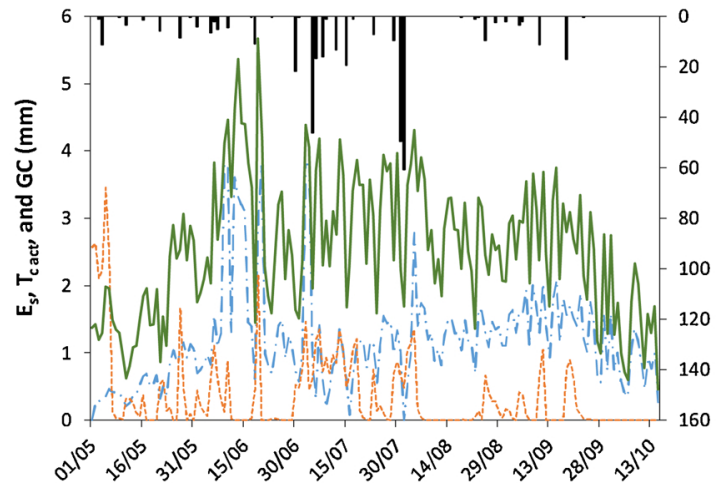

\section{Dry year}

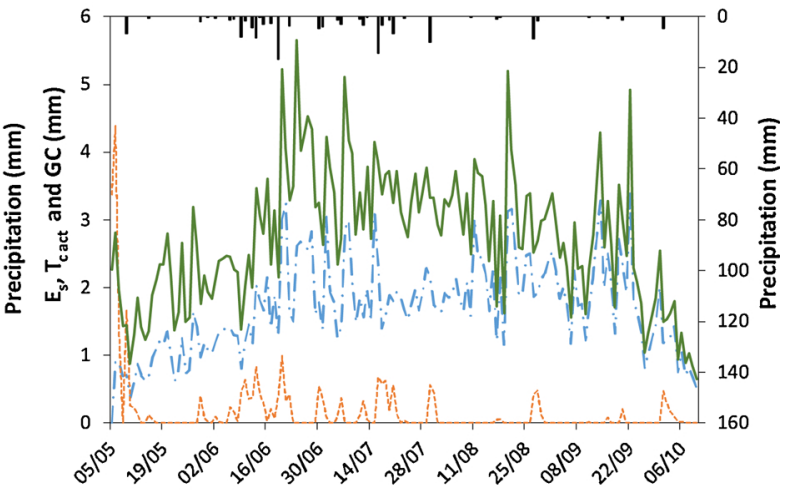

(|) precipitation; (- -) soil evaporation ( $\left.E_{s}\right)$; (-) actual crop transpiration ( $\left.T_{c \text { act }}\right)$; $(--)$ groundwater contribution from the shallow water table $(\mathrm{GC})$

Fig. 8. Daily water balance of a groundwater dependent Leymus chinensis grassland in eastern Inner Mongolia, China, comparing a wet and a dry year with focusing on the groundwater contribution from a shallow water table (adapted from Wu et al., 2016).

Table 4

The terms of the water balance of a groundwater dependent Leymus chinensis grassland of eastern Inner Mongolia, China, comparing a wet and a dry year with focus on the groundwater contribution from a shallow watertable (adapted from Wu et al., 2016).

\begin{tabular}{|c|c|c|c|c|c|c|c|c|c|c|c|}
\hline \multirow[t]{3}{*}{ Year } & \multirow[t]{3}{*}{ Crop growth stages } & \multirow{2}{*}{\multicolumn{4}{|c|}{ Water supply (mm) }} & \multicolumn{4}{|l|}{ Water use $(\mathrm{mm})$} & \multicolumn{2}{|l|}{ GC indicators } \\
\hline & & & & & & \multirow{2}{*}{$\begin{array}{l}\text { Non-consumptive } \\
\text { Recharge }\end{array}$} & \multicolumn{3}{|c|}{ Consumptive } & \multirow[t]{2}{*}{ GC/TWS (\%) } & \multirow{2}{*}{$\mathrm{GC} / \mathrm{T}_{\mathrm{c} \text { act }}(\%)$} \\
\hline & & $\mathrm{P}$ & GC & $\triangle \mathrm{ASW}$ & TWS & & $\mathrm{ET}_{\mathrm{c} \text { act }}$ & $\mathrm{T}_{\mathrm{c} \text { act }}$ & $\mathrm{E}_{\mathrm{s}}$ & & \\
\hline \multirow[t]{4}{*}{2008 , wet } & Initial & 16 & 5 & 15 & 36 & 0 & 36 & 19 & 17 & 14 & 26 \\
\hline & Development & 33 & 24 & 8 & 65 & 0 & 65 & 57 & 8 & 37 & 42 \\
\hline & Mid & 326 & 141 & -13 & 467 & 119 & 336 & 302 & 33 & 30 & 47 \\
\hline & Late & 0 & 28 & 23 & 51 & 0 & 51 & 49 & 2 & 55 & 57 \\
\hline \multirow[t]{5}{*}{2009 , dry } & Initial & 7 & 17 & 26 & 50 & 0 & 50 & 39 & 11 & 34 & 44 \\
\hline & Development & 30 & 28 & -5 & 58 & 0 & 53 & 48 & 5 & 48 & 58 \\
\hline & Mid & 89 & 200 & 35 & 324 & 0 & 323 & 314 & 10 & 62 & 64 \\
\hline & Late & 5 & 24 & 1 & 30 & 0 & 30 & 29 & 1 & 80 & 83 \\
\hline & Season & 131 & 269 & 57 & 457 & 0 & 456 & 430 & 27 & 59 & 63 \\
\hline
\end{tabular}

P - precipitation, GC - groundwater contribution; $\triangle \mathrm{ASW}$ - variation of the available soil water, TWS - total water supply; Recharge - deep percolation used to recharge the groundwater, $\mathrm{ET}_{\mathrm{c} \text { act }}$ - actual crop evapotranspiration, $\mathrm{T}_{\mathrm{c} \text { act }}-$ actual crop transpiration, $\mathrm{E}_{\mathrm{s}}-$ soil evaporation.

fluxes from the shallow water table were the main fraction of the water supply to the studied grassland. GC is essential to meet the water requirements of this crop. GC was small when there was enough soil water for extraction by the grassland but increased when crop water demand was high and the SWC decreased. Comparing both years (Fig. 8), it is evident that $\mathrm{T}_{\mathrm{c}}$ act was similar in both years because GC supplemented rainfall, thus becoming much higher in the dry year, when rainfall was insufficient. Considering that ground cover by the grassland was very large, $E_{s}$ depended on precipitation only, thus being higher in the wet year.

Results in Table 4 show that, despite rainfall in the wet year was nearly 3 times that of the dry year, $\mathrm{ET}_{\mathrm{c}}$ act were not very different in both years, and $\mathrm{T}_{\mathrm{c}}$ act were quite similar because GC effectively supplemented the lack of rainfall. The ratios between GC and the total water supply (TWS, $\mathrm{mm}$ ) were very distinct, with GC/TWS $=33 \%$ in the wet year and $59 \%$ in the dry year. These ratios quantified well the relative importance of GC for the water supply of the considered grassland. The ratios between GC and actual transpiration also showed the role of GC in meeting the grassland water requirements since $\mathrm{GC} / \mathrm{T}_{\mathrm{c}}$ act increased from 46 to $63 \%$ from the wet to the dry year.

\section{Trends in real time irrigation scheduling}

Real time irrigation scheduling aims at optimizing the timing and amount of water applied in the day-to-day irrigation management. It requires combining a model with data streaming from diverse sources such as weather forecasts, soil and plant sensors, or remote sensing data. Models referred in Tables 1 and 2 may be adopted for this purpose but they are generally used to support research.

In the past, several attempts to adapt and use SWB for supporting real time irrigation have been performed. Teixeira et al. (1995) developed and tested RELREG, a model derived from ISAREG, that could be updated every day, and used weather data predicted around three days in advance. Other models were developed and in use at farm level, e.g. SCHED for center-pivot irrigation (Buchleiter, 1995) and, for application at large scale, models such as RENANA (Giannerini, 1995). The latter has been continuously updated and gave origin to IRRIFRAME and IRRINET, widely used in Italy (Mannini et al., 2013; Giannerini and Genovesi, 2015), which enter in the era of the cloud data models.

In South Africa, a review of irrigation scheduling atmospheric-based computer models was published by Annandale et al. (2011). Computerized real-time irrigation scheduling revolved around a number of 
historic models such as BEWAB (pre-plant seasonal irrigation schedules based on target yields; Bennie et al., 1988), "SWB" (providing daily water schedules based on calculated $\mathrm{ET}_{\mathrm{c}}$ act; Annandale et al., 1999), PUTU (De Jager et al., 2001), and various specialized models for irrigation management of sugarcane (Singels, 2007). The adoption of scientific irrigation scheduling was investigated in a technical project by Stevens et al. (2005). The outcomes were that the uptake of scientific irrigation scheduling by farmers is low, it is highly dependent on many other day-to-day farming and business operations, and there is generally need for engaging dedicated managers, extensionists or consultants to run a scientifically-based irrigation scheduling program on commercial farms.

There are several web-based tools that were purposefully designed for supporting farmers in real-time irrigation decision-making such as IRRINET (Mannini et al., 2013; Giannerini and Genovesi, 2015) in Emilia Romagna Italy, the California Irrigation Management System (CIMIS, https://cimis.water.ca.gov/, accessed on 27 May 2020), the Arkansas Irrigation Scheduler (AIS, https://irrigweb.uaex.edu/, accessed on 27 May 2020), or the Mississippi irrigation scheduling tool (MIST). The SAPWAT model, originally developed by Crosby and Crosby (1999) with several improved versions (van Heerden and Walker, 2016), is used to determine crop water requirements and water allocations in South African water management areas. Other models with diverse workflows and computational procedures are applied for supporting farmers decision making, namely integrating SWB models, but they are rarely the object of scientific publications or information about calibration. Examples are the IRRIGA SYSTEM@ (https://www. irrigasystem.com/, accessed on 25 May 2020) used both in South America and in Europe, IrrigaSys (http://irrigasys.maretec.org/, accessed on 27 May 2020) used in Vale do Sorraia, Portugal, and Irristrat $^{\mathrm{TM}}$ (http://www.hidrosoph.com/EN/index.html, accessed on 27 May 2020) also applied in Portugal for both orchards and annual crops.

The developing field of information and communication technology (ICT) opened up a variety of opportunities for smart agriculture in general, and irrigation scheduling in particular, by making use of Internet of Things (IoT), satellites and drones, robotics and artificial intelligence to improve farming operations, management of irrigation schedules and fertigation, and to achieve better yields, quality of products and profits. Tzounis et al. (2017) provided a review of potential applications of IoT technologies in agriculture. The drivers for these technologies are large volumes of data that are generated in space and time, and commonly referred to as Big Data. Big Data can be defined as huge datasets (commonly in the order of magnitude of TB) originating from a diversity of sources that makes them difficult to be collected, stored and analysed by conventional tools and techniques (Chen and Zhang, 2014; Ylijoki and Porras, 2016). They can be categorized into structured data that can be easily stored in tabular format (e.g. soil and plant measurements, remote sensing georeferenced data), unstructured data (e.g. text, video, audio and images) or semi-structured data (e.g. emails and XML files) that are usually inconsistent to store and process in customary databases (Lee, 2017). In order to extract usable information from the variety of sources of information to the benefit of researchers, practitioners and farm managers, these data need to be processed through systems, such as machine learning, and packaged into tools that facilitate interpretation and decision-making.

Systems of heterogeneous sensors and networks for collection and communication of data are commonly referred to as Internet of Things (IoT). Given the vast amount of information and storage space that is often required, the processing, storage and analyses of these data can be done via Internet servers and infrastructure that are specifically designed for this purpose (e.g. Cloud Computing) (Tzounis et al., 2017). Ultimately, data need to be packaged into information tools, prescriptive/predictive models and decision-support systems that can aid decision-making on farms. Depending on data volume and computing requirements, irrigation scheduling tools can reside on cloud-based platforms (Bartlett et al., 2015). This is particularly the case when the tools/apps require information from large databases, e.g. soil properties, climate, satellite-derived observations. In other instances, soil input and climatic data can be obtained from localized sources, e.g. soil measurements and weather forecasts, and all calculations can be performed in reasonable time with algorithms running in the background (e.g. Internet apps). Several examples of these IoT applications for irrigation scheduling were reported in the literature and described below.

The IoT infrastructure provides the opportunity to replace models, such as the above-mentioned SCHED, with automation-model systems applied to lateral moving systems coupled with sensors that provide for variable rate irrigation and nutrients applications, thus moving from the simple water scheduling to precision agriculture (Han et al., 2009). A review on variable rate issues for sprinkler systems, including an analysis of sensor systems usable for such purposes, was recently proposed by O'Shaughnessy et al. (2016). Similar approaches are used with drip-irrigated horticultural crops (Perea et al., 2017) and woody crops (Fernández, 2017). Payero et al. (2017) developed a communication system for transferring wireless soil water sensors data to an opensources platform (https://thingspeak.com, accessed on 25 May 2020), where data are hosted and visualized in the form of usable information to support decision-making.

However, SWB models remain popular tools for supporting irrigation scheduling. For operational irrigation schedules, using real-time models requires daily updated actual weather data, which may not be fully available. Thus, alternative sources of climatic data have been tested showing good accuracy, such as the use of re-analysis data for estimating PM-ET o (e.g. Paredes et al., 2018a), or satellite derived climatic products as referred by Paredes et al. (2020b). Since weather forecasts generally provide for incomplete data sets (precipitation and temperature), computing $\mathrm{ET}_{\mathrm{o}}$ requires simplified approaches using temperature data only, namely the Penman-Monteith temperature (PMT) and the Hargreaves and Samani equation (HS-eq) (Paredes and Pereira, 2019; Paredes et al., 2020a). Thus, a main challenge in using models for supporting irrigation scheduling is to use short-term weather forecasts that could support real-time irrigation scheduling and, considering larger range forecasts, to plan irrigation in advance (Kusunose and Mahmood, 2016; Klemm and McPherson, 2017). Studies on the use of short-term weather forecasts to support irrigation scheduling focus more on precipitation than on climatic demand $\left(\mathrm{ET}_{\mathrm{o}}\right)$. The study by Cai et al. (2009) focused on the use of short-term weather forecast messages provided by the National Meteorological Institute of China for estimating $\mathrm{ET}_{\mathrm{o}}$ and supporting irrigation scheduling, showing the good adequacy particularly for estimation of crop ET using a SWB model. A similar but updated approach is reported by Zhang et al. (2018). Lorite et al. (2015) developed a methodology based on the use of weather forecast data from freely and easily accessible online information for determining irrigation scheduling, reporting good accuracy for $\mathrm{ET}_{\mathrm{o}}$ estimations.

Other studies focus on evaluating the use of short-term forecasts for real-time decision support for irrigation scheduling in terms of net profit and water savings. Cai et al. (2011) assessed the use of rainfall short-term forecasts provided by the National Oceanic and Atmospheric Administration (NOAA). Despite the imperfect forecasts, results showed net profit of up to $8.5 \%$ as well as high water savings ranging from 11.0 to $26.9 \%$ when compared to modelled soil moisture information. The study by Hejazi et al. (2014) focused on the use of reanalysis-based short-term weather forecasts relative to rainfall and $\mathrm{ET}_{\mathrm{o}}$ for supporting irrigation decision-making, reporting on average an expected profit of up to $3 \%$ and a water saving ranging from 4 to $6 \%$. Jamal et al. (2018), using the Soil Water Atmosphere Plant (SWAP) model, reported an overall good performance of using probabilistic seasonal weather forecasts to support chickpea real-time irrigation scheduling. Differently, Linker et al. (2018), using the AquaCrop model for irrigation scheduling and yield predictions coupled with 4 to 6-day weather forecasts, reported an overall inadequacy of the forecasts for several locations (Denmark, Greece, Italy and Portugal) and crops (potato, 
cotton, tomato and maize); in addition, these authors also outlined that there was no considerable advantage of using those forecasts relative to historical average data. Overall, the use of short-term weather forecasts keeps being a bottleneck due to their uncertainty/inaccuracy.

Combining SWB model predictions with plant indicators (Ferreira, 2017) and/or soil sensors, is also an option that has been investigated, e.g. Cancela et al. (2015) used SIMDualKc with an automatic control irrigation system supported by a low cost wireless soil moisture sensors network. Thus, these tools rely less on weather data, and more on soil and plant sensors, which calls for new approaches in using the FAO56 method. An example of such new approaches is the model reported by Schwartz et al. (2020) aimed at actual $\mathrm{K}_{\mathrm{c}}$ for maize when deficit irrigation is used and non-uniform soils also affect the crop and the available soil water. The use of soil water sensors is recognized as having a great importance for the accuracy of modern SWB modeling approaches (El-Naggar et al., 2020). The use of canopy temperature sensors is also recognized as contributing to improved accuracy (Han et al., 2018).

Remote sensing data provide the opportunity to model at large scale and they typically fall in the domain of Big Data. This includes both data originating from unmanned aerial vehicles (UAV, Ortega-Farias et al., 2016; Tang et al., 2019) and satellites. Two main approaches may be considered: energy balance models and vegetation indices. Models such as SEBAL (Surface Energy Balance Algorithm of Land), TSEB (TwoSource Energy Balance) and METRIC (Mapping Evapotranspiration with Internalized Calibration) are quite accurate in assessing crop evapotranspiration from the energy balance (Bastiaanssen et al., 1998; Allen et al., 2011a; French et al., 2015; Dhungel et al., 2016). ET from remote sensing may also be used to derive $\mathrm{K}_{\mathrm{c}}$ or $\mathrm{K}_{\mathrm{cb}}$ values. Vegetation indices, mainly the Normalized Difference Vegetation Index (NDVI) and the Soil Adjusted Vegetation Index (SAVI), are often used to estimate $\mathrm{K}_{\mathrm{c}}$ and $\mathrm{K}_{\mathrm{cb}}$ values (Johnson and Trout, 2012; Pôças et al., 2015; Campos et al., 2017). Satellite $K_{c}$ data are then assimilated into SWB models. Another issue is the assessment of crop stress indicators from remote sensing (Pôças et al., 2017), namely using UAV. The use of optical/ thermal satellite imagery at farm level would also allow drawing water requirement maps and implementing precise irrigation (Hendrickx et al., 2016).

Melton et al. (2012, 2020) described the SIMS framework that combines NASA's Terrestrial Observation and Prediction System (TOPS), Landsat and MODIS satellite imagery, and a surface sensors network to map indicators of crop irrigation demand and to develop information products to support irrigation management and other water use decisions. Li et al. (2018) described and tested a new method for sequential data assimilation that allows integrating soil water content measurements into the Community Land Model (CLM) aiming to improve irrigation scheduling. Evaluation of the method was performed on several citrus orchards allowing to save on average $24 \%$ of water relative to the farmers' irrigation schedules while the use of the irrigation schedules based upon the FAO56 SWB provided for similar average water savings of $22 \%$.

The development of mobile and on-line applications (apps) has also been investigated, with support of cloud computing and IoT. This kind of tools allows to provide to farmers easy-to-use information (Car et al., 2012), particularly when the information is conveyed using text messaging service (SMS). Todorovic et al. (2016) described and evaluated an automatized decision support system (Hydro-Tech) available as an app; Hydro-Tech integrates FAO56 methods, including the SWB, with continuous soil sensor-based monitoring, short-term weather forecasts, remote monitoring of the water supply network, diverse tools for datacloud processing, and an economic and eco-efficiency assessment tool for optimizing irrigation scheduling. Evaluations performed in farmers' fields with diverse crops (vegetables and fruit orchards) in the Apulia region, Italy, showed potential water savings ranging from $5 \%$ to $20 \%$ relative to the schedules used by farmers. Goap et al. (2018) presented an IoT-based smart irrigation management system, available as an app, using machine learning technology to predict crop irrigation requirements when combining sensing soil moisture along with the forecasts of precipitation, air temperature and humidity. Good accuracy of soil moisture predictions was reported thus allowing improving irrigation scheduling. An irrigation scheduling app (Bluleaf ${ }^{\circledast}$ ) was evaluated by Abi-Saab et al. (2019) using field observations and showing its accuracy for estimations of soil moisture content and leaf water potential along the wheat season. In addition, the tool was able to enhance water savings by almost $26 \%$ relative to the farmer's traditional schedule.

The progression of the satellite-based SEBAL model into an operational tool for irrigation scheduling is of particular interest. The private venture eLEAF (https://eleaf.com, accessed on 25 May 2020) developed a number of applications of interest to irrigation scheduling, namely PiMapping ${ }^{\circledR} 7$ (Pixel Intelligence Mapping), CropLook for field crops, as well as GrapeLook and FruitLook for grapes and fruit trees in the Western Cape, South Africa. The applications are based on satellite information to produce evapotranspiration maps and data that farmers and practitioners can access through a web portal (https://www. fruitlook.co.za/, accessed on 25 May 2020). A similar service providing information that can be accessed with different devices is IrriSat (https://www.irrisat.com/en/home-2, accessed on 25 May 2020). The Portuguese Association of Horticulture also makes available to farmers an app for real-time irrigation advice, Manna Irrigation Intelligence (https://aphorticultura.pt/2020/01/13/manna-irrigation-intelligencetecnologia-de-deteccao-remota/, accessed on 27 May 2020), which bases upon a SWB model, remote sensing data and weather forecasts.

Advances in ICT provide great opportunities to make use of large volumes of data and sources (sensors, models, remote sensing, images, tweets, farmers' knowledge and experience, etc.). For using the $\mathrm{K}_{\mathrm{c}}-\mathrm{ET}_{\mathrm{o}}$ approach, $\mathrm{ET}_{\mathrm{o}}$ may be estimated with reduced datasets using the PMT and HS-eq approaches which require, among other, ground observed data, gridded and reanalysis data, and/or Meteosat Second Generation products, as well as forecasted weather data (Allen et al., 2020; Paredes et al., 2020a, b). $K_{c}$ data sets refer to the updated tabulated standard $K_{c}$ and $K_{c b}$ values (Pereira et al., 2020a,b) and to the use of the A\&P approach to compute $\mathrm{K}_{\mathrm{cb}}$ and $\mathrm{K}_{\mathrm{c}}$ from $\mathrm{f}_{\mathrm{c}}$ and height (Allen and Pereira, 2009; Pereira et al., 2020c,d). The challenge is to streamline these diversely structured data into usable and reliable information. Although major advances have been documented in the literature, the level of uptake is still not widespread mainly due to the need to own devices, applications, costs of services, etc. Maintenance of these systems can also be expensive in terms of hardware (e.g. sensors exposed in the field), securing a steady power supply, network and software stability, data storage infrastructure, security and access control. Nevertheless, given the volume of usable information that can potentially be produced to optimize farming production, it can be expected that IoT will become a more and more prominent feature in smart farming.

\section{Conclusions and recommendations}

The current review has shown that SWB models have an enormous potential for irrigation scheduling including the assessment of alternative crop management practices, as well as biophysical and economic indicators of crop water productivity. The FAO56 methodology adopted in SWB is very accurate with moderate data requirements; simpler SWB models have been adopted for supporting irrigation scheduling but likely at a greater risk of water balance inaccuracies, namely when deep percolation and capillary rise are not properly taken into consideration and when $\mathrm{K}_{\mathrm{c}}$ estimation is less appropriate. Research users may also prefer to adopt mechanistic, high-input intensive models having capabilities to simulate crop growth and yield as depending not only on water, but also on nutrients and other practices. Trends for future also refer to the adoption of crop growth and yield models for irrigation scheduling, at least for research purposes; the adoption of the FAO56 method in the DSSAT models already performed (DeJonge and Thorp, 2017) consists of an excellent foundation for this purpose. 
Easy to parameterize and calibrate, field and crop-focused SWB models will likely continue to be used by farmers and farm advisers as well as using the cloud data facilities at the large scale. However, trends for IoT and cloud computing seem to lean towards simple crop ET computations, likely using the $\mathrm{K}_{\mathrm{c}}-\mathrm{ET}_{\mathrm{o}}$ approach. Then, $\mathrm{ET}_{\mathrm{o}}$ is likely estimated from temperature using the FAO56 recommended approaches (PMT and HS-eq), or is derived from reanalysis products, gridded data or Meteosat Second Generation products, as well as using forecasted weather data.

Future trends are also envisaged with farmers using models with ready to use information through mobile phones and smartphone apps. This approach is easier to apply with IoT or cloud data. In fact, simpler models provide acceptable to good indicative information to support basic irrigation decisions while more complex models are difficult to be deployed for the variety of users in terms of crops and cropping practices and management. It is therefore recommended that IoT models use the FAO56 method, including the updated FAO56 temperature based $\mathrm{ET}_{\mathrm{o}}$, and the updated data sets of $\mathrm{K}_{\mathrm{c}}$ and $\mathrm{K}_{\mathrm{cb}}$, or with application of the A\&P approach to estimate $\mathrm{K}_{\mathrm{cb}}$ and $\mathrm{K}_{\mathrm{c}}$ from the fraction of ground cover and crop height, that are well proved and tested at various locations. Innovation in cloud data and IoT models needs to enlarge the present focus on solving data acquisition and sensors management to the quality of crop and ET computations, since this approach may support attaining better water productivity and water saving, which are definitely relevant in terms of facing climate change.

A main opportunity for future is the use of remote sensing and the integration of remotely-sensed data into the SWB and crop growth models. Two main approaches may be considered (energy balance models and vegetation indices) as well as diverse sources of information (satellite imagery, imagery obtained from drones and infrared thermometry measurements on the ground). The dual $\mathrm{K}_{\mathrm{c}}$ approach is already used in remote sensing applications for estimating $\mathrm{ET}_{\mathrm{c}}$ of various crops, which compared well with the $\mathrm{K}_{\mathrm{cb}}$ estimated using the SIMDualKc model for many crops. Thus, results show that for real-time irrigation management the $\mathrm{K}_{\mathrm{cb}}$ derived from remotely sensed vegetation indices may be used to adjust SIMDualKc and similar models' simulations in near real-time, particularly when using sensors from satellites with high revisiting frequency.

An effective exchange between research and practice represents a great challenge in SWB models use and development. Research uses models to better and more accurately understand the processes relative to soil water fluxes and transport in the soil-plant-atmosphere continuum. Irrigators need that a SWB model responds to their need for knowing when and how much water to apply to a crop in a given environment and in a defined development stage. The users require timely and simple responses, very easy to interpret. SWB models for research and practice already are, and will keep being distinct. The question is therefore how and which information created from research shall pass into practice and which type of SWB will facilitate both new knowledge and its transfer to practice. Likely this requires that research considers transferability as a main option, but that freedom of research is not affected by the need for transferability of results. Is the development of more and more sophisticated models a need? Is scrutiny of field data quality a priority? Is the consideration of the energy balance, namely through crop coefficients, an essential approach in research? Is empirical research, with a minimal use of models to be continued? Would it be advantageous to bring into research the models used in practice? These are questions that future research should debate and substantiate.

\section{Declaration of Competing Interest}

The authors declare that they have no known competing financial interests or personal relationships that could have appeared to influence the work reported in this paper.

\section{Acknowledgements}

The support of the Fundação para a Ciência e a Tecnologia, Portugal, through the research grant attributed to the research unit LEAF (UIDP/04129/2020) and to the second author (DL 57/2016/ CP1382/CT0022) is acknowledged.

\section{References}

Abi-Saab, M.T., Albrizio, R., Nangia, V., Karam, F., Rouphael, Y., 2014. Developing scenarios to assess sunflower and soybean yield under different sowing dates and water regimes in the Bekaa valley (Lebanon): simulations with Aquacrop. Int. J. Plant Prod. 8 (4), 457-482.

Abi-Saab, M.T., Jomaa, I., Skaf, S., Fahed, S., Todorovic, M., 2019. Assessment of a smartphone application for real-time irrigation scheduling in Mediterranean environments. Water 11, 252. https://doi.org/10.3390/w11020252.

Acharya, S., Mylavarapu, R.S., 2015. Modeling shallow water table dynamics under subsurface irrigation and drainage. Agric. Water Manage. 149, 166-174.

Agrawal, M.K., Panda, S.N., Panigrahi, B., 2004. Modeling water balance parameters for rainfed rice. J.Irrig. Drain. Eng. 130 (2), 129-139.

Allen, R.G., Pereira, L.S., 2009. Estimating crop coefficients from fraction of ground cover and height. Irrig. Sci. 28, 17-34.

Allen, R.G., Jensen, M.E., Wright, J.L., Burman, R.D., 1989. Operational estimates of reference evapotranspiration. Agron. J. 81, 650-662.

Allen, R.G., Smith, M., Perrier, A., Pereira, L.S., 1994a. An update for the definition of the reference evapotranspiration. ICID Bull. 43 (2), 1-34.

Allen, R.G., Smith, M., Pereira, L.S., Perrier, A., 1994b. An update for the calculation of reference evapotranspiration. ICID Bull. 43 (2), 35-92.

Allen, R.G., Pereira, L.S., Raes, D., Smith, M., 1998. Crop Evapotranspiration. Guidelines for Computing Crop Water Requirements. FAO Irrig. Drain. Pap. 56. FAO, Rome 300pp.

Allen, R.G., Pereira, L.S., Smith, M., Raes, D., Wright, J.L., 2005a. FAO-56 Dual crop coefficient method for estimating evaporation from soil and application extensions. J. Irrig. Drain Eng. 131 (1), 2-13.

Allen, R.G., Pruitt, W.O., Raes, D., Smith, M., Pereira, L.S., 2005b. Estimating evaporation from bare soil and the crop coefficient for the initial period using common soils information. J. Irrig. Drain Eng. 131 (1), 14-23.

Allen, R.G., Pruitt, W.O., Wright, J.L., Howell, T.A., Ventura, F., Snyder, R., Itenfisu, D., Steduto, P., Berengena, J., Baselga, J., Smith, M., Pereira, L.S., Raes, D., Perrier, A., Alves, I., Walter, I., Elliott, R., 2006. A recommendation on standardized surface resistance for hourly calculation of reference ET $_{0}$ by the FAO56 Penman-Monteith method. Agric. Water Manage. 81, 1-22.

Allen, R.G., Wright, J.L., Pruitt, W.O., Pereira, L.S., Jensen, M.E., 2007. Water requirements. In: Hoffman, G.J., Evans, R.G., Jensen, M.E., Martin, D.L., Elliot, R.L. (Eds.), Design and Operation of Farm Irrigation Systems, 2nd ed. ASABE, St. Joseph, MI, USA, pp. 208-288.

Allen, R.G., Irmak, A., Trezza, R., Hendrickx, J.M.H., Bastiaanssen, W., Kjaersgaard, J., 2011a. Satellite-based ET estimation in agriculture using SEBAL and METRIC. Hydrol. Process. 25, 4011-4027.

Allen, R.G., Pereira, L.S., Howell, T.A., Jensen, M.E., 2011b. Evapotranspiration information reporting: I. Factors governing measurement accuracy. Agric. Water Manage. 98 (6), 899-920.

Allen, R., Dhungel, R., Dhungara, B., Huntington, J., Kilic, A., Morton, C., 2020. Conditioning point and gridded weather data under aridity conditions during calculation of reference evapotranspiration. Agric. Water Manage (submitted for publication).

Alves, I., Pereira, L.S., 2000. Modelling surface resistance from climatic variables? Agric. Water Manage. 42, 371-385.

Alves, I., Perrier, A., Pereira, L.S., 1998. Aerodynamic and surface resistances of complete cover crops: how good is the 'big leaf? Trans. ASAE 41 (2), 345-351.

Andales, A.A., Bauder, T.A., Arabi, M., 2014. A mobile irrigation water management system using a collaborative GIS and weather station networks. In: Ahuja, L.R., Ma, L., Lascano, R. (Eds.), Practical Applications of Agricultural System Models to Optimize the Use of Limited Water, Advances in Agricultural Systems Modeling. ASA, CSSA, and SSSA, Madison, WI, USA, pp. 53-84.

Annandale, J.G., Benadé, N., Jovanovic, N.Z., Steyn, J.M., Du Sautoy, N., 1999. Facilitating Irrigation Scheduling by Means of the Soil Water Balance Model. WRC Report No. 753/1/99. Water Research Commission, Pretoria, South Africa 285 pp.

Annandale, J.G., Jovanovic, N.Z., Campbell, G.S., Du Sautoy, N., Benadé, N., 2003. A twodimensional water balance model for micro-irrigated hedgerow tree crops. Irrig. Sci. $22,157-170$.

Annandale, J.G., Stirzaker, R.J., Singels, A., van der Laan, M., Laker, M.C., 2011. Irrigation scheduling research: South African experiences and future prospects. Water SA 37 (5), 751-763.

ASAE, 1981. In: Irrigation Scheduling for Water and Energy Conservation in the 80'S: Proc. Irrigation Scheduling Conf., Chicago, ASAE Publication 23-81 St. Joseph, Michigan.

ASAE, 1985. Advances in evapotranspiration. In: Proc. National Conference on Advances in Evapotranspiration, ASAE Publication 14-85. St. Joseph, Michigan.

ASAE, 1990. Visions of the future. In: Proc. Third National Irrigation Symposium, Phoenix, Arizona, ASAE Publication 04-90. St. Joseph, Michigan.

Bartlett, A.C., Andales, A.A., Arabi, M., Bauder, T.A., 2015. A smartphone app to extend use of a cloud-based irrigation scheduling tool. Comput. Electron. Agric. 111, 
$127-130$

Bastiaanssen, W.G.M., Menenti, M., Feddes, R.A., Holtslag, A.A.M., 1998. A remote sensing surface energy balance algorithm for land (SEBAL) 1. Formulation. J. Hydrol. 212-213, 198-212.

Belmans, C., Wesseling, J.G., Feddes, R.A., 1983. Simulation model of the water balance of a cropped soil: SWATRE. J. Hydrol. 63, 271-286.

Bennie, A.T.P., Coetzee, M.J., van Antwerpen, R., Van Rensburg, L.D., Burger, R.D., 1988. Water Balance Model for Irrigation Based on Soil Profile Water Supply Rate. WRC Report No. 144/1/88. Water Research Commission, Pretoria, South Africa 405 pp.

Bhadra, A., Bandyopadhyay, A., Singh, R., Raghuwanshi, N.S., 2013. Development of a user friendly water balance model for paddy. Paddy Water Environ. 11, 331-341.

Boegh, E., Poulsen, R.N., Butts, M., Abrahamsen, P., Dellwik, E., Hansen, S., Hasager, C.B., Ibrom, A., Loerup, J.-K., Pilegaard, K., Soegaard, H., 2009. Remote sensing based evapotranspiration and runoff modeling of agricultural, forest and urban flux sites in Denmark: from field to macro-scale. J. Hydrol. 377, 300-316.

Bos, M.G., Burton, M.A., Molden, D.J., 2005. Irrigation and Drainage Performance Assessment. Practical Guidelines. CABI Publish, Wallingford, UK.

Branco, R.P., Teodoro, P.R., Pereira, L.S., 2005. WebISAREG - web based decision system support for irrigation management. In: Boaventura Cunha, J., Morais, R. (Eds.), Proc. Joint 5th EFITA Conf and 3rd WCCA, Vila Real). Univ. Trás-Os-Montes E Alto Douro, Vila Real, CD-ROM. pp. 537-542.

Buchleiter, G.W., 1995. Improved irrigation management under center pivots with SCHED. In: Pereira, L.S., van den Broek, B.J., Kabat, P., Allen, R.G. (Eds.), CropWater-Simulation Models in Practice. Wageningen Pers, Wageningen, pp. 27-47.

Burt, C.M., Clemmens, A.J., Strelkoff, T.S., Solomon, K.H., Bliesner, R.D., Hardy, L.A., Howell, T.A., Eisenhauer, D.E., 1997. Irrigation performance measures: efficiency and uniformity. J. Irrig. Drain. Eng. 123, 423-442.

Cahn, M.D., Johnson, L.F., 2017. New approaches to irrigation scheduling of vegetables. Horticulturae 3, 28. https://doi.org/10.3390/horticulturae3020028.

Cai, J.B., Liu, Y., Xu, D., Paredes, P., Pereira, L.S., 2009. Simulation of the soil water balance of wheat using daily weather forecast messages to estimate the reference evapotranspiration. Hydrol. Earth Syst. 13, 1045-1059.

Cai, X., Hejazi, M.I., Wang, D., 2011. Value of probabilistic weather forecasts: assessment by real-time optimization of irrigation scheduling. J. Water Resour. Plan. Manage. 137 (5), 391-403.

Campos, I., González-Piqueras, J., Carrara, A., Villodre, J., Calera, A., 2016. Estimation of total available water in the soil layer by integrating actual evapotranspiration data in a remote sensing-driven soil water balance. J. Hydrol. 534, 427-439.

Campos, I., Neale, C.M.U., Suyker, A.E., Arkebauer, T.J., Gonçalves, I.Z., 2017 Reflectance based crop coefficients REDUX: for operational evapotranspiration estimates in the age of high producing hybrid varieties. Agric. Water Manage. 187, 140-153.

Cancela, J.J., Fandiño, M., Rey, B.J., Martínez, E.M., 2015. Automatic irrigation system based on dual crop coefficient, soil and plant water status for Vitis vinifera (cv Godello and cv Mencía). Agric. Water Manage. 151, 52-63.

Car, N.J., Christen, E.W., Hornbuckle, J.W., Moore, G.A., 2012. Using a mobile phone Short Messaging Service (SMS) for irrigation scheduling in Australia - farmers' participation and utility evaluation. Comput. Electron. Agric. 84, 132-143.

Chen, D.-C., Lei, X.-Y., Cao, W., Li, Y., 2012. Design and implementation of an irrigation decision support system for cotton in Xinjiang. China. Sensor Letters 10, 459-464.

Chen, P.C.L., Zhang, C.Y., 2014. Data-intensive applications, challenges, techniques and technologies: a survey on Big Data. Inf. Sci. 275, 314-347.

Cholpankulov, E.D., Inchenkova, O.P., Paredes, P., Pereira, L.S., 2008. Cotton irrigation scheduling in Central Asia: model calibration and validation with consideration of groundwater contribution. Irrig. Drain. 57, 516-532.

Chopart, J.L., Mézino, M., Aure, F., Le Mézo, L., Mété, M., Vauclin, M., 2007. OSIRI: a simple decision-making tool for monitoring irrigation of small farms in heterogeneous environments. Agric. Water Manage. 87, 128-138.

Combre, J.C., Kamieniarz, C., 1992. Un logiciel multi parcelles et multi utilisateurs d'avertissement irrigation et de gestion des périmètres irrigués. ICID Bull. 41 (2), 135-152.

Consoli, S., Licciardello, F., Vanella, D., Pasotti, L., Villani, G., Tomei, F., 2016. Testing the water balance model criteria using TDR measurements, micrometeorological data and satellite-based information. Agric. Water Manage. 170, 68-80.

Corbari, C., Salerno, R., Ceppi, A., Telesca, V., Mancini, M., 2019. Smart irrigation forecast using satellite LANDSAT data and meteohydrological modeling. Agric. Water Manage. 212, 283-294.

Crosby, C.T., Crosby, C.P., 1999. SAPWAT - a Computer Program for Establishing Irrigation Requirements and Scheduling Strategies in South Africa. WRC Report No: 624/1/99. Water Research Commission Pretoria, South Africa 12 p.

Danuso, F., Gani, M., Giovanardi, R., 1995. Field water balance: BIdriCo 2. In: Pereira, L.S., van den Broek, B.J., Kabat, P., Allen, R.G. (Eds.), Crop-Water-Simulation Models in Practice. Wageningen Pers, Wageningen, pp. 49-73.

Darouich, H., Pedras, C.M.G., Gonçalves, J.M., Pereira, L.S., 2014. Drip vs. surface irrigation: a comparison focusing on water saving and economic returns using multicriteria analysis applied to cotton. Biosyst. Eng. 122, 74-90.

Darouich, H., Cameira, M.R., Gonçalves, J.M., Paredes, P., Pereira, L.S., 2017. Comparing sprinkler and surface irrigation for wheat using multi-criteria analysis: water saving vs. economic returns. Water 9, 50. https://doi.org/10.3390/w9010050.

De Goes Calmon, M., Vadas, R.G., Rego, N.C., Raes, D., 1992. Computer support system for irrigation scheduling - case study: Pirapora Project (Brazil). ICID Bull. 41 (2), 19-27.

De Jager, J.M., Mottram, R., Kennedy, J.A., 2001. Research on a Computerised Weather Based Irrigation Water Management System. WRC Report No. 581/1/01. Water Research Commission, Pretoria, South Africa 180 pp.

de Silva, C.S., Rushton, K.R., 2008. Representation of rainfed valley rice fields using a soil-water balance model. Agric Water Manage 95, 271-282.

DeJonge, K.C., Thorp, K.R., 2017. Implementing standardized reference evapotranspiration and dual crop coefficient approach in the DSSAT cropping system model. Trans. ASABE 60 (6), 1965-1981.

DeJonge, K.C., Ascough, J.C., Andales, A.A., Hansen, N.C., Garcia, L.A., Arabi, M., 2012. Improving evapotranspiration simulations in the CERES-Maize model under limited irrigation. Agric. Water Mgmt. 115, 92-103.

Dhungel, R., Allen, R.G., Trezza, R., 2016. Improving iterative surface energy balance convergence for remote sensing based flux calculation. J. Appl. Remote Sens. 10 (2), 026033.

Doorenbos, J., Kassam, A.H., 1979. Yield response to Water. Irrig. Drain. Paper 33. FAO, Rome 193 pp.

Doorenbos, J., Pruitt, W.O., 1977. Guidelines for predicting crop-water requirements. FAO Irrig. Drain. Paper 24, 2nd rev. ed. FAO, Rome 156 pp.

El-Naggar, A.G., Hedley, C.B., Horne, D., Roudier, P., Clothier, B.E., 2020. Soil sensing technology improves application of irrigation water. Agric. Water Manage. 228, 105901.

Er-Raki, S., Chehbouni, A., Guemouria, N., Duchemin, B., Ezzahar, J., Hadria, R., 2007. Combining FAO-56 model and ground-based remote sensing to estimate water consumptions of wheat crops in a semi-arid region. Agric. Water Manage. 87, 41-54.

Fandiño, M., Cancela, J.J., Rey, B.J., Martínez, E.M., Rosa, R.G., Pereira, L.S., 2012. Using the dual-Kc approach to model evapotranspiration of Albariño vineyards (Northwest Spain) with consideration of active ground cover. Agric. Water Manage. 112, 75-87.

Fandiño, M., Olmedo, J.L., Martínez, E.M., Valladares, J., Paredes, P., Rey, B.J., Mota, M., Cancela, J.J., Pereira, L.S., 2015. Assessing and modelling water use and the partition of evapotranspiration of irrigated hop (Humulus lupulus), and relations of transpiration with hops yield and alpha-acids. Ind. Crop. Prod. 77, 204-217.

Feddes, R.A., Kowalik, P.J., Zaradny, H., 1978. Simulation of field water use and crop yield. Simulation Monographs Pudoc. Wageningen, The Netherlands.

Fernández, J.E., 2017. Plant-based methods for irrigation scheduling of woody crops. Horticulturae 3, 35. https://doi.org/10.3390/horticulturae3020035.

Fernández, J.E., Alcon, F., Diaz-Espejo, A., Hernandez-Santana, V., Cuevas, M.V., 2020. Water use indicators and economic analysis for on-farm irrigation decision: A case study of a super high density olive tree orchard. Agric. Water Manage. 237, 106074

Ferreira, M.I., 2017. Stress coefficients for soil water balance combined with water stress indicators for irrigation scheduling of woody crops. Horticulturae 3, 38. https://doi. org/10.3390/horticulturae3020038.

Feyen, J. (Ed.), 1987. Simulation Models for Cropping Systems in Relation to Water Management. Commission of the European Communities, Luxembourg.

French, A.N., Hunsaker, D.J., Thorp, K.R., 2015. Remote sensing of evapotranspiration over cotton using the TSEB and METRIC energy balance models. Remote Sens. Environ. 158 (1), 281-294.

Genovesi, R., Bazzani, G.M., Liserra, T., 2019. Bilancio idrico di un canale irriguo dotato di paratoie mobili in controllo remoto guidate dal servizio IrriNET di programmazione delle irrigazioni. L'Acqua 4, 49-58.

George, B.A., Raghuwanshi, N.S., Singh, R., 2004. Development and testing of a GIS integrated irrigation scheduling model. Agric. Water Manage. 66, 221-237.

Giannerini, G., 1995. RENANA: a model for irrigation scheduling, employed on a large scale. In: Pereira, L.S., van den Broek, B.J., Kabat, P., Allen, R.G. (Eds.), Crop-WaterSimulation Models in Practice. Wageningen Pers, Wageningen, pp. 17-25.

Giannerini, G., Genovesi, R., 2015. The water saving with Irriframe platform for thousands of Italian farms. J. Agric. Informatics 6 (4), 49-55.

Giménez, L., García-Petillo, M., Paredes, P., Pereira, L.S., 2016. Predicting maize transpiration, water use and productivity for developing improved supplemental irrigation schedules in western Uruguay to cope with climate variability. Water 8, 309. https://doi.org/10.3390/w8070309.

Giménez, L., Paredes, P., Pereira, L.S., 2017. Water use and yield of soybean under various irrigation regimes and severe water stress. Application of AquaCrop and SIMDualKc models. Water 9, 393. https://doi.org/10.3390/w9060393.

Goap, A., Sharma, D., Shukla, A.K., Krishna, C.R., 2018. An IoT based smart irrigation management system using Machine learning and open source technologies Comput. Electron. Agric. 155, 41-49.

Han, Y.J., Khalilian, A., Owino, T.O., Farahani, H.J., Moore, S., 2009. Development of Clemson variable-rate lateral irrigation system. Comput. Electron. Agric. 68, $108-113$.

Han, M., Zhang, H., Chávez, J.L., Ma, L., Trout, T.J., DeJonge, K.C., 2018. Improved soil water deficit estimation through the integration of canopy temperature measurements into a soil water balance model. Irrig. Sci. 36, 187-201.

Hanks, R.J., 1974. Model for predicting plant yield as influenced by water use. Agron. J. $66,660-664$.

Hanks, R.J., Hill, R.W., 1980. Modeling crop responses to irrigation in relation to soils, climate and salinity. In: IIIC Publ. nr. 6, Bet Dagan. Israel. pp.66.

Heermann, D.F., Solomon, K.H., 2007. Efficiency and uniformity. In: Hoffman, G.J., Evans, R.G., Jensen, M.E., Martin, D.L., Elliot, R.L. (Eds.), Design and Operation of Farm Irrigation Systems, 2nd ed. ASABE, St. Joseph, MI, pp. 108-119.

Hejazi, M.I., Cai, X., Yuan, X., Liang, X.-Z., Kumar, P., 2014. Incorporating reanalysisbased short-term forecasts from a regional climate model in an irrigation scheduling optimization problem. J. Water Resour. Plan. Manage. 140 (5), 699-713.

Helman, D., Bonfil, D.J., Lensky, I.M., 2019. Crop RS-Met: a biophysical evapotranspiration and root-zone soil water content model for crops based on proximal sensing and meteorological data. Agric. Water Manage. 211, 210-219.

Hendrickx, J.M.H., Allen, R.G., Brower, A., Byrd, A.R., Hong, S., Ogden, F.L., Pradhan, N.R., Robison, C.W., Toll, D., Trezza, R., Umstot, T.G., Wilson, J.L., 2016. Benchmarking optical/thermal satellite imagery for estimating evapotranspiration and soil moisture in decision support tools. J. Am. Water Resour. Ass. 52 (1), 89-119.

Hess, T., 1996. A microcomputer scheduling program for supplementary irrigation. In: 
Smith, M., Pereira, L.S., Berengena, J., Itier, B., Goussard, J., Ragab, R., Tollefson, L., Van Hoffwegen, P. (Eds.), Irrigation Scheduling: From Theory to Practice, FAO Water Report 8. FAO, Rome, pp. 59-68.

HiIl, R.W., 1991. Irrigation scheduling. In: Modeling Plant and Soil Systems, Agronomy Monograph no. 31, ASA-CSSA-SSSA. Madison, WI, USA. pp. 491-509.

Howell, T.A., Steiner, J.L., Schneider, A.D., 1990. Evapotranspiration of irrigated grain sorghum and corn - Southern High Plains. In: Visions of the Future. Proc. Third National Irrigation Symposium, Phoenix, Arizona, ASAE Publication 04-90. St. Joseph, MI. pp. 140-147.

Inthavong, T., Tsub, M., Fukai, S., 2011. A water balance model for characterization of length of growing period and water stress development for rainfed lowland rice. Field Crop. Res. 121, 291-301.

Irmak, S., Mutiibwa, D., 2009. On the dynamics of evaporative losses from PenmanMonteith with fixed and variable canopy resistance during partial and complete maize canopy. Trans. ASABE 52 (4), 1139-1153.

Jamal, A., Linker, R., Housh, M., 2018. Comparison of various stochastic approaches for irrigation scheduling using seasonal climate forecasts. J. Water Resour. Plan. Manage. 144 (7), 04018028.

Jensen, M.E., 1968. Water consumption by agricultural plants. In: Kozlowski, T.T. (Ed.), Water Deficit and Plant Growth. Academic Press, New York, NY, USA, pp. 1-22.

Jensen, M.E., Allen, R.G., 2016. Evaporation, Evapotranspiration, and Irrigation Water Requirements. ASCE Manuals and Reports on Engineering Practice No. 70, 2nd ed. Reston, Virginia, pp. 744.

Jeon, J.-H., Yoon, C.G., Ham, J.-H., Jung, K.-W., 2005. Model development for surface drainage loading estimates from paddy rice fields. Paddy Water Environ. 3, 93-101.

Jiang, Y., Zhang, L., Zhang, B., He, C., Jin, X., Bai, X., 2016. Modeling irrigation management for water conservation by DSSAT-maize model in arid northwestern China. Agric. Water Manage. 177, 37-45.

Johnson, L.F., Trout, T.J., 2012. Satellite NDVI assisted monitoring of vegetable crop evapotranspiration in California's San Joaquin Valley. Remote Sens. 4 (2), 439-455.

Jovanovic, N.Z., Ehlers, L., Bennie, A.T.P., Du Preez, C.C., Annandale, J.G., 2004. Modelling the contribution of root accessible water tables towards crop water requirements. S. Afr. J. Plant Soil 21 (3), 171-181.

Jovanovic, N., Pereira, L.S., Paredes, P., Pôças, I., Cantore, V., Todorovic, M., 2020. Methods, technologies and devices to reduce non-beneficial consumptive water use on farms with focus on the use of updated FAO56 methods. Agric. Water Manage. 239, 106267.

Kabat, P., van den Broek, B.J., Feddes, R.A., 1992. SWACROP, a water management and crop production simulation model. ICID 41 (2), 61-84.

Khepar, S.D., Yadav, A.K., Sondhi, S.K., Siag, M., 2000. Water balance model for paddy fields under intermittent irrigation practices. Irrig. Sci. 19, 199-208.

Kipkorir, E.C., Raes, D., Bargerei, R.G., Mugalavai, E.M., 2007. Evaluation of two risk assessment methods for sowing maize in Kenya. Agric. For. Meteorol. 144, 193-199.

Klemm, T., McPherson, R.A., 2017. The development of seasonal climate forecasting for agricultural producers. Agric. Forest Meteorol. 232, 384-399.

Kurnik, B., Louwagie, G., Erhard, M., Ceglar, A., Kajfež, L.B., 2014. Analysing seasonal differences between a soil water balance model and in situ soil moisture measurements at nine locations across Europe. Environ. Model. Assess. 19, 19-34.

Kusunose, Y., Mahmood, R., 2016. Imperfect forecasts and decision making in agriculture. Agric. Syst. 146, 103-110.

Lascano, R.J., 1991. Review of models for predicting soil water balance. Soil Water Balance in the Sudano-Sahelian Zone (Proc. Niamey Workshop) 443-458 IAHS Publ. no. 199.

Lecina, S., Isidoro, D., Playán, E., Aragüiés, R., 2010. Irrigation modernization and water conservation in Spain: The case of Riegos del Alto Aragón. Agric. Water Manage. 97, 1663-1675.

Lee, I., 2017. Big data: dimensions, evolution, impacts, and challenges. Bus. Horiz. 60 (3), 293-303.

Li, H., Li, J., Shen, Y., Zhang, X., Lei, Y., 2018. Web-based irrigation decision support system with limited inputs for farmers. Agric. Water Manage. 210, 279-285.

Linker, R., Sylaios, G., Tsakmakis, I., Ramos, T., Simionesei, L., Plauborg, F., Battilani, A., 2018. Sub-optimal model-based deficit irrigation scheduling with realistic weather forecasts. Irrig. Sci. 36, 349-362.

Liu, Y., Pereira, L.S., Fernando, R.M., 2006. Fluxes through the bottom boundary of the root zone in silty soils: parametric approaches to estimate groundwater contribution and percolation. Agric. Water Manage. 84, 27-40.

Lollato, R.P., Patrignani, A., Ochsner, T.E., Edwards, J.T., 2016. Prediction of plant available water at sowing for winter wheat in the Southern Great Plains. Agron. J. 108, 745-757.

López-Urrea, R., Domínguez, A., Pardo, J.J., Montoya, F., García-Vila, M., MartínezRomero, A., 2020. Parameterization and comparison of the AquaCrop and MOPECO models for a high-yielding barley cultivar under different irrigation levels. Agric. Water Manage. 230, 105931.

Lorite, I.J., Ramírez Cuesta, J.M., Cruz-Blanco, M., Santos, C., 2015. Using weather forecast data for irrigation scheduling under semi arid conditions. Irrig. Sci. 33, $411-427$.

Lovelli, S., Perniola, M., Arcieri, M., Rivelli, A.R., Di Tommaso, T., 2008. Water use assessment in muskmelon by the Penman-Monteith "one-step" approach. Agric. Water Manage. 95, 1153-1160.

Ma, Y., Feng, S., Song, X., 2013. A root zone model for estimating soil water balance and crop yield responses to deficit irrigation in the North China Plain. Agric. Water Manage. 127, 13-24.

Mailhol, J.C., Revol, P., Ruelle, P., 1996. PILOTE: un modele operationnel pour deceler l'apparition du stress hydrique. In: Ragab, R., El-Quosy, D.E., van den Broek, B., Pereira, L.S. (Eds.), Crop-Water-Environment Models, (Proc. Workshop, Cairo). Egypt Nat. Com. ICID, Cairo, pp. 209-222.
Mailhol, J.C., Zairi, A., Slatni, A., Ben Nouma, B., El Amani, H., 2004. Analysis of irri gation systems and irrigation strategies for durum wheat in Tunisia. Agric. Water Manage. 70, 19-37.

Mailhol, J.-C., Albasha, R., Cheviron, B., Lopez, J.-M., Ruelle, P., Dejean, C., 2018. The PILOTE-N model for improving water and nitrogen management practices: Application in a Mediterranean context. Agri. Water Manage. 204, 162-179.

Malano, H.M., Turral, H.N., Wood, M.L., 1996. Surface irrigation management in real time in southeastern Australia: irrigation scheduling and field application. In: Smith, M., Pereira, L.S., Berengena, J., Itier, B., Goussard, J., Ragab, R., Tollefson, L., Van Hoffwegen, P. (Eds.), Irrigation Scheduling: From Theory to Practice, FAO Water Report 8. FAO, Rome, pp. 105-118.

Mancosu, N., Spano, D., Orang, M., Sarreshteh, S., Snyder, R.L., 2016. SIMETAW\# - a model for agricultural water demand planning. Water Resour. Manage. 30, 541-557.

Mandal, U.K., Victor, U.S., Srivastava, N.N., Sharma, K.L., Ramesh, V., Vanaja, M., Korwar, G.R., Ramakrishna, Y.S., 2007. Estimating yield of sorghum using root zone water balance model and spectral characteristics of crop in a dryland Alfisol. Agric. Water Manage. 87, 315-327.

Mannini, P., Genovesi, R., Letterio, T., 2013. IRRINET: large scale DSS application for onfarm irrigation scheduling. Procedia Environ. Sci. 19, 823-829.

Mao, Z., Dong, B., Pereira, L.S., 2004. Assessment and water saving issues for Ningxia paddies, upper Yellow River Basin. Paddy Water Environ. 2 (2), 99-110.

Mateus, P., Correia, L., Pereira, L.S., 2007. HIDROGEST, a GIS framework for integration of decision support tools for improved water use and participatory management in pressurized on-demand irrigation systems. In: Lamaddalena, N., Boglioti, C., Todorovic, M., Scardigno, A. (Eds.), Water Saving in Mediterranean Agriculture \& Future Research Needs, Options Mediterranéennes. Série B, 56, vol. I, pp. 303-317.

Melton, F.S., Johnson, L.F., Lund, C.P., Pierce, L.L., Michaelis, A.R., Hiatt, S.H., Guzman, A., Adhikari, D.D., Purdy, A.J., Rosevelt, C., Votava, P., Trout, T.J., Temesgen, B., Frame, K., Sheffner, E.J., Nemani, R.R., 2012. Satellite irrigation management support with the terrestrial observation and prediction system: a framework for integration of satellite and surface observations to support improvements in agricultural water resource management. IEEE J. Sel. Top. Appl. Earth Observ. Remote Sens. 5 (6), 1709-1721.

Melton, F., Johnson, L.F., Guzman, A., Post, K., Wang, T., Lund, C.P., Zaragosa, I., Hang, M., Carrara, W., Doherty, C., Anderson, R.G., Temesgen, B., Trezza, R., Cahn, M.D., Pereira, L.S., 2020. The Satellite Irrigation Management Support (SIMS) System: Satellite mapping of crop coefficients to support advances in irrigation management. Remote Sens. Environ (submitted).

Miao, Q., Rosa, R.D., Shi, H., Paredes, P., Zhu, L., Dai, J., Gonçalves, J.M., Pereira, L.S., 2016. Modeling water use, transpiration and soil evaporation of spring wheat-maize and spring wheat-sunflower relay intercropping using the dual crop coefficient approach. Agric. Water Manage. 165, 211-229.

Minhas, P.S., Ramos, T.B., Ben-Gal, A., Pereira, L.S., 2020. Coping with salinity in irrigated agriculture: crop evapotranspiration and water management issues. Agric. Water Manage. 227, 105832.

Molden, D., Sakthivadivel, R., 2011. Water accounting to assess use and productivity of water. Int. J. Water Resour. Develop. 15 (1-2), 55-71.

Monteith, J.L., 1965. Evaporation and environment. The State and Movement of Water in Living Organisms, 19th Symp. Soc. Exp. Biol. Cambridge University Press, Cambridge, pp. 205-234.

Montoya, F., Otero, Á., 2019. Is irrigating soybean profitable in Uruguay? A modeling approach. Agron. J. 111, 1-15.

Moriasi, D.N., Arnold, J.G., Van Liew, M.W., Bingner, R.L., Harmel, R.D., Veith, T.L., 2007. Model evaluation guidelines for systematic quantification of accuracy in watershed simulations. Trans. ASABE 50, 885-900.

O'Shaughnessy, S.A., Evett, S.R., Colaizzi, P.D., Howell, T.A., 2012. A crop water stress index and time threshold for automatic irrigation scheduling of grain sorghum. Agric Water Manage. 107, 122-132. https://doi.org/10.1016/j.agwat.2012.01.018.

O'Shaughnessy, S.A., Evett, S.R., Andrade, M.A., Workneh, F., Price, J.A., Rush, C.M., 2016. Site-specific variable-rate irrigation as a means to enhance water use efficiency. Trans. ASABE 59 (1), 239-249.

Olioso, A., Inoue, Y., Ortega-Farias, S., Demarty, J., Wigneron, J.-P., Braud, I., Jacob, F. Lecharpentier, P., Ottlé, C., Calvet, J.-C., Brisson, N., 2005. Future directions for advanced evapotranspiration modeling: assimilation of remote sensing data into crop simulation models and SVAT models. Irrig. Drain. Syst. Eng. 19, 377-412.

Olivera-Guerra, L., Merlin, O., Er-Raki, S., Khabba, S., Escorihuela, M.J., 2018. Estimating the water budget components of irrigated crops: combining the FAO-56 dual crop coefficient with surface temperature and vegetation index data. Agric. Water Manage. 208, 120-131.

Ortega-Farias, S.O., Olioso, A., Antonioletti, R., Brisson, N., 2004. Evaluation of the Penman-Monteith model for estimating soybean evapotranspiration. Irrig. Sci. $23,1-9$.

Ortega-Farias, S.O., Olioso, A., Fuentes, S., Valdes, H., 2006. Latent heat flux over a furrow-irrigated tomato crop using Penman-Monteith equation with a variable surface canopy resistance. Agric. Water Manage. 82, 421-432.

Ortega-Farias, S.O., Ortega-Salazar, S., Poblete, T., Kilic, A., Allen, R., Poblete-Echeverría C., Ahumada-Orellana, L., Zuñiga, M., Sepúlveda, D., 2016. Estimation of energy balance components over a drip-irrigated olive orchard using thermal and multispectral cameras placed on a helicopter-based unmanned aerial vehicle (UAV). Remote Sens. 8, 638. https://doi.org/10.3390/rs8080638.

Paço, T.A., Ferreira, M.I., Rosa, R.D., Paredes, P., Rodrigues, G.C., Conceição, N., Pacheco, C.A., Pereira, L.S., 2012. The dual crop coefficient approach using a density factor to simulate the evapotranspiration of a peach orchard: SIMDualKc model vs. eddy covariance measurements. Irrig. Sci. 30 (2), 115-126.

Paço, T.A., Paredes, P., Pereira, L.S., Silvestre, J., Santos, F.L., 2019. Crop coefficients and transpiration of a super intensive arbequina olive orchard using the dual Kc approach 
and the Kcb computation with the fraction of ground cover and height. Water 11, 383. https://doi.org/10.3390/w11020383.

Panigrahi, B., Panda, S.N., 2003. Field test of a soil water balance simulation model. Agric. Water Manage. 58, 223-240.

Paredes, P., Pereira, L.S., 2019. Computing FAO56 reference grass evapotranspiration PM-ET $\mathrm{O}_{\mathrm{o}}$ from temperature with focus on solar radiation. Agric. Water Manage. 215, 86-102.

Paredes, P., Rodrigues, G.C., Alves, I., Pereira, L.S., 2014. Partitioning evapotranspiration, yield prediction and economic returns of maize under various irrigation management strategies. Agric. Water Manage. 135, 27-39 Corrigendum in Agric. Water Manage. $141,84$.

Paredes, P., Pereira, L.S., Rodrigues, G.C., Botelho, N., Torres, M.O., 2017a. Using the FAO dual crop coefficient approach to model water use and productivity of processing pea (Pisum sativum L.) as influenced by irrigation strategies. Agric. Water Manage. 189, 5-18.

Paredes, P., Rodrigues, G.C., Cameira, M.R., Torres, M.O., Pereira, L.S., 2017b. Assessing yield, water productivity and farm economic returns of malt barley as influenced by the sowing dates and supplemental irrigation. Agric. Water Manage. 179, 132-143.

Paredes, P., Martins, D., Pereira, L.S., Cadima, J., Pires, C., 2018a. Accuracy of daily estimation of grass reference evapotranspiration using ERAInterim reanalysis products with assessment of alternative bias correction schemes. Agric. Water Manage. 210, 340-353.

Paredes, P., Rodrigues, G.J., Petry, M.T., Severo, P.O., Carlesso, R., Pereira, L.S., 2018b. Evapotranspiration partition and crop coefficients of Tifton 85 bermudagrass as affected by the frequency of cuttings. Application of the dual Kc approach. Water 10, 558. https://doi.org/10.3390/w10050558.

Paredes, P., Pereira, L.S., Almorox, J., Darouich, H., 2020a. Reference grass evapotranspiration with reduced data sets: parameterization of the FAO Penman-Monteith temperature approach and the Hargeaves-Samani equation using local climatic variables. Agric. Water Manage. 240, 106210. https://doi.org/10.1016/j.agwat. 2020.106210

Paredes, P., Trigo, I., De Bruin, H., Simões, N., Pereira, L.S., 2020b. Daily grass reference evapotranspiration with Meteosat Second Generation shortwave radiation and reference ET products. Agric. Water Manage (submitted for publication).

Paulo, A.M., Pereira, L.A., Teixeira, J.L., Pereira, L.S., 1995. Modeling paddy rice irrigation. In: Pereira, L.S., van den Broek, B.J., Kabat, P., Allen, R.G. (Eds.), Crop-WaterSimulation Models in Practice. Wageningen Pets, Wageningen, pp. 287-302.

Payero, J.O., Mirzakhani-Nafchi, A., Khalilian, A., Qiao, X., Davis, R., 2017. Development of a low-cost Internet-of-Things (IoT) system for monitoring soil water potential using Watermark 200SS Sensors. Adv. Internet Things 7, 71-86.

Peddinti, S.R., Kambhammettu, B.V.N.P., 2019. Dynamics of crop coefficients for citrus orchards of central India using water balance and eddy covariance flux partition techniques. Agric. Water Manage. 212, 68-77.

Perea, R.G., García, I.F., Arroyo, M.M., Rodríguez Díaz, J.A., Camacho Poyato, E., Montesinos, P., 2017. Multiplatform application for precision irrigation scheduling in strawberries. Agric. Water Manage. 183, 194-201.

Pereira, L.S., 2017. Water, agriculture and food: challenges and issues. Water Res. Manage. 31 (10), 2985-2999.

Pereira, L.S., Perrier, A., Ait Kadi, M., Kabat, P. (Eds.), 1992. Crop-Water Models. Special issue of the ICID Bulletin, ICID, New Delhi 200 pp.

Pereira, L.S., van den Broek, B., Kabat, P., Allen, R.G. (Eds.), 1995. Crop-Water Simulation Models in Practice. Wageningen Pers, Wageningen, The Netherlands.

Pereira, L.S., Perrier, A., Allen, R.G., Alves, I., 1999. Evapotranspiration: review of concepts and future trends. J. Irrig. Drain Eng. 125 (2), 45-51.

Pereira, L.S., Teodoro, P.R., Rodrigues, P.N., Teixeira, J.L., 2003. Irrigation scheduling simulation: the model ISAREG. In: Rossi, G., Cancelliere, A., Pereira, L.S., Oweis, T., Shatanawi, M., Zairi, A. (Eds.), Tools for Drought Mitigation in Mediterranean Regions. Kluwer, Dordrecht, The Netherlands, pp. 161-180.

Pereira, L.S., Gonçalves, J.M., Dong, B., Mao, Z., Fang, S.X., 2007. Assessing basin irrigation and scheduling strategies for saving irrigation water and controlling salinity in the upper Yellow River Basin, China. Agric. Water Manage. 93, 109-122.

Pereira, L.S., Cordery, I., Iacovides, I., 2009. Coping with Water Scarcity. Addressing the Challenges. Springer, Dordrecht, The Netherlands 382 pp.

Pereira, L.S., Cordery, I., Iacovides, I., 2012. Improved indicators of water use performance and productivity for sustainable water conservation and saving. Agric. Water Manage. 108, 39-51.

Pereira, L.S., Allen, R.G., Smith, M., Raes, D., 2015a. Crop evapotranspiration estimation with FAO56: past and future. Agric. Water Manage. 147, 4-20.

Pereira, L.S., Paredes, P., Rodrigues, G.C., Neves, M., 2015b. Modeling barley water use and evapotranspiration partitioning in two contrasting rainfall years. Assessing SIMDualKc and AquaCrop models. Agric. Water Manage. 159, 239-254.

Pereira, L.S., Paredes, P., López-Urrea, R., Hunsaker, D.J., Mota, M., Mohammadi Shad, Z., 2020a. Standard single and basal crop coefficients for vegetable crops, an update of FAO56 crop water requirements approach. Agric. Water Manage.(240). https:// doi.org/10.1016/j.agwat.2020.106196.

Pereira, L.S., Paredes, P., Hunsaker, D.J., López-Urrea, R., Mohammadi Shad, Z., 2020b. Standard single and basal crop coefficients for field crops. Updates and advances to the FAO56 crop water requirements method. Agric. Water Manage submitted for publication.

Pereira, L.S., Paredes, P., Melton, F., Johnson, L., Wang, T., López-Urrea, R., Cancela, J.J., Allen, R., 2020c. Prediction of crop coefficients from fraction of ground cover and height. Background and validation using ground and remote sensing data. Agric Water Manage.(240). https://doi.org/10.1016/j.agwat.2020.106197.

Pereira, L.S., Paredes, P., Mota, M., Melton, F., Wang, T., Johnson, L., 2020d. Prediction of crop coefficients from fraction of ground cover and height. Indicative $\mathrm{K}_{\mathrm{c}}$ and $\mathrm{K}_{\mathrm{cb}}$ values for vegetable, field and fruit crops. Agric. Water Manage submitted for publication.

Perrier, A., 1982. Land surface processes: vegetation. In: Eagleson, P.S. (Ed.), Land Surface Processes in Atmospheric General Circulation Models. Cambridge University Press, pp. 395-448.

Plauborg, F., Andersen, M.N., Heidmann, T., Oleson, J.E., 1996. MARKVAND: an irrigation scheduling system for use under limited irrigation capacity in a temperate humid climate. In: Smith, M., Pereira, L.S., Berengena, J., Itier, B., Goussard, J., Ragab, R., Tollefson, L., Van Hoffwegen, P. (Eds.), Irrigation Scheduling: From Theory to Practice, FAO Water Report 8. FAO, Rome, pp. 177-184.

Pôças, I., Paço, T.I., Paredes, P., Cunha, M., Pereira, L.S., 2015. Estimation of actual crop coefficients using remotely sensed vegetation indices and soil water balance modelled data. Remote Sens. 7, 2373-2400. https://doi.org/10.3390/rs70302373.

Pôças, I., Gonçalves, J., Costa, A.P., Gonçalves, I., Pereira, L.S., Cunha, M., 2017. Hyperspectral based predictive modelling of grapevine water status in the Portuguese Douro wine region. Int. J. Appl. Earth Obs. Geoinf. 58, 177-190.

Popova, Z., Ivanova, M., Martins, D., Pereira, L.S., Doneva, K., Alexandrov, V., Kercheva, M., 2014. Vulnerability of Bulgarian agriculture to drought and climate variability with focus on rainfed maize systems. Nat. Hazards 74, 865-886.

Qiu, R., Du, T., Kang, S., Chen, R., Wu, L., 2015. Assessing the SIMDualKc model for estimating evapotranspiration of hot pepper grown in a solar greenhouse in Northwest China. Agric. Syst. 138, 1-9.

Raes, D., Lemmens, P., Van Aelst, M., Van den Bulcke, M., Smith, M., 1988. IRSIS Irrigation Scheduling Information. Lab. Land Management, Fac. Agricultural Sciences, K.U. Leuven, Belgium.

Raes, D., Geerts, S., Kipkorir, E., Wellens, J., Sahli, A., 2006. Simulation of yield decline as a result of water stress with a robust soil water balance model. Agric. Water Manage. 81, 335-357.

Raes, D., Steduto, P., Hsiao, T.C., Fereres, E., 2016. Crop water productivity. Calculation procedures and calibration guidance. AquaCrop Version 4.6. FAO, Land Water Dev. Div., Rome, Italy.

Ragab, R., 2002. A holistic generic integrated approach for irrigation, crop and field management: the SALTMED model. Environ. Model. Softw. 17 (4), 345-361.

Ragab, R., El-Quosy, D.E., van den Broek, B., Pereira, L.S. (Eds.), 1996. Crop Water Environment Models (Selected Papers ICID Workshop). Egypt Nat. Com. ICID, Cairo.

Rallo, G., Paço, T.A., Puig, A., Paredes, P., Massai, R., Provenzano, G., Pereira, L.S., 2020. Updated single and dual crop coefficients for tree and vine fruit crops. Agric. Water Manage (submitted).

Ramos, T.B., Šimůnek, J., Gonçalves, M.C., Martins, J.C., Prazeres, A., Castanheira, N.L., Pereira, L.S., 2011. Field evaluation of a multicomponent solute transport model in soils irrigated with saline waters. J. Hydrol. 407, 129-144.

Ramos, T.B., Šimůnek, J., Gonçalves, M.C., Martins, J.C., Prazeres, A., Pereira, L.S., 2012 Two-dimensional modeling of water and nitrogen fate from sweet sorghum irrigated with fresh and blended saline waters. Agric. Water Manage. 111, 87-104.

Rana, G., Katerji, N., Mastrorilli, M., 1997. Environmental and soil-plant parameters for modelling actual crop evapotranspiration under water stress conditions. Ecol. Modell. 101, 363-371.

Rana, G., Katerji, N., Perniola, M., 2001. Evapotranspiration of sweet sorghum: a general model and multilocal validity in semiarid environmental conditions. Water Resour. Res. 37, 3237-3246.

Ritchie, J.T., 1972. Model for predicting evaporation from a row crop with incomplete cover. Water Resour. Res. 8, 1204-1213.

Rosa, R.D., Paredes, P., Rodrigues, G.C., Alves, I., Fernando, R.M., Pereira, L.S., Allen, R.G., 2012a. Implementing the dual crop coefficient approach in interactive software. 1. Background and computational strategy. Agric. Water Manage. 103, 8-24.

Rosa, R.D., Paredes, P., Rodrigues, G.C., Fernando, R.M., Alves, I., Pereira, L.S., Allen, R.G., 2012b. Implementing the dual crop coefficient approach in interactive software. 2. Model testing. Agric. Water Manage. 103, 62-77.

Saadi, S., Boulet, G., Bahir, M., Brut, A., Delogu, É., Fanise, P., Mougenot, B., Simonneaux, V., Lili Chabaane, Z., 2018. Assessment of actual evapotranspiration over a semiarid heterogeneous land surface by means of coupled low-resolution remote sensing data with an energy balance model: comparison to extralarge aperture scintillometer measurements. Hydrol. Earth Syst. Sci. 22, 2187-2209.

Santos, C., Lorite, I.J., Tasumi, M., Allen, R.G., Fereres, E., 2008. Integrating satellitebased evapotranspiration with simulation models for irrigation management at the scheme level. Irrig. Sci. 26, 277-288.

Saraiva, K.R., Viana, T.V.A., Bezerra, F.M.L., Costa, S.C., Gondim, R.S., 2017. Regulated deficit irrigation and different mulch types on fruit quality and yield of watermelon. Rev. Caatinga, Mossoró 30 (2), 437-446.

Sarr, B., Lecoeu, J., Clouvel, P., 2004. Irrigation scheduling of confectionery groundnut (Arachis hypogeaea L.) in Senegal using a simple water balance model. Agric. Water Manage. 67, 201-220.

Schwartz, R.C., Domínguez, A., Pardo, J.J., Colaizzi, P.D., Baumhardt, R.L., Bell, J.M., 2020. A crop coefficient -based water use model with non-uniform root distribution. Agric. Water Manage. 228, 105892.

Shang, S., Mao, X., 2006. Application of a simulation based optimization model for winter wheat irrigation scheduling in North China. Agric. Water Manage. 85, 314-322.

Sheikh, V., Visser, S., Stroosnijder, L., 2009. A simple model to predict soil moisture: Bridging Event and Continuous Hydrological (BEACH) modelling. Environ. Model Softw. 24, 542-556.

Shrestha, N., Geerts, S., Raes, D., Horemans, S., Soentjens, S., Maupas, F., Clouet, P., 2010. Yield response of sugar beets to water stress under Western European conditions. Agric. Water Manage. 97, 346-350.

Shuttleworth, W.J., Wallace, J.S., 1985. Evaporation from sparse crops - an energy combination theory. Q. J. R. Meteorol. Soc. 111, 839-855.

Silva, L., Ragab, R., Duarte, I., Lourenço, E., Simões, N., Chaves, M., 2012. Calibration and validation of SALTMED model under dry and wet year conditions using chickpea field 
data from Southern Portugal. Irrig. Sci. 30, 1-9.

Šimünek, J., Hopmans, J.W., 2009. Modeling compensated root water and nutrient uptake. Ecol. Model. 220, 505-521.

Singels, A., 2007. A new approach to implementing computer-based decision support for sugarcane farmers and extension staff. The case of My Canesim. Proc. Int. Soc. Sugar Cane Technol. 26, 211-219 (also published in Sugar Cane Int. 26 22-25).

Singh, K.B., Gajri, P.R., Arora, V.K., 2001. Modelling the effects of soil and water management practices on the water balance and performance of rice. Agric. Water Manage. 49 (2), 77-95.

Smith, M., 1988. Manual for CROPWAT - a Computer Program for IBM-PC or Compatibles. Land and Water Development Division, FAO, Rome, Italy.

Smith, M., 1992. CROPWAT: A Computer Program for Irrigation Planning and Management. FAO Irrig. Drain. Paper 46. Rome, Italy (http://www.fao.org/landwater/databases-and-software/cropwat/en/; version 8.0 assessed 31.01.2020). .

Smith, M., 2000. The application of climatic data for planning and management of sustainable rainfed and irrigated crop production. Agric. Forest Meteorol. 103, 99-108.

Smith, M., Allen, R.G., Monteith, J., Perrier, A., Pereira, L.S., Segeren, A., 1991. Report on the Expert Consultation on Revision of FAO Methodologies for Crop Water Requirements. FAO, Rome 54 p.

Smith, M., Pereira, L.S., Berengena, J., Itier, B., Goussard, J., Ragab, R., Tollefson, L., Van Hofwegen, P. (Eds.), 1996. Irrigation Scheduling: From Theory to Practice. FAO Water Reports 8. FAO, Rome.

Snyder, R., 1986. Normal scheduling program documentation. In: Snyder, R., Henderson, D.W., Pruitt, W.O., Dong, A. (Eds.), California Irrigation Information System. Final Report. Vol. II, Dep. Land, Air and Water Resources. Univ. California, Davis, pp. 1-30.

Stevens, J.B., Duvel, G.H., Steyn, G.J., Marobane, W., 2005. The Range, Distribution and Implementation of Irrigation Scheduling Models and Methods in South Africa. WRC Report No. 1137/1/05. Water Research Commission, Pretoria, South Africa 208 pp.

Stewart, J.I., Hagan, R.M., Pruitt, W.O., Danielson, R.E., Franklin, W.T., Hanks, R.J., Riley, J.P., Jackson, E.B., 1977. Optimizing Crop Production through Control of Water and Salinity Levels in the Soil. Reports Paper 67. Utah Water Research Laboratory, Logan, Utah $191 \mathrm{pp}$

Tang, J., Han, W., Zhang, L., 2019. UAV multispectral imagery combined with the FAO56 dual approach for maize evapotranspiration mapping in the North China Plain. Remote Sens. 11, 2519. https://doi.org/10.3390/rs11212519.

Teixeira, J.L., Pereira, L.S., 1992. ISAREG, an irrigation scheduling model. ICID Bull. 41, $29-48$.

Teixeira, J.L., Fernando, R.M., Pereira, L.S., 1995. RELREG: a model for real time irrigation scheduling. In: Pereira, L.S., van den Broek, B.J., Kabat, P., Allen, R.G. (Eds.), Crop-Water-Simulation Models in Practice. Wageningen Pers, Wageningen, The Netherlands, pp. 3-15.

Teixeira, J.L., Paulo, A.M., Pereira, L.S., 1996. Simulation of irrigation demand hydrographs at sector level. Irrig. Drain. Syst. 10, 159-178.

Thorp, K.R., Barnes, E.M., Hunsaker, D.J., Kimball, B.A., White, J.W., Nazareth, V.J. Hoogenboom, G., 2014. Evaluation of CSM-CROPGRO-Cotton for simulating effects of management and climate change on cotton growth and evapotranspiration in an arid environment. Trans. ASABE 57 (6), 1627-1642.

Thorp, K.R., Hunsaker, D.J., French, A.N., Bautista, E., Bronson, K.F., 2015. Integrating geospatial data and cropping system simulation within a geographic information system to analyze spatial seed cotton yield, water use, and irrigation requirements. Precis. Agric. 16, 532-557.

Thorp, K.R., Hunsaker, D.J., Bronson, K.F., Andrade-Sanchez, P., Barnes, E.M., 2017. Cotton irrigation scheduling using a crop growth model and FAO-56 methods: field and simulation studies. Trans. ASABE 60 (6), 2023-2039.

Tian, F., Yang, P., Hu, H., Dai, C., 2016. Partitioning of cotton field evapotranspiration under mulched drip irrigation based on a dual crop coefficient model. Water 8, 72. https://doi.org/10.3390/w8030072.

Todorovic, M., Riezzo, E.E., Buono, V., Zippitelli, M., Galiano, A., Cantore, V., 2016. Hydro-Tech: an automated smart-tech Decision Support Tool for eco-efficient irrigation management. Int. Agric. Eng. J. 25 (2), 44-45.

Tuzet, A., Perrier, A., Masaad, C., 1992. Crop water budget. Estimation of irrigation requirements. ICID Bull 41 (2), 1-17.

Tzounis, A., Katsoulas, N., Bartzanas, T., Kitta, C., 2017. Internet of Things in agriculture, recent advances and future challenges. Biosyst. Eng. 164, 31-48.

Van Genuchten, M.Th., 1980. A closed form equation for predicting the hydraulic conductivity of unsaturated soils. Soil Sci. Soc. Am. J. 44, 892-898.

van Heerden, P.S., Walker, S., 2016. Upgrading of SAPWAT3 as a Management Tool to Estimate the Irrigation Water Use of Crops. revised edition sapwat4. Water Research Commission Report No. TT 662/16, South Africa 231p.

Vazifedoust, M., van Dam, J.C., Feddes, R.A., Feizi, M., 2008. Increasing water productivity of irrigated crops under limited water supply at field scale. Agric. Water Manage. 95, 89-102.

Vazifedoust, M., van Dam, J.C., Bastiaanssen, W.G.M., Feddes, R.A., 2009. Assimilation of satellite data into agrohydrological models to improve crop yield forecasts. Int. J. Remote Sens. 30, 2523-2545.

Walker, W.R., Prajamwong, S., Allen, R.G., Merkley, G.P., 1995. USU command area decision support model - CADSM. In: Pereira, L.S., van den Broek, B.J., Kabat, P., Allen, R.G. (Eds.), Crop-Water-Simulation Models in Practice. Wageningen Pers, Wageningen, pp. 231-271.

Wang, X., Williams, J.R., Gassman, P.W., Baffaut, C., Izaurralde, R.C., Jeong, J., Kiniry, J.R., 2012. EPIC and APEX:model use, calibration, and validation. Trans. ASABE 55, 1447-1462.

Wei, Z., Paredes, P., Liu, Y., Chi, W.-W., Pereira, L.S., 2015. Modelling transpiration, soil evaporation and yield prediction of soybean in North China Plain. Agric. Water Manage. 147, 43-53.

Wright, J.L., 1982. New evapotranspiration crop coefficients. J. Irrig. Drain. Eng. 108, 57-74.

Wu, Y., Liu, T., Paredes, P., Duan, L., Wang, H., Wang, T., Pereira, L.S., 2016. Ecohydrology of groundwater dependent grasslands of the semi-arid Horqin sandy land of Inner Mongolia focusing on evapotranspiration partition. Ecohydrol. 9, 1052-1067. https://doi.org/10.1002/eco.1702.

Xevi, E., Feyen, J., 1992. Combined soil water dynamic model (SWATRER) and summary crop simulation model (SUCROS). ICID 41 (2), 85-98.

Xu, X., Huang, G., Sun, C., Pereira, L.S., Ramos, T.B., Huang, Q., Hao, Y., 2013. Assessing the effects of water table depth on water use, soil salinity and wheat yield: Searching for a target depth for irrigated areas in the upper Yellow River basin. Agric. Water Manage. 125, 46-60.

Yang, J., Wan, S., Deng, W., Zhang, G., 2007. Water fluxes at a fluctuating water table and groundwater contributions to wheat water use in the lower Yellow River flood plain. China. Hydrol. Process. 21, 717-724.

Yang, Y., Wilson, L.T., Wang, J., 2012. Site-specific and regional on-farm rice water conservation analyzer (RiceWCA): development and evaluation of the water balance model. Agric. Water Manage. 115, 66-82.

Ylijoki, O., Porras, J., 2016. Perspectives to definition of big data: a mapping study and discussion. J. Innov. Manage. 4 (1), 69-91.

Zhang, B., Liu, Y., Xu, D., Cai, J., Li, F., 2011. Evapotranspiration estimation based on scaling up from leaf stomatal conductance to canopy conductance. Agric. Forest Meteorol. 151, 1086-1095.

Zhang, B., Liu, Y., Xu, D., Zhao, N., Lei, B., Rosa, R.D., Paredes, P., Paço, T.A., Pereira, L.S., 2013. The dual crop coefficient approach to estimate and partitioning evapotranspiration of the winter wheat-summer maize crop sequence in North China Plain. Irrig. Sci. 31, 1303-1316.

Zhang, L., Cui, Y., Xiang, Z., Zheng, S., Traore, S., Luo, Y., 2018. Short-term forecasting of daily crop evapotranspiration using the 'Kc-ETo' approach and public weather forecasts. Arch. Agron. Soil Sci. 64, 903-915.

Zhao, N., Liu, Y., Cai, J., Paredes, P., Rosa, R.D., Pereira, L.S., 2013. Dual crop coefficient modelling applied to the winter wheat-summer maize crop sequence in North China Plain: basal crop coefficients and soil evaporation component. Agric. Water Manage. 117, 93-105.

Zheng, H.X., Li, H.P., Zhang, S., Zhang, J.C., 2014. Study optimization irrigation schedule of winter wheat in Hetao Irrigation District. Appl. Mechan. Mater. 641-642, 217-221.

Zhou, J., Cheng, G., Li, X., Hu, B.X., Wang, G., 2012. Numerical modeling of wheat irrigation using coupled HYDRUS and WOFOST models. Soil Sci. Soc. Am. J. 76, 648-662. 